\title{
WestVirginiaUniversity
}

THE RESEARCH REPOSITORY @ WVU

Graduate Theses, Dissertations, and Problem Reports

2011

\section{Production Analysis of Marcellus Shale}

Hossein Belyadi

West Virginia University

Follow this and additional works at: https://researchrepository.wvu.edu/etd

\section{Recommended Citation}

Belyadi, Hossein, "Production Analysis of Marcellus Shale" (2011). Graduate Theses, Dissertations, and Problem Reports. 2242.

https://researchrepository.wvu.edu/etd/2242

This Thesis is protected by copyright and/or related rights. It has been brought to you by the The Research Repository @ WVU with permission from the rights-holder(s). You are free to use this Thesis in any way that is permitted by the copyright and related rights legislation that applies to your use. For other uses you must obtain permission from the rights-holder(s) directly, unless additional rights are indicated by a Creative Commons license in the record and/ or on the work itself. This Thesis has been accepted for inclusion in WVU Graduate Theses, Dissertations, and Problem Reports collection by an authorized administrator of The Research Repository @ WVU. For more information, please contact researchrepository@mail.wvu.edu. 
Production Analysis of Marcellus Shale

Hossein Belyadi

Thesis submitted to the College of Engineering and Mineral Resources at West Virginia University in partial fulfillment of the requirements for the degree of

Master of Science

in

Petroleum and Natural Gas Engineering

Kashy Aminian, PhD., Committee Chairperson

Samuel Ameri, M.S.

Chris Bise, PhD.

Department of Petroleum and Natural Gas Engineering

Morgantown, West Virginia

2011 


\section{Abstract \\ Production Analysis of Marcellus Shale \\ Hossein Belyadi}

The purpose of this thesis was to analyze the production potential of Marcellus shale using actual field data. By using real field production data for 9 vertical and 3 horizontal wells it was possible to predict and understand the cause and effect relationship between the specific reservoir parameters and the overall production outlook of the reservoir in the long run. Using an assumed base model and narrowing each parameter down to match historically to the actual field data the forecast of the reservoir behavior was attained. The main model relied upon in this thesis was the Dual Porosity Model, which was used to analyze the real field production data using Eclipse. In addition to history matching, another goal of this thesis was to understand the effect of each parameter on the production curve so as to further the predictability of these variables. Over five hundred runs have been performed to establish the history matching in order to document the specific effect of each parameter on the production data using Eclipse. The recorded history match results for each well can permit the prediction of the future forecast for the reservoir. Lastly, based on the final parameters that were used to historically match the real field data, two models were created and run to differentiate the reserves and recovery factor for both vertical and horizontal wells. 


\section{Acknowledgments}

I would like to express my special thanks and appreciation to Dr. Aminian for his commitment and his infinite help throughout my research. In addition, I would like to extend my acknowledgment to Professor Samuel Ameri and Dr. Chris Bise for their marked contribution and cooperation in this research. Furthermore, I would like to thank my brother, Abbas Belyadi for his guidance regarding the software problems that I have encountered while conducting this research. Finally, I would like to thank my parents and loving wife, Renee Hardman, for supporting me while completing my M.S. degree.

Also, my appreciation extends to all my friends and professors at WVU who motivated me throughout my M.S. program and transferring technical knowledge in the area of Reservoir Simulation, Hydraulic Fracturing, and Reservoir Engineering. 


\section{Table of Contents}

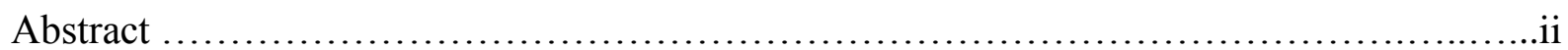

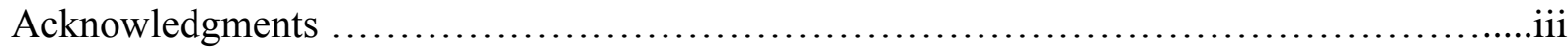

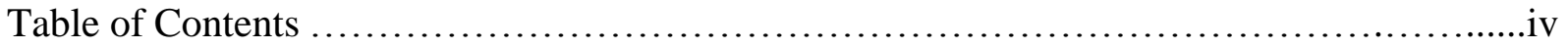

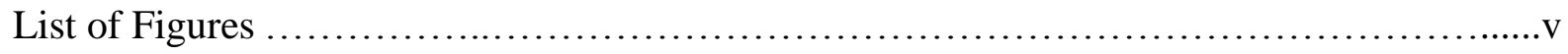

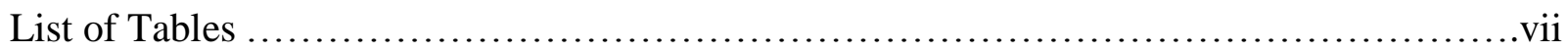

List of Symbols/ Nomenclatures .....................................................ii

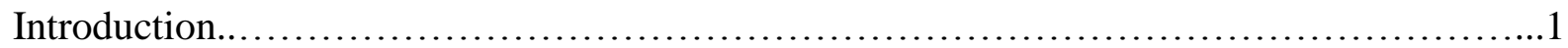

Literature Review.....................................................................

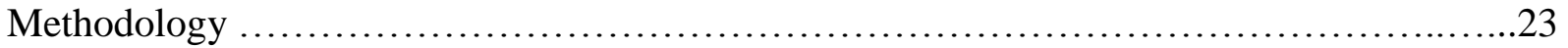

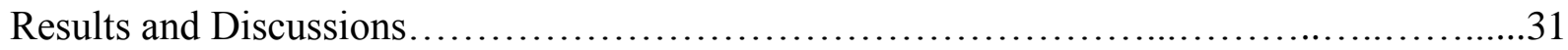

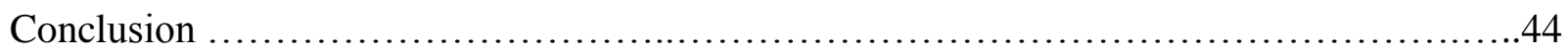

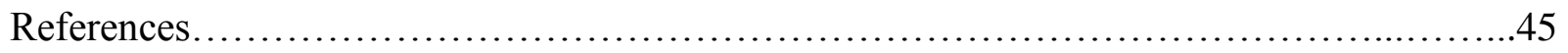

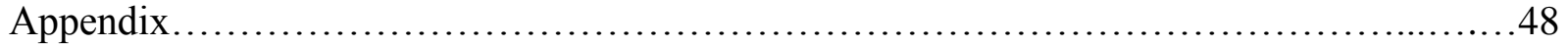

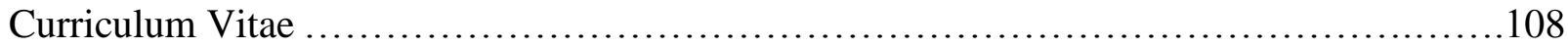




\section{List of Figures}

Figure 1. United States Shale Gas Plays (EIA, 2008) ....................................................................... 4

Figure 2. Stratigraphy of the Marcellus Shale (NETL, 2010) ................................................................. 5

Figure 3. Marcellus Shale Thickness (NETL, 2010) ........................................................................... 6

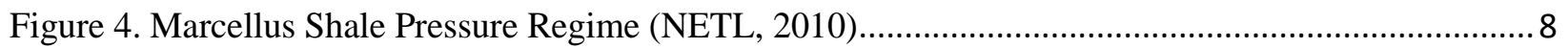

Figure 5. Thermal Maturity of the Marcellus (NETL, 2010) .................................................................

Figure 6. Depth to the bottom of the Marcellus (Geology, 2008) ......................................................... 10

Figure 7. Horizontal Drilling (Geology, 2008) ................................................................................... 11

Figure 8. Marcellus Shale Hydraulic Fracturing (Hydraulic Fracturing, 2011) ......................................... 15

Figure 9. Actual Reservoir Vs Model Reservoir (Root, The behavior of naturally fractured reservoirs,

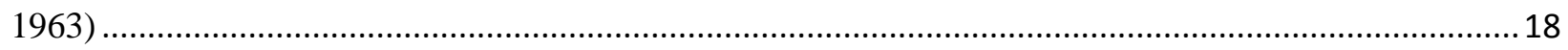

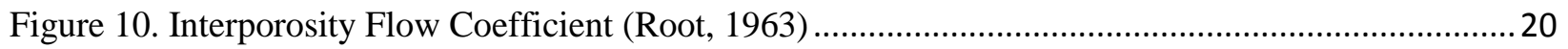

Figure 11. Log Cycle Separation (Root, 1963) …............................................................................ 21

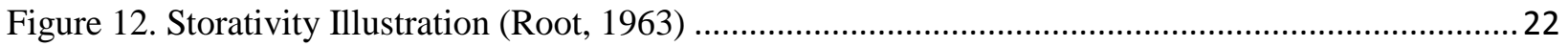

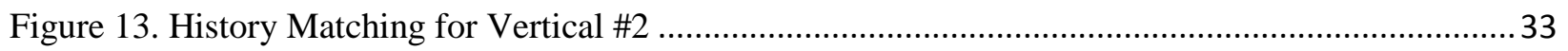

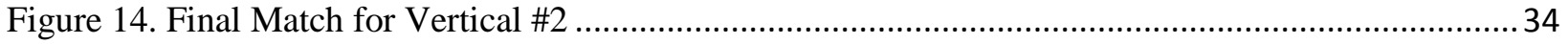

Figure 15. History Matching for Horizontal \#1 .............................................................................. 36

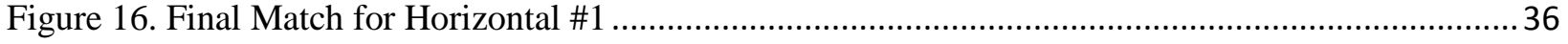

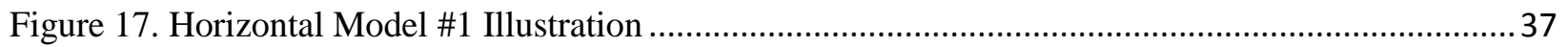

Figure 18. Final Production Rate Behavior for Vertical Model............................................................ 40

Figure 19. Final Cumulative Production Behavior for Vertical Model ................................................... 40

Figure 20. Final Production Rate Behavior for Horizontal Model ...................................................... 42

Figure 21. Final Cumulative Production Behavior for Horizontal Model ............................................... 43 


\section{List of Tables}

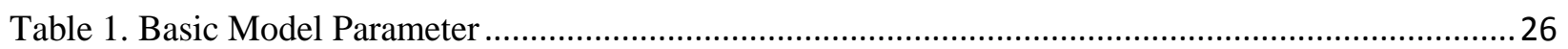

Table 2. Initial and final values of the parameters for vertical \#2 ….................................................... 32

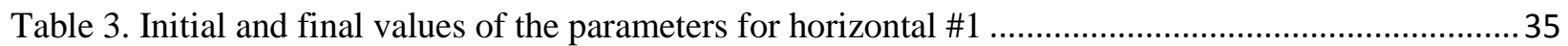

Table 4. Final Parameters for Horizontal and Vertical Wells ................................................................. 38

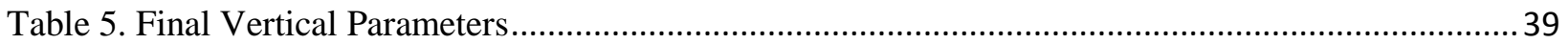

Table 6. Recovery Factor for Final Vertical Model ........................................................................... 41

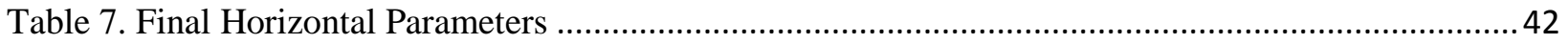

Table 8. Recovery Factor for Final Horizontal Model.......................................................................... 43 


\section{List of Symbols/ Nomenclatures}

$\mathrm{K}=$ formation permeability, md

$\mathrm{K}_{\mathrm{f}}=$ natural fracture permeability, md

$\emptyset_{\mathrm{f}}=$ natural fracture porosity, fraction

$\mathrm{K}_{\mathrm{m}}=$ matrix permeability, md

$\emptyset_{\mathrm{m}}=$ matrix porosity, fraction

$\mathrm{X}_{\mathrm{f}}=$ fracture half length, $\mathrm{ft}$

$\mathrm{K}_{\mathrm{hf}}=$ hydraulic fracture permeability, md

$\emptyset_{\mathrm{hf}}=$ hydraulic fracture porosity, $\%$

$\mathrm{W}_{\mathrm{hf}}=$ hydraulic fracture width, in

$\mathrm{P}_{\mathrm{L}}=$ Langmuir pressure, psia

$\mathrm{V}_{\mathrm{L}}=$ Langmuir volume, $\mathrm{SCF} /$ ton

$\mathrm{T}=$ temperature, ${ }^{\circ} \mathrm{F}$

$\mathrm{F}_{\mathrm{CD}}=$ dimensionless fracture conductivity

$\lambda=$ interporosity flow coefficient

$\mathrm{w}=$ storativity

OGIP= original gas in place, $\mathrm{MSCF}$

$\mathrm{RF}=$ recovery factor, $\%$

$\mathrm{EUR}=$ estimated ultimate recovery, MSCF

$\mathrm{h}=$ thickness, $\mathrm{ft}$

$\mathrm{r}_{\mathrm{e}}=$ drainage radius, $\mathrm{ft}$

$\mathrm{r}_{\mathrm{w}}=$ wellbore radius, $\mathrm{ft}$

$\mathrm{P}_{\mathrm{wf}}=$ bottom hole pressure

$\mathrm{A}=$ area, acreage 


\section{Chapter 1}

\section{Introduction}

Marcellus shale is a giant field in the Appalachians that is believed to have trillions of cubic feet of gas in place; however the percentage of this gas that can be recovered is controversial with varying estimates. It is very important to understand how much gas can be recovered over the life of the play. This amount is referred to as Estimated Ultimate Recovery (EUR). The production data available from different vertical and horizontal wells only indicates the short-term production recovery and reservoir simulation can be used to understand the longterm production recovery for both vertical and horizontal wells. This thesis will be a new study on the production analysis of the Marcellus Shale using reservoir simulation and history matching techniques.

There is not an abundance of public information regarding the Marcellus Shale production in the long run. This thesis focuses on analyzing the Marcellus Shale production for both vertical and horizontal wells after 30 years and historically matches the real field data in order to forecast the future behavior of the reservoirs long run production. Marcellus shale is a new discovery and the production data available from the Marcellus is typically for a few years. As a result, it is essential to build various models using the dual porosity system in reservoir simulation in order to understand and forecast the behavior of the reservoir after so many years.

Range Resources started drilling for Marcellus shale with the first well being drilled in 2003 in Washington County, Pennsylvania. They have discovered a promising flow of natural gas. Furthermore, using horizontal drilling and hydraulic fracturing, it was discovered that the 
flow of natural gas can be significantly increased. Resulting from these discoveries, the first Marcellus gas production began in 2005. (Geology, 2008)

Shale gas is present across much of the lower forty eight States. The most active shales to date are the Barnett Shale, the Haynesville/Bossier Shale, the Antrim Shale, the Fayetteville Shale, the Marcellus Shale, and the New Albany Shale. Each of these gas shale basins is different and each has an exclusive set of exploration criteria. Because of these differences, the development of shale gas resources in each of these areas faces potentially unique challenges. As new technologies are developed, shale gas plays once believed to have limited economic feasibility are now being re-evaluated. (NETL, 2010)

The combination of hydraulic fracture treatments and horizontal well completions has been very important in facilitating the development of shale gas reservoirs. Before the successful development of these two technologies, shale gas resources in many basins had been disregarded because of low production rate. The low natural permeability of shale had been the limiting factor to the production of shale gas resources because it only allows small volumes of gas to flow naturally to a wellbore. For gas shales to be economically produced, these restrictions must be overcome. The combination of reduced economics and low permeability of gas shale formations historically caused operators to bypass these formations and focus on other resources. (NETL, 2010) 


\section{Chapter 2 \\ Literature Review}

\subsection{Marcellus Shale:}

Marcellus shale has been one of the most important developments in the past few years. Having a good understand of what this gigantesque gas reservoir can do to shape the future of natural gas industry is essential in today's U.S. economy. Marcellus shale is rich black organic shale with low density that occurs in West Virginia, Pennsylvania, and New York. In addition, small areas of Maryland, Kentucky, Tennessee, and Virginia are also affected by the Marcellus Shale. A few years ago, it was very hard to believe that Marcellus Shale could be productive and economical because of its low permeability structure; however with recent advances in specialized horizontal drilling and hydraulic fracturing technologies, it is now known as the largest potential gas field in the U.S. (Geology, 2008)

Figure 1 is a visual illustration of the location of these shale gas plays and Marcellus Shale in the U.S.

\subsection{Marcellus Shale Stratigraphy:}

Marcellus is bounded by the Hamilton group shale and below by limestone of the Tristate group. Figure 2 illustrates that Marcellus is located in the lower middle Devonian shale.

\subsection{Characteristics of Productive Marcellus Shale in West Virginia:}

1) Net thickness of organic rich Marcellus Shale>30 feet;

2) Pressure gradient of $0.40 \mathrm{psi} / \mathrm{ft}$;

3) Thermal maturation $>1.25 \%$ vitrinite reflectance $\left(R_{o}\right)$;

4) Depth $>5000 \mathrm{ft}$ 


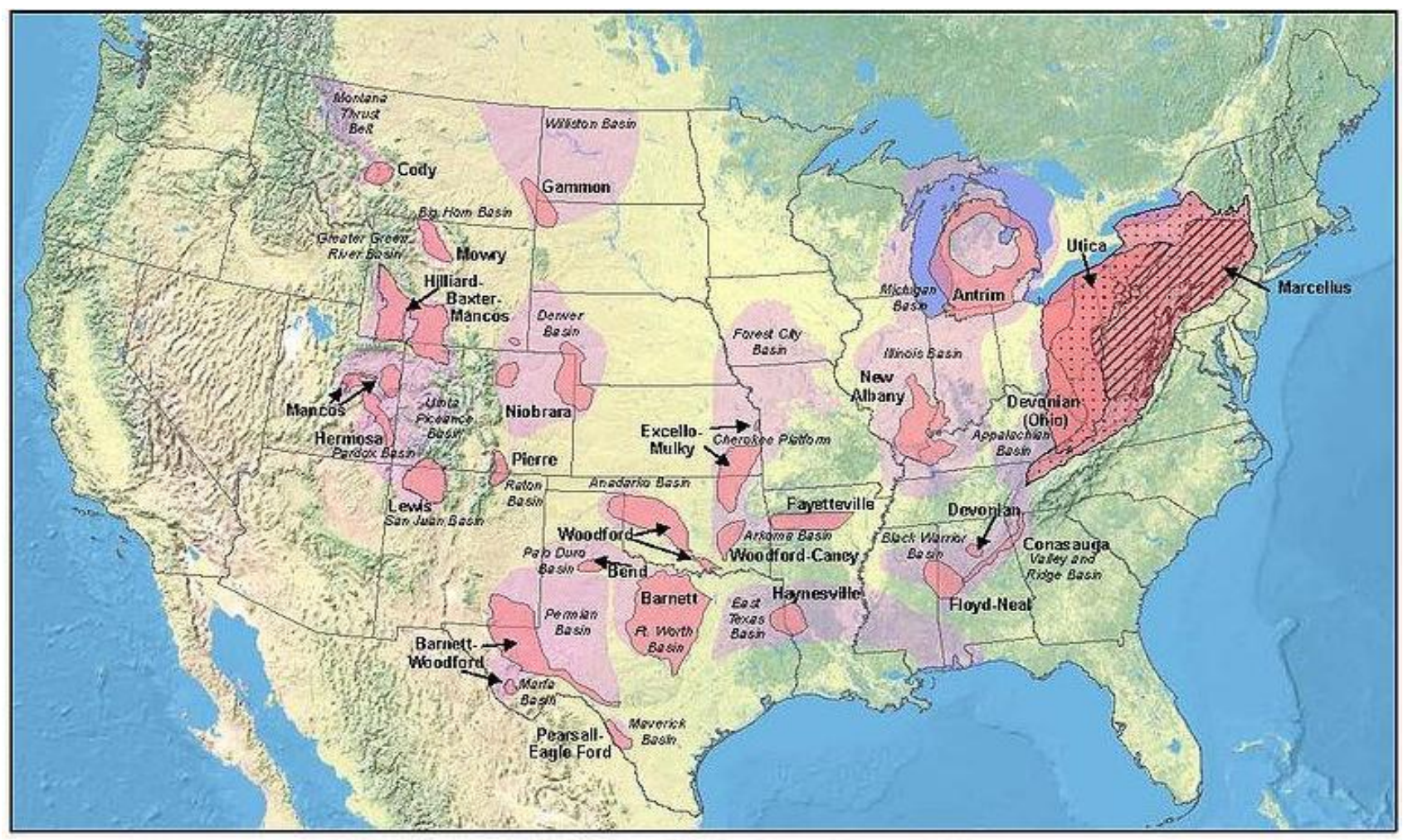

\section{United States Shale Gas Plays}
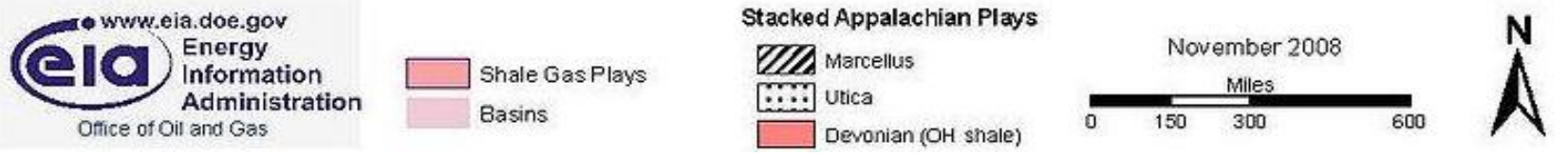

Figure 1. United States Shale Gas Plays (EIA, 2008)

\subsubsection{Net thickness of organic rich Marcellus Shale>30 feet:}

Average thickness of Marcellus in West Virginia is estimated to be $10 \mathrm{ft}$ to $100 \mathrm{ft}$. Since this thesis is going to use vertical and horizontal wells in West Virginia counties, it is imperative to understand the thickness variation across the states. The thickness of Marcellus Shale is different across the state but it is known to be the thickest in the northeast central counties and thin to zero in the Southwest. Figure 3 is a map that illustrates the thickness of the Marcellus across the West Virginia counties. (NETL, 2010) 


\begin{tabular}{|c|c|c|c|}
\hline \multicolumn{2}{|c|}{ Period } & \multicolumn{2}{|c|}{ Group/Unit } \\
\hline Penn & & Pottsv & \\
\hline Miss & & Pocon & \\
\hline \multirow{14}{*}{ 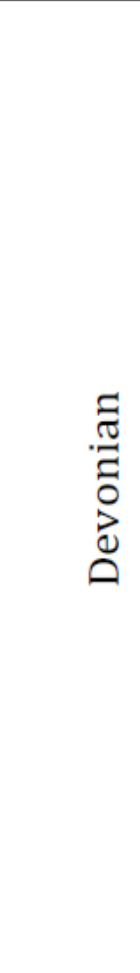 } & \multirow{6}{*}{ Upper } & Conen & ngo \\
\hline & & Conne & \\
\hline & & \multicolumn{2}{|c|}{ Canadaway } \\
\hline & & \multicolumn{2}{|c|}{ West Falls } \\
\hline & & \multicolumn{2}{|c|}{ Sonyea } \\
\hline & & \multicolumn{2}{|c|}{ Genesee } \\
\hline & \multirow{5}{*}{ Middle } & \multicolumn{2}{|c|}{ Tully } \\
\hline & & \multirow{4}{*}{ 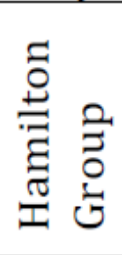 } & Moscow \\
\hline & & & Ludlowville \\
\hline & & & Skaneateles \\
\hline & & & Marcellus \\
\hline & & \multicolumn{2}{|c|}{ Onandaga } \\
\hline & \multirow{2}{*}{ Lower } & \multicolumn{2}{|c|}{ Tristates } \\
\hline & & \multicolumn{2}{|c|}{ Helderberg } \\
\hline
\end{tabular}

Figure 2. Stratigraphy of the Marcellus Shale (NETL, 2010)

\subsubsection{Pressure gradient of $0.40 \mathrm{psi} / \mathrm{ft}$ :}

Marcellus exhibits different pressure regimes in West Virginia. Typically it is under-pressure to the Southwest and even though not a lot of data is available, it has been determined that the Marcellus is potentially over pressured to the Northeast with a transitional area in between. Figure 4 shows these pressure regimes with a question mark indicating the uncertainty associated with the normal to over pressured area. It is understandable that the highest ultimate recoveries will be from the normal to over pressured areas. The presence of these separate pressure regimes indicates different approaches to well stimulation. (NETL, 2010) 
(FEET)

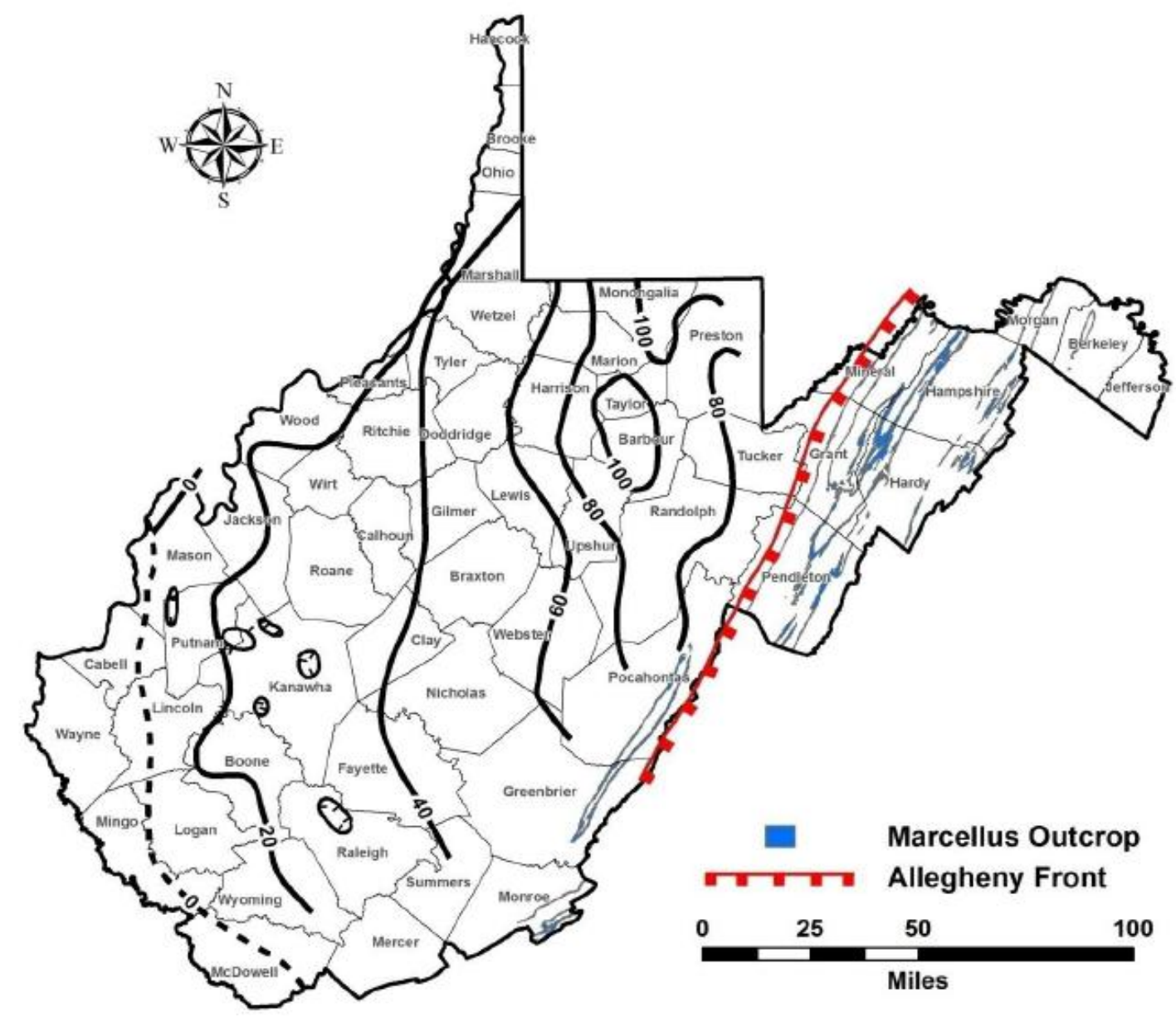

Figure 3. Marcellus Shale Thickness (NETL, 2010)

Figure 4 is an illustration of pressure distribution in West Virginia counties.

\subsubsection{Thermal maturation $>1.25 \%$ vitrinite reflectance $\left(R_{0}\right)$ :}

It is essential to understanding the meaning of each of the above terms, which are used in the Petroleum industry to classify the highest production potential of Marcellus Shale. Thermal maturity refers to a measure of the heat-induced process of converting organic matter to oil or natural gas can be distinguished by several factors and it should be converted to the universal standard vitrinite reflectance $\left(\mathrm{R}_{\mathrm{o}}\right)$. In addition, vitrinite reflectance is a measurement of the maturity of organic matter with respect to whether it has generated hydrocarbons or could be an 
effective source rock. The measurement of the thermal maturity of organic matter was developed to rank the maturity of coals and now it is being used in other rocks. Rock units are heterogeneous. The gas in the Marcellus Shale is apparently the result of its contained organic content. Thinking about the highest production potential of a shale rock, it can be determined that the more organic material in the rock, the greater is the ability to yield gas. It can be distinguished that the area with the highest production potential can be the areas with highest content of organic matter and highest level of thickness. (NETL, 2010)

Based on the 2010 NETL report, the most profitable shale formations have $R_{o}$ values of greater than $1.2 \%$. Shale with $\mathrm{R}_{\mathrm{o}}$ less than that will likely produce more oil than gas. It can be seen in Figure 5 that thermal maturity is greatest toward the East in West Virginia. Figure 5 is the thermal maturity for West Virginia's counties. (NETL, 2010)

\subsubsection{Depth $>5000 \mathrm{ft}$}

The estimated depth of Marcellus Shale is between 3,000 ft to 9,000 ft. Figure 6 shows the depth to the bottom of the Marcellus Shale in the Marcellus Shale's regions. (Geology, 2008)

\subsection{Horizontal Drilling:}

Within the last 2 to 3 decades horizontal drilling is one of the newest and most formative technological advancements in the Petroleum Industry. Horizontal drilling increases productivity compared to vertical well productivity. For example when drilling for a vertical well with a thickness of $100 \mathrm{ft}$ the contact area is only $100 \mathrm{ft}$. However, in horizontal wells this contact can be held for thousands and thousands of feet. Some horizontal wells in the Marcellus Shale have initial flows that suggest that they are capable of yielding millions of cubic feet of gas per day, making them the most productive gas wells in the Eastern United States. In addition to the 
productivity increase, horizontal wells improve the overall cost-effectiveness depending on the reservoir. While the cost factor for a horizontal well may be as much as two or three times that of a vertical well the production factor can be enhanced making it attractive as a new method for drilling. To have an idea of the effectiveness of horizontal drilling, the U.S. department of energy indicates that using horizontal drilling can lead to an increase in reserves in place by about $2 \%$ of the original gas in place. (Horizontal Drilling, 2008)

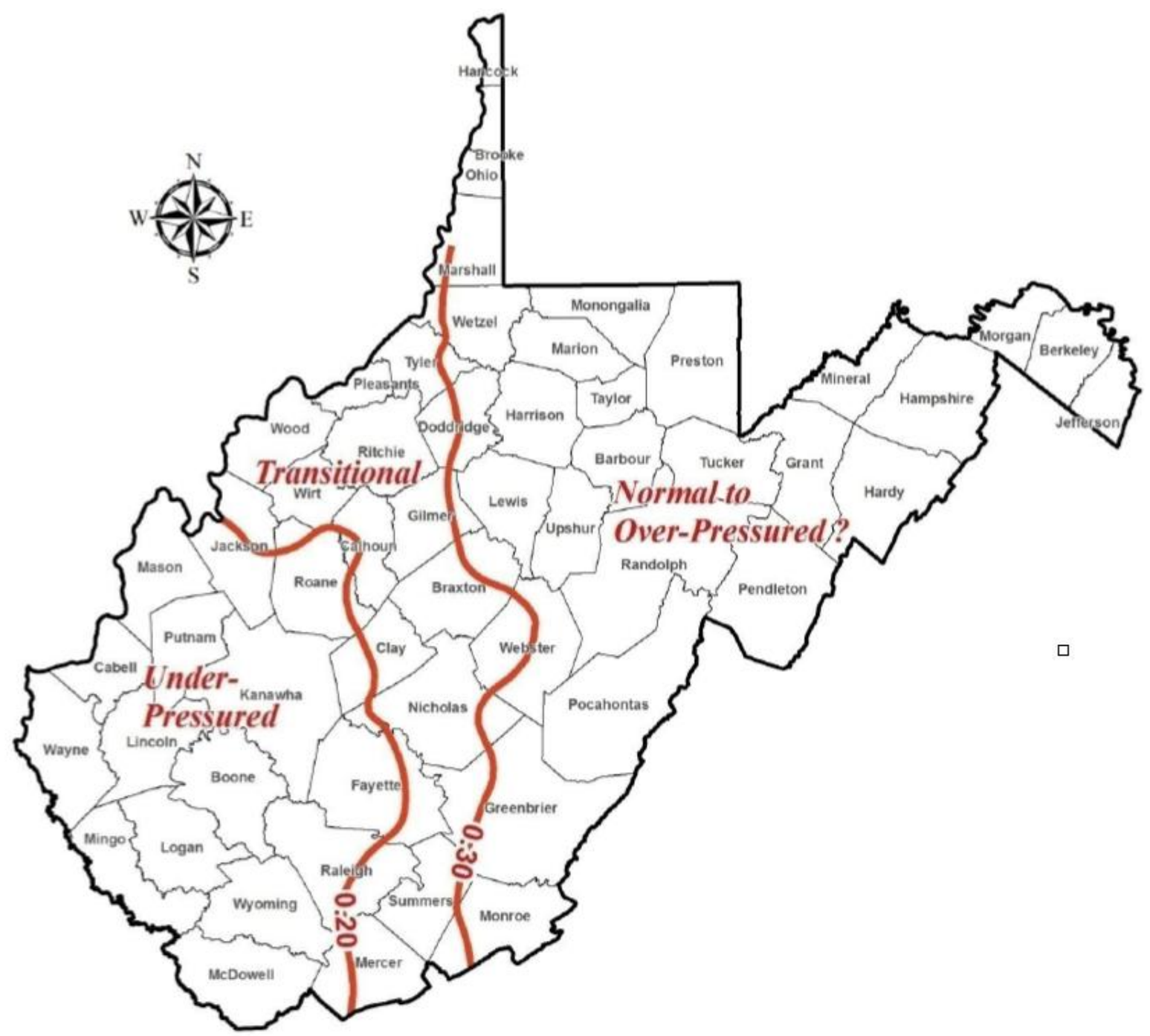

Figure 4. Marcellus Shale Pressure Regime (NETL, 2010) 


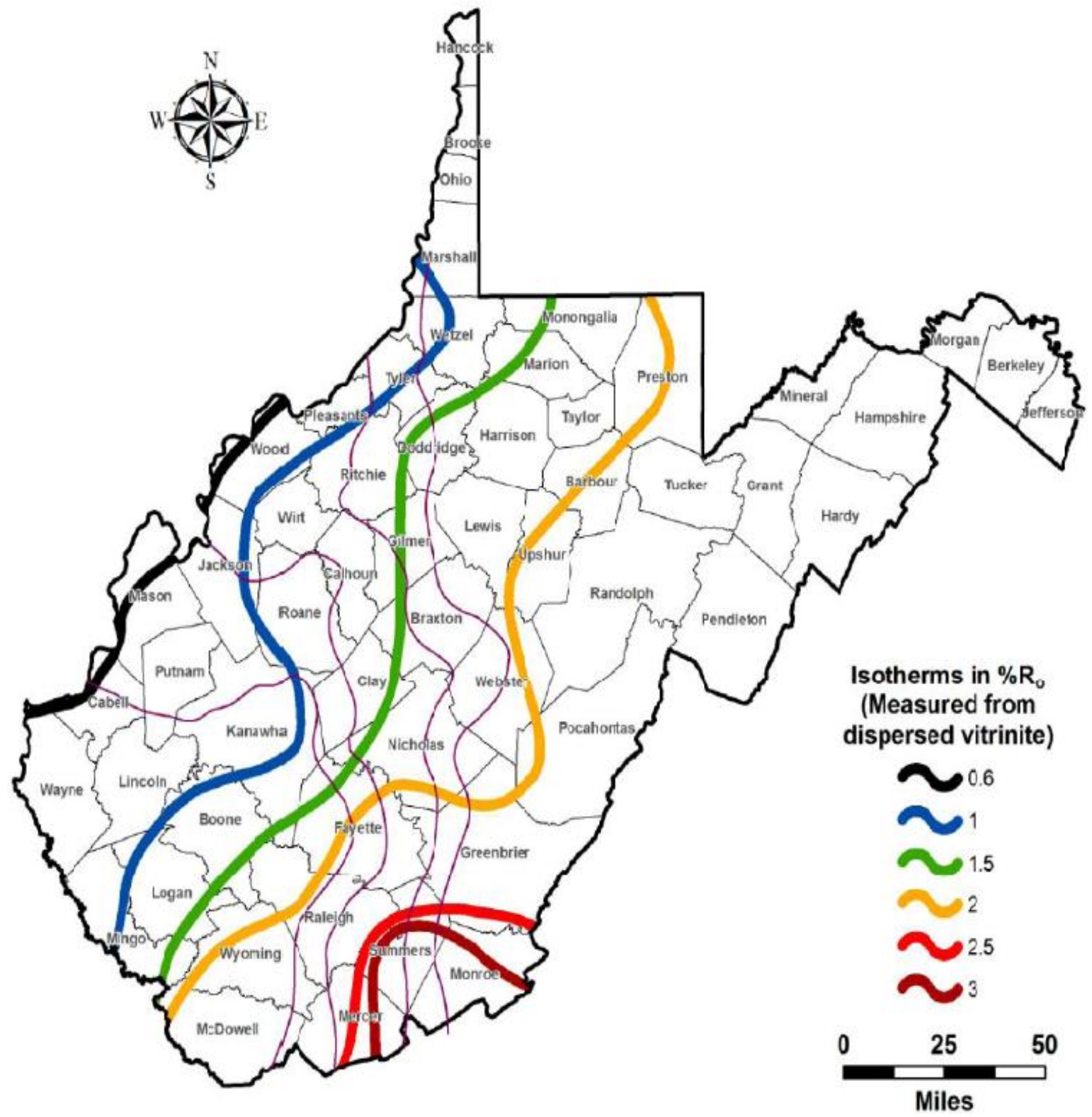

Figure 5. Thermal Maturity of the Marcellus (NETL, 2010)

Figure 7 is an illustration of horizontal drilling with some hydraulic fracturing zones. 


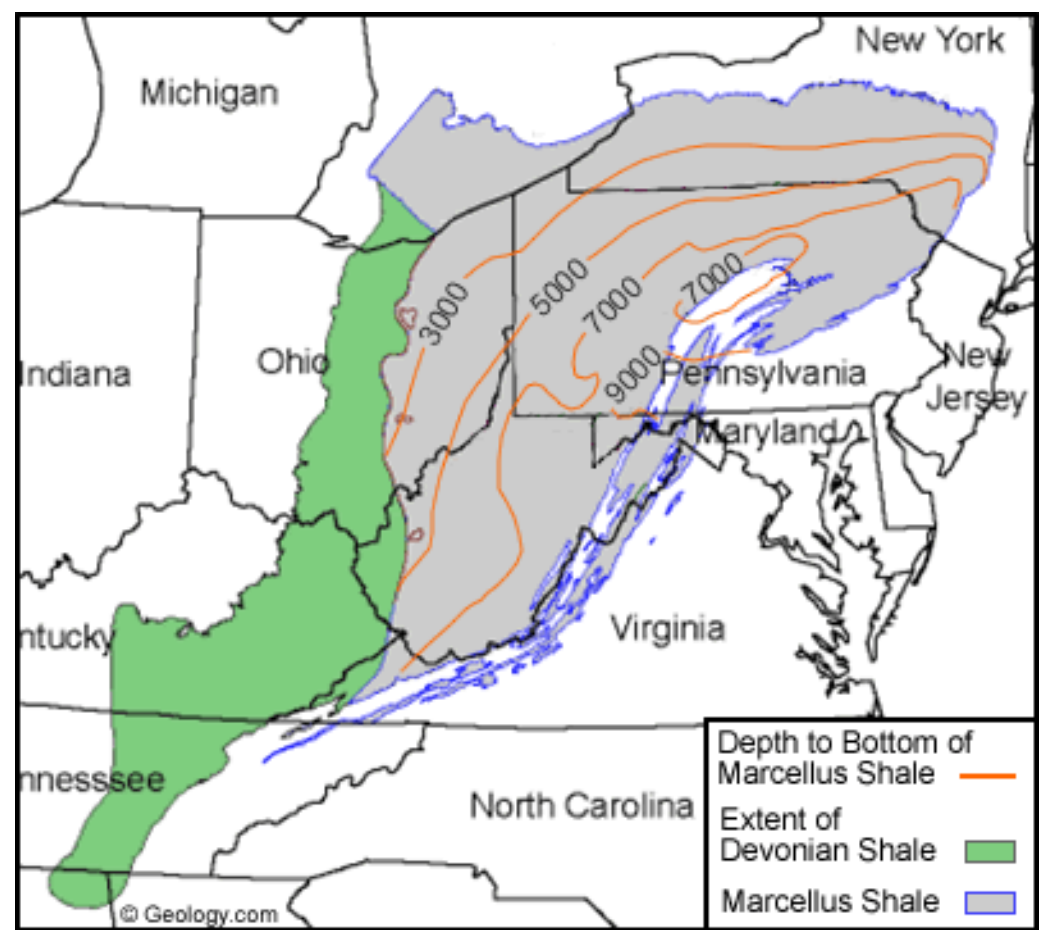

Figure 6. Depth to the bottom of the Marcellus (Geology, 2008)

\subsection{Hydraulic Fracturing:}

Hydraulic fracturing is one of the first necessary steps and costs in shale gas horizontal or vertical reservoirs. Fracing allows for the exploitation of the natural gas and oil from rock formations deep below the earth's surface. At deep formations, there may not be enough porosity and permeability to permit natural gas and oil to flow from the rock into the wellbore at economic rates. For example, conductive fractures in the rock are essential to produce gas from shale reservoirs because of the extremely low natural permeability of shale which is usually in the scale of microdarcy or nanodarcy. The fracture provides a conductive path connecting a larger area of the reservoir to the well, thus increasing the area from which natural gas and liquids can be recovered from the given formation. (Hydraulic Fracture, 2010) 


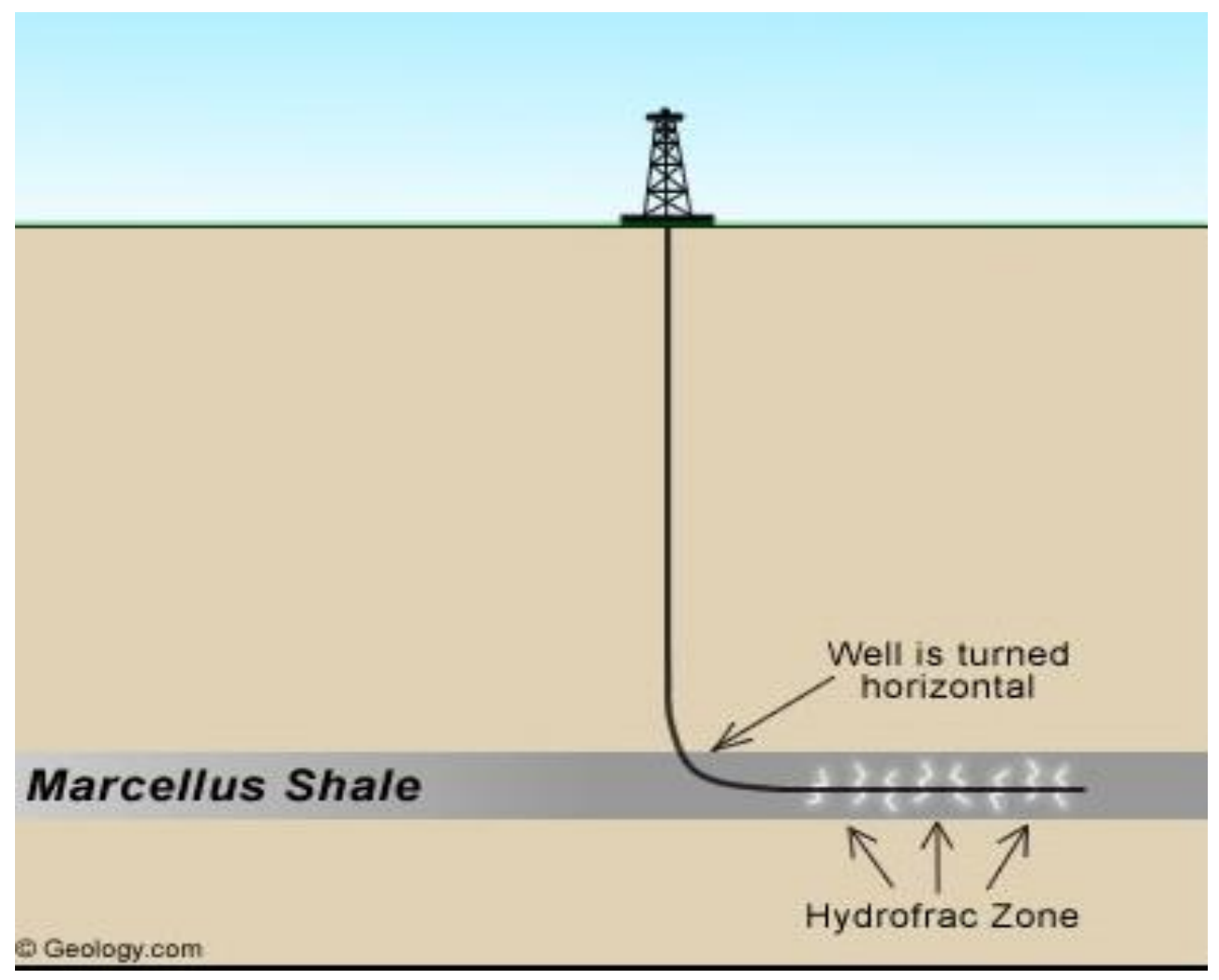

Figure 7. Horizontal Drilling (Geology, 2008)

A hydraulic fracture is created by pumping fracturing fluid into the wellbore at a specific velocity to increase the downhole pressure to a value in excess of the fracture gradient of the formation rock. This applied pressure causes the formation to crack (i.e. fracture), allowing the fracture fluid to enter and extend the crack farther into the formation. This fracture that is created by pumping millions of gallons of fluids can be closed after the injection procedure is completed, so to maintain this fracture open after the injection stops, a solid proppant is added to the fracture fluid. The propped hydraulic fracture then becomes a high permeability conduit through which the formation fluid can flow to the well. (Hydraulic Fracture, 2010)

Drilling a well always involved applying downhole pressure to a rotating drill bit. This drilling action produces rock chips and fine rock particles that are highly possible to enter crack 
and pore space at the wellbore wall, resulting in damage to the permeability at the end of the wellbore. This damage reduces flow into the wellbore from the surrounding rock formations. Hydraulic fracturing can be used to diminish this damage as well. (Hydraulic Fracture, 2010)

As previously mentioned, hydraulic fracture stimulation is commonly used in low permeability wells. It is estimated that $90 \%$ of the natural gas wells in the U.S. are hydraulically fractured to produce gas at economic rate. It is very clear that hydraulic fracturing is one of the most important costs in drilling a well in the U.S. since vast group of the formations are shale. With the Marcellus Shale development in the Appalachians, majority of petroleum companies are hiring entry level and experienced engineers to help fasten the procedure of hydraulically fracturing of all the wells. (Hydraulic Fracture, 2010)

As previously mentioned, there are many different applications for hydraulic fracturing such as:

1) Increase the flow rate of oil and/or gas from low permeability reservoirs

2) Increase the flow rate of oil and/or gas from wells that have been damaged

3) Connect the natural fractures and/or cleats in a formation to the wellbore

4) Decrease the pressure drop around the well to minimize sand production

5) Decrease the pressure drop around the wells to minimize problems with asphaltine and/or paraffin deposition

6) Increase the drainage area or the amount of formation in contact with the wellbore

7) Connect the full vertical scope of a reservoir to a slanted or horizontal well. (DOE, 2004) 
There could be other uses of hydraulic fracturing, but majority of the frac jobs are pumped because of the seven above reasons. A low permeability reservoir means it has high resistance to fluid flow. In many formations, chemical or physical processes alter a reservoir rock over geologic time. Sometimes, these digenetic processes restrict the openings in the rock and reduce the ability of fluid to flow through the rock. Low permeability rocks are typically excellent candidates for stimulation by hydraulic fracturing. (DOE, 2004)

\subsubsection{Dimensionless fracture conductivity:}

Dimensionless fracture conductivity is one important calculation in reservoir stimulation. Calculating this parameter will allow the engineers in charge to make a better decision as to what zones to stimulate and finally accurately calculate the economical analysis for that particular frac job. To determine the optimum fracture conductivity, the design engineer should use the dimensionless fracture conductivity shown as equation 1. (DOE, 2004)

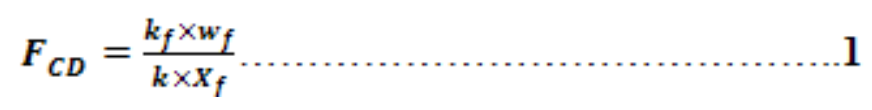

Where $\mathrm{w}_{\mathrm{f}}$ is the fracture width $(\mathrm{ft}), \mathrm{k}_{\mathrm{f}}$ is the proppant permeability (md), $\mathrm{k}$ is the formation permeability (md), and $\mathrm{X}_{\mathrm{f}}$ is the fracture half length ( $\mathrm{ft}$ ). The engineer needs to design the treatment to create a fracture wide enough and pump proppant at high concentration to achieve high conductivity required to optimize the treatment. There are two types of fractures. The first one is called the high (infinite conductivity) and this occurs when $\mathrm{F}_{\mathrm{CD}}>100$ and in this type of fracture, no appreciable pressure loss can be found in the fracture. The second type of fracture is called low (finite) conductivity and this type of fracture occurs when $\mathrm{F}_{\mathrm{CD}}<100$. (DOE, 2004) 


\subsubsection{Main risk in hydraulic fracturing:}

One of the main risks in hydraulic fracturing is that money is spent, but for whatever reason, the well does not produce at the desired flow rates or it does not recover the expected cumulative recovery. On a lot of occasions, mechanical problems with the well or the surface equipment cause the treatment to fail. On the other hand, the reservoir does not respond as expected. (DOE, 2004)

\subsubsection{Typical hydraulic fracturing procedure:}

1) Set the bridge plug below the target interval

2) Perforate target interval

3) Perform fracture treatment

- Pad stage (no proppant): pad is used to initiate or propagate fracture, develop adequate width and provide sacrificial fluid for leak off.

- Slurry stage (fracturing fluid + proppant): the goal is to inject slurry with constant proppant concentration through the entire fracture length at the end of the pumping. We can achieve that by increasing the maximum proppant concentration. Please note that during the leak off (fluid), our fracture is going to get dehydrated.

- Flush stage: Slurry is flushed to perforation.

4) Repeat the step at the next location

5) Drill out plugs

6) Set production tubing (Hydraulic Fracture, 2010) 
Figure 8 is a visual demonstration of the Marcellus Shale hydraulic fracturing.

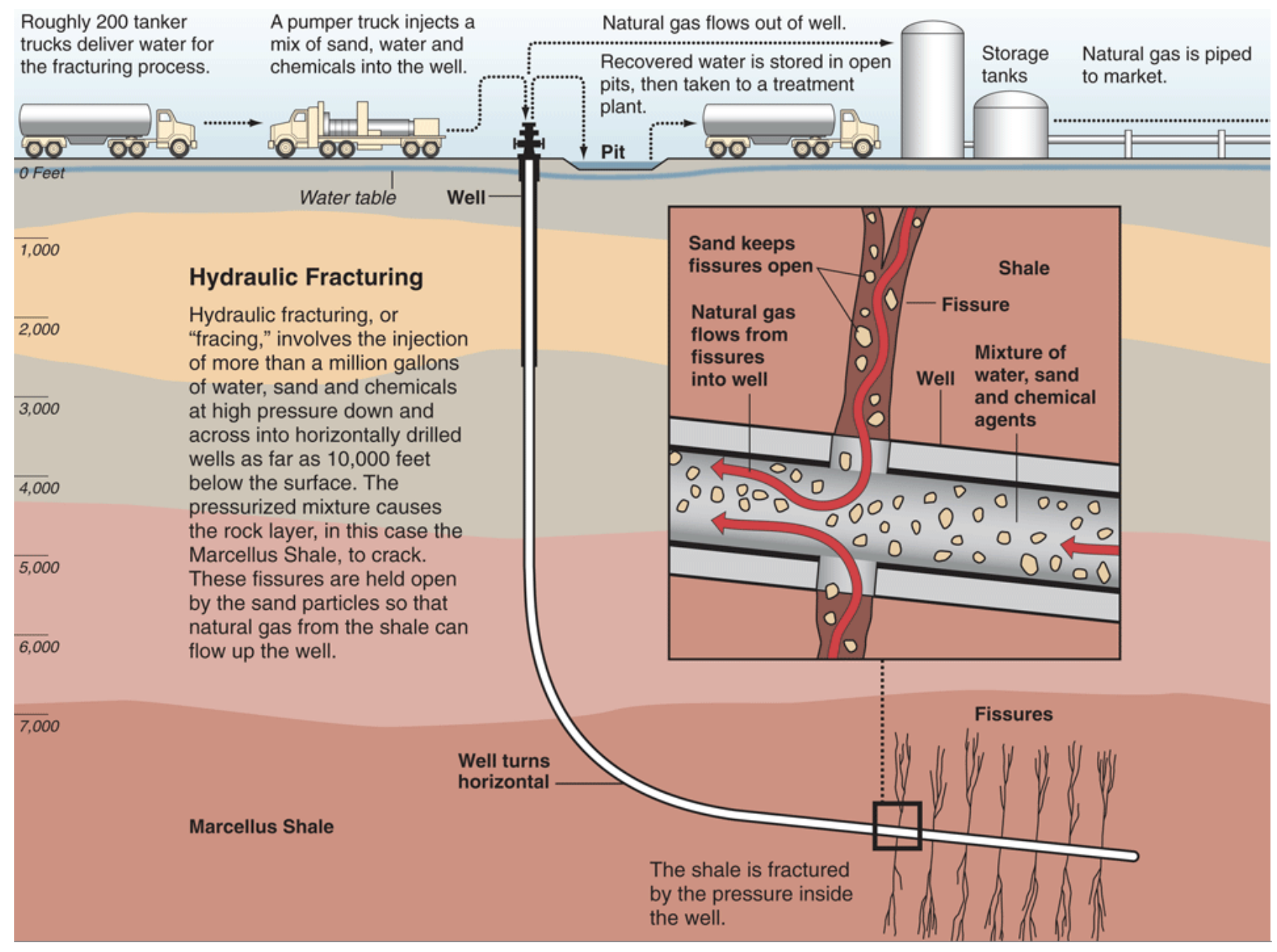

Figure 8. Marcellus Shale Hydraulic Fracturing (Hydraulic Fracturing, 2011)

\subsubsection{Horizontal well fracturing:}

\section{Transverse Fractures:}

1) More suitable for low permeability reservoirs

2) Can achieve greater contact with reservoirs and higher productivity

3) Have higher risk of screen out due to tortuosity

4) Have convergence flow around the wellbore in fracture (Hydraulic Fracture, 2010) 


\section{Longitudinal Fracture:}

1) More suitable for high permeability reservoirs

2) More suitable for cases with significant convergence flow effect

3) Productivity equivalent to a very long fracture

4) Minimum convergence flow effect

For example, for Marcellus Shale, it is very important to do transverse fracture because of low permeability shale formation. (Hydraulic Fracture, 2010)

\subsection{Dual Porosity Model:}

For many years it was assumed that for the purpose of making engineering studies, two parameters were sufficient to describe the single phase flow properties of a producing formation (the absolute permeability and the effective porosity). More recently, it was recognized that at least one additional parameter was required to illustrate the behavior of a porous system containing regions which contributed significantly to the pore volume but contributed negligibly to the flow capacity. Microscopically, these regions could be "dead end" or storage pores or macroscopically, they could be discrete volumes of low permeability matrix rock combined with natural fissures in a reservoir. These two classes of porosity can be described as follows,

1) Primary porosity: is intergranular and controlled by deposition and lithification. It is highly interconnected and typically can be correlated with permeability since it is largely dependent on the geometry, size distribution, and spatial distribution of the grains. The void systems of sand, sandstones, and oolitic limestones are typical of this type. (Root, The behavior of naturally fractured reservoirs, 1963) 
2) Secondary porosity: is controlled by fracturing, jointing and/or solution in circular water although it may be modified by in-filling as a result of precipitation. It is not highly interconnected and cannot be correlated with permeability. Joints or fissures which occur in massive, extensive formations composed of shale, siltstone, schist, limestone or dolomite are generally vertical and they are recognized to tensional failures during mechanical deformation. Shrinkage cracks are the result of a chemical process (dolomitization) and do not appear to have any preferred orientation. (Root, The behavior of naturally fractured reservoirs, 1963)

In most general case, both classes of porosity are present and the internal void volume of the rock is intermediate in nature, i.e, an independent system of secondary porosity is superimposed on the primary system. When modeling the dual porosity, all matrix blocks are homogenous, and they have the same size.

As can be seen in Figure 9, Matrix porosity contains bigger part of the reservoir while the natural fracture porosity has smaller porosity in the system. In real life, the distribution of natural fracture is not the same throughout the reservoir, however as previously mentioned dual porosity model assumes that all the matrix blocks are homogeneous and have the same size. Fracture porosity is basically what percent of the bulk volume is naturally fractured.(Aminian, 2011)

Figure 9 is a visual representation of how matrix and fracture porosity are distributed in the reservoir.

In dual porosity reservoir, fluids exist in two interconnected systems.

1) The rock matrix, which usually provides the bulk of the reservoir volume

2) The highly permeable rock fractures 


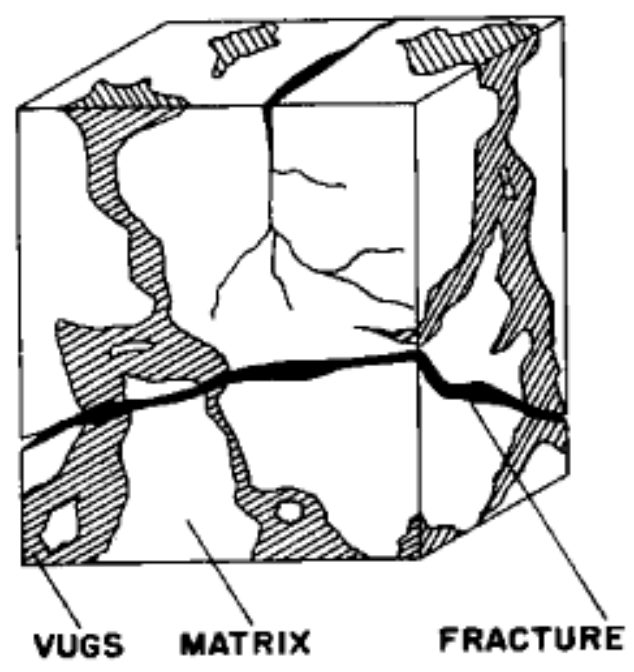

ACTUAL RESERVOIR

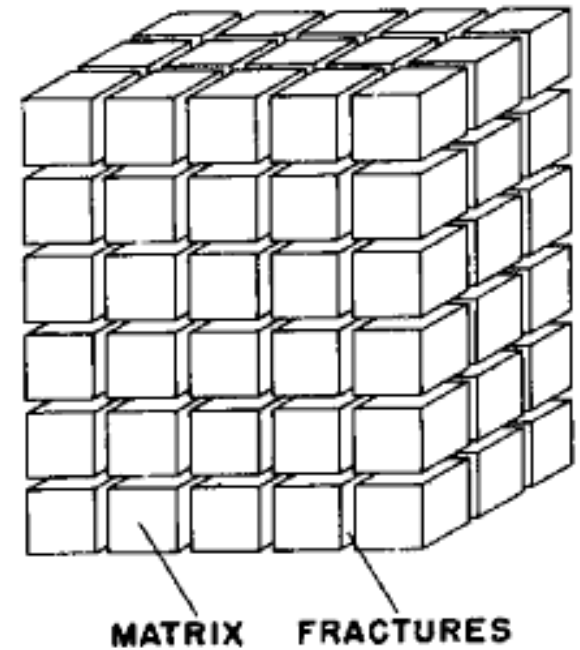

MODEL RESERVOIR

Figure 9. Actual Reservoir Vs Model Reservoir (Root, The behavior of naturally fractured reservoirs, 1963)

If the matrix blocks are linked only through the fracture system, this conventionally could be regarded as a dual porosity single permeability system, since fluid flow through the reservoir takes place only in the fracture network with matrix blocks acting as sources. If there is a possibility of flow directly between neighboring matrix blocks, this is conventionally considered to be a dual porosity dual permeability system. It should be noted that dual porosity dual permeability runs are computationally more expensive than dual porosity single permeability runs. To model such systems, two simulation cells are associated with each block in the geometric grid, representing the matrix and fracture volumes of the cell. In ECLIPSE the porosity, permeability, depth etc. of these may be independently defined (Schlumberger, 2009)

Typically, natural fractures have a lower porosity compared to matrix and as a result, they are capable of storing relatively small fraction of reservoir hydrocarbons. In dual porosity systems, the natural fractures have much higher permeability than the matrix. When the well begins to 
flow, fluid travels from high permeability natural fractures to wellbore and is quickly produced. Once the natural fractures have been drained, the large volumes of hydrocarbon contained within the bulk of your reservoir (refers to as matrix) starts to flow. These hydrocarbons flow to natural fractures and then transported to the wellbore via these fractures. (Root, 1963)

\subsubsection{Interporosity flow coefficient:}

Interporosity flow coefficient refers to the ability of the matrix to flow into fissures and can be calculated using equation 2. (Aminian, 2011)

$$
\begin{gathered}
\lambda=\alpha \times \mathrm{r}_{\mathrm{w}}^{2} \times \frac{\mathrm{k}_{\mathrm{m}}}{\mathrm{k}_{\mathrm{f}}} \ldots \ldots \ldots \ldots \ldots \ldots \ldots \ldots \ldots \ldots \ldots \ldots \ldots \ldots \ldots \ldots \ldots \ldots \\
r_{m}=\frac{n(n+2)}{r_{m}^{2}} \\
\text { Surface Area of Matrix Block }
\end{gathered}
$$

As shown in figure 10, as the interporosity flow coefficient decreases, the transition between the two semi-log straight lines is delayed. This indicates the larger fracture permeability in a comparison to the matrix and basically the more natural fractures will have to drain before the contribution from the matrix becomes significant. . (Root, 1963)

There are two types of interporosity flow which are used to model dual porosity system,

1) Pseudo-steady state interporosity flow: This is the most common dual porosity used. This type of interporosity flow considers the presence of minerals in the fissure network that reduces the flow from matrix to fissures. The restricted interporosity flow is also called 
the pseudo steady state interporosity flow model, or Warren and Root model. (Root, 1963)

2) Transient interporosity flow: this type of interporosity flow considers no flow restriction at the matrix-fissure interface and matrix blocks response starts earlier. The unrestricted interporosity flow model is also called transient interporosity flow model. Some dual porosity systems are considered to have transient interporosity flow with an interporosity skin rather than the more popular pseudo-steady state interporosity flow. This is a distributed parameter model and assumes that the flow between the two porosities is a transient mode and that a positive skin exists at the interface between the two porosities. If this skin in large, then the transient model becomes equivalent to the pseudo-steady state. . (Root, 1963)

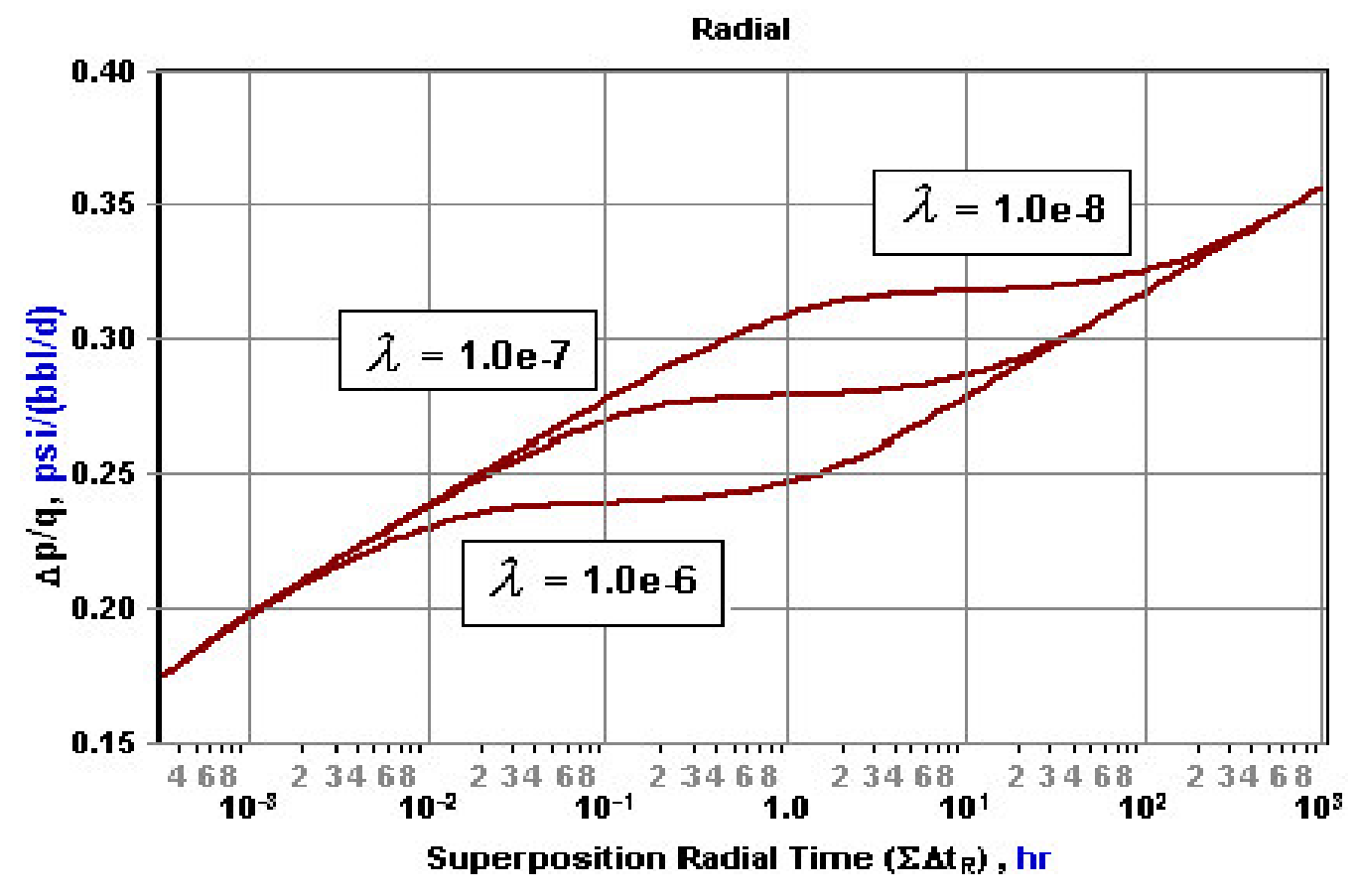

Figure 10. Interporosity Flow Coefficient (Root, 1963) 


\subsubsection{The storativity ratio:}

The storativity ratio expresses the contribution of fissured system to total storativity and can be calculated using the equation 3. (Aminian, 2011)

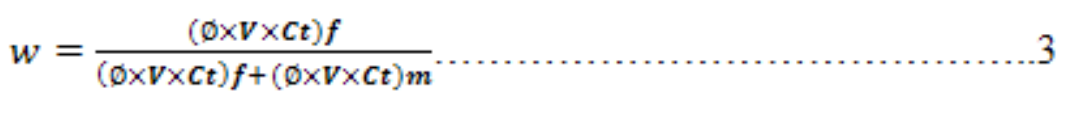

Fissured Formations: $w=10^{-3}$ to $10^{-2}$

Multilayered Formations: w $=10^{-1}$

This parameter essentially represents the time separation in log cycles between the two semi-log straight lines as shown in Figure 11.

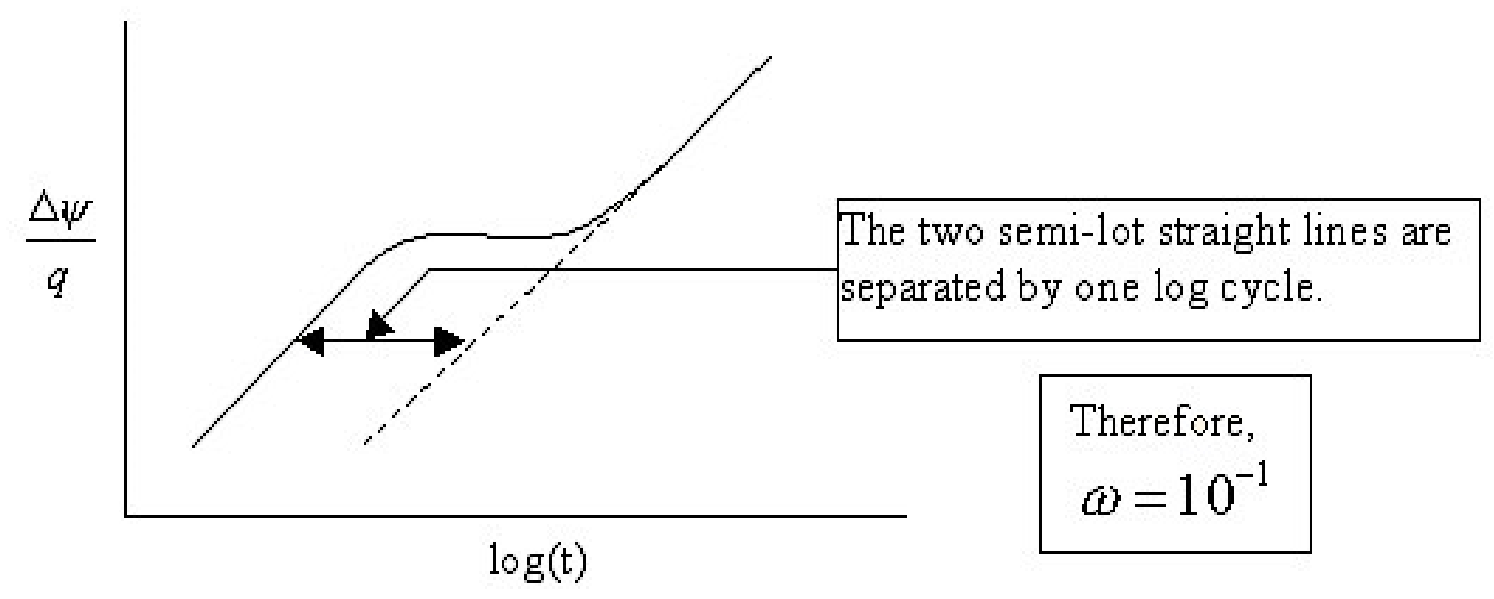

Figure 11. Log Cycle Separation (Root, 1963)

A storativity of 1 is a single porosity system with all of the reserves inside the fractures and a storativity approaching 0 is a single porosity reservoir with all the reserves in the matrix. So, as the storativity ratio decreases, a greater portion of reserves are contained in the matrix and the longer it takes for the matrix and fracture system to reach a state of equilibrium. Figure 13 illustrates this concept. 


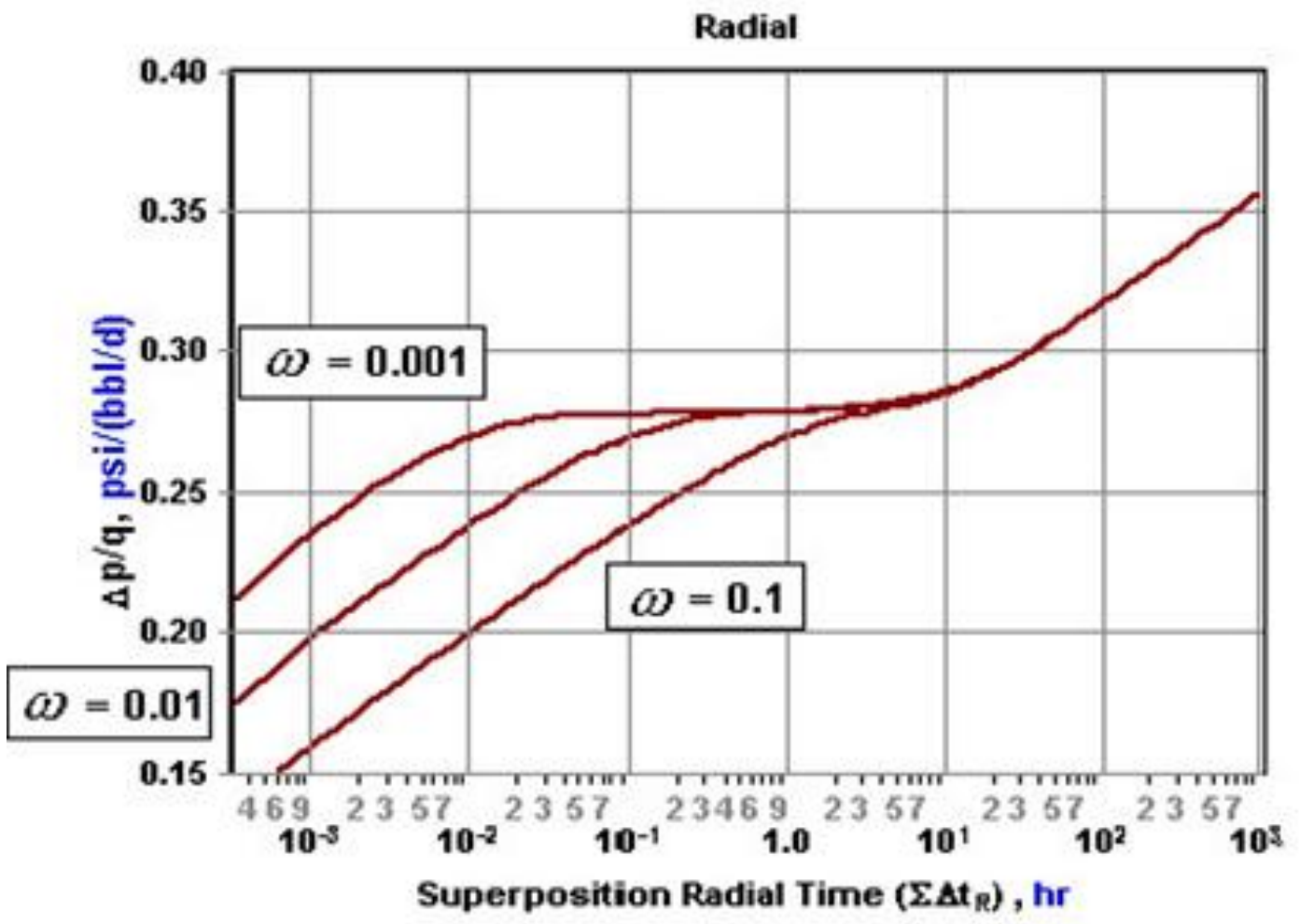

Figure 12. Storativity Illustration (Root, 1963) 


\section{Chapter 3}

\section{Methodology}

The purpose of this thesis is to analyze the production potential of Marcellus shale using actual field data. Since Marcellus shale has not been producing for a long period of time and has been only recently recoverable, this thesis will focus on the future performance of the Marcellus Shale formations for both vertical and horizontal wells for the next 30 years using history matching. In order to achieve the above objective the followings steps have been taken:

\section{1) Gathering vertical and horizontal production data}

2) Production data plot

\section{3) Development of base model}

\section{4) History matching}

\section{5) Development of final vertical and horizontal models}

\section{6) Estimation of the recovery for horizontal and vertical wells}

\subsection{Gathering vertical and horizontal production data:}

This step is gathering production data for vertical and horizontal Marcellus Shale that has a reasonable decline curve. In this step, the West Virginia Geological Survey is used to gather all of the necessary production data for the Marcellus Shale formation. There are hundreds of vertical wells illustrated on their website; however a minority of the wells are located in the Marcellus Shale zones. The production rate for some of the formations appeared to be low. One of the reasons for such a low production could be that these wells were not hydraulically fractured when this information was recorded. In addition, some wells have a low production history. For instance, the production starts in January and ends in April. This amount of 
production time (e.g. 4 months) is not enough data to be used for an accurate history matching and as a result they will not be used. After plotting some of the vertical wells they appear to have an abundance of fluctuations. This can be for a number of reasons including changing bottom hole pressures, equipment problems, and so forth. For this particular thesis 9 vertical wells that have the longest and smoothest production history are selected.

There are approximately 51 horizontal Marcellus Shale wells available in the West Virginia Geological Survey. The production data for majority of these horizontal wells are either unavailable or incomplete with too many fluctuations. After analyzing the data of these 51 wells only 3 had a long enough production history to be used for this thesis. Thus 3 horizontal wells with longest and smoothest production data are selected to work on.

The completion data for some of the vertical and horizontal wells are provided. However, the logging data is missing for the majority of the vertical and horizontal wells with the smoothest and longest production history. Gathering this information is the most tedious step that needs to be done. (APPENDIX B)

\subsection{Production Data Plot:}

As the reservoir is being produced the pressure decreases and gas production rate declines as a function of time. In this step the production plot for each vertical and horizontal well is plotted to demonstrate the rate at which each well is declining. Typically the production plots used in this thesis are from 1 to 3 years for both vertical and horizontal wells. (APPENDIX C) 


\subsection{Creation of base model:}

Using the literature (SPE papers, Field representatives, etc.) a base model for vertical and horizontal wells is established. A base model is an essential part of this thesis because it will be used to build the shale model for vertical and horizontal wells. A dual porosity model is used for all of the runs since this is an unconventional shale performance analysis. In the model definition two phases (gas and water) are used with 1) the employment of non-equilibrium initialization, 2) the included shale properties, and 3) the instant adsorption model. This model is run for 30 years not only to have an understanding of the early and late part of each parameter, but also to predict the future behavior of the reservoir for the next 30 years.

5 layers of production for the Marcellus shale have been assumed for all the runs to see the impact of the natural fracture, matrix permeability, and porosity as much as possible in the production results. In addition, the length and width of the reservoir depends on the drainage area, which is assumed based on the real field production data from vertical and horizontal wells. Furthermore, thicknesses of the reservoir are available for some of the vertical and horizontal wells using the "Pay Zone" data from the West Virginia Geological Survey Website. For the wells with thicknesses that are not provided, the Marcellus Shale thickness map in West Virginia is used to estimate the thickness. After going through multiple SPE papers, natural fracture porosity and permeability parameters have been defined. Since all the real field production data available for the vertical and horizontal wells have about 1 to 3 years of production history and the production duration is very short, hydraulic fracture porosity will not have much impact on the initial production for vertical wells. Please note that the natural fracture and matrix permeability in $\mathrm{z}$ direction are $1 / 10$ of the $\mathrm{x}$ and $\mathrm{y}$ direction because of overburden and 
compaction pressure which cause the permeability in $\mathrm{z}$ direction to be $1 / 10$ lower than $\mathrm{x}$ and $\mathrm{y}$ directions.

Table 1. Basic Model Parameter

\begin{tabular}{|c|c|}
\hline \multicolumn{2}{|c|}{ Basic Model Parameters } \\
\hline \multicolumn{2}{|l|}{ Reservoir Parameters } \\
\hline Depth, ft & 7000 \\
\hline Thickness, ft & 75 \\
\hline \multicolumn{2}{|l|}{ Rock Properties } \\
\hline Porosity type & Dual \\
\hline Fracture Porosity, fraction & 0.005 \\
\hline Matrix porosity, fraction & 0.05 \\
\hline Fracture perm, $l, j, k, m d$ & $0.002,0.002,0.0002$ \\
\hline Matrix perm, $l, j, k$, md & $0.0002,0.0002,0.0002$ \\
\hline Coal Compress, $1 / p$ sia & $1 \times 10^{-5}$ \\
\hline Density, $\mathrm{Ib} / \mathrm{ft}^{3}$ & 100 \\
\hline \multicolumn{2}{|l|}{ Initial Conditions } \\
\hline Reservoir pressure, psia & 3500 \\
\hline Water saturation, fraction & 0.15 \\
\hline \multicolumn{2}{|l|}{ Hydraulic Fractures Properties } \\
\hline Half length, $\mathrm{ft}$ & 500 \\
\hline Width, in & 0.01 \\
\hline Top of Fracture, $\mathrm{ft}$ & 7000 \\
\hline Bottom of Fracture, $\mathrm{ft}$ & 7075 \\
\hline porosity, fraction & 0.2 \\
\hline \multicolumn{2}{|l|}{ Well Production Controls } \\
\hline$P_{\text {me }}$ psia & 500 \\
\hline \multicolumn{2}{|l|}{ Fluid Properties } \\
\hline Standard Pressure, psia & 14.7 \\
\hline Standard Temperature, ${ }^{\circ} \mathrm{F}$ & 60 \\
\hline Reference Temperature, ${ }^{\circ} \mathrm{F}$ & 120 \\
\hline \multicolumn{2}{|l|}{ Adsorption } \\
\hline Gas Diffusion Coefficient, $\mathrm{ft}^{2} / \mathrm{day}$ & 1 \\
\hline Sorption Time, day & 62 \\
\hline Langmuir Pressure, psia & 635 \\
\hline Langmuir Concentration, MSCF/ton & 0.08899 \\
\hline
\end{tabular}


The Initial Reservoir Condition is based upon the Total Vertical Depth which is about $7000 \mathrm{ft}$ for the Marcellus shale around counties selected for this project. Based on the depth the initial reservoir pressure can be estimated using the hydrostatic pressure relationship. In addition, the water saturation is set to be $15 \%$ for all simulation runs.

Hydraulic fracture properties are assumed after discussing the issue with different companies exploring hydraulic fracturing and also based on the literature review of different SPE papers. More than anything else the hydraulic fracture properties usually impact the initial production. For example changing the permeability of the hydraulic fracture of any of the wells would yield a significant change in the initial production.

Bottom hole pressure production control mode is necessary in reservoir simulation because below that pressure all simulation runs will be terminated. The above value is a typical minimum bottom hole pressure and most companies usually drain the reservoir to 500 psia after so many years of production.

Finally the fluid properties are created for the base model. In a shale reservoir there are two types of gas. The first type of gas is called the free gas which can be obtained in a conventional reservoir as well as an unconventional reservoir. Free gas exists in the reservoir in the gaseous phase rather than in a solution. As soon as the formation pressure drops below the bubble point the gas is evolved. The gas is referred to as free gas while it is in the reservoir. The second type of gas, which separates the shale formation from other conventional reservoirs, is sorbed gas. The gas accumulates on the surface of a solid material such as reservoir rock grains or more pertinently organic particles in a shale reservoir. Measuring the adsorbed gas and 
interstitial gas (i.e. gas contained in formation pores) allows for the calculation of the gas in place in a given reservoir. (Schlumberegr, 2011)

Langmuir Concentration refers to the gas content in the reservoir. Its unit of measurement for the unconventional gas in place calculation is SCF/U.S. Langmuir pressure constant $\left(\mathrm{P}_{\mathrm{L}}\right)$ represents the pressure at which the gas storage capacity equals one half of the maximum storage capacity $\left(\mathrm{V}_{\mathrm{L}}\right)$. Finally, sorption time is the time required to desorb $63.2 \%$ of the initial gas volume. (Aminian, Fundamental Concept of Coalbed Methane)

By imputing all of the above adsorption parameters into the model the simulation can calculate the gas content (SCF/TON), and finally initial gas in place using Equation 4.

\subsubsection{Gas in place calculation for unconventional shale formations:}

Gas in place can be calculated using equation 4 which contains free gas and sorbed gas.

$\mathrm{G}_{\mathrm{i}}$, free $+\mathrm{G}_{\mathrm{i}}$, sorbed $=\operatorname{Ah}\left[\frac{43560 \times \emptyset \times(1-S w)}{B_{g i}}\right]+1.359 \times \mathrm{A} \times \mathrm{h} \times \rho_{\mathrm{c}} \times \mathrm{G}_{\mathrm{c}}$ 4

$\mathrm{G}_{\mathrm{i}, \text { free }}=$ free gas in place at initial reservoir condition, MSCF

$\mathrm{G}_{\mathrm{i} \text {, sorbed }}=$ sorbed gas in place, $\mathrm{MCF}$

$\mathrm{A}=$ reservoir drainage area, acres

$\mathrm{h}=$ reservoir net thickness

$\mathrm{f}=$ effective fracture porosity, fraction

$\mathrm{S}_{\mathrm{w}}=$ initial water saturation in the fracture, fraction

$\mathrm{B}_{\mathrm{gi}}=$ gas formation volume factor at $\mathrm{P}_{\mathrm{i}}, \mathrm{ft}^{3} / \mathrm{Mscf}$ 
$\mathrm{A}=$ reservoir drainage area, acres

$\mathrm{h}=$ reservoir net thickness

$\mathrm{G}_{\mathrm{c}}=$ Ave in-situ gas content, $\mathrm{SCF} /$ ton

$\mathrm{P}_{\mathrm{c}}=$ average coal density, $\mathrm{g} / \mathrm{cc}$

\subsection{History Matching:}

By varying parameters including the reservoir drainage area, natural fracture permeability, natural fracture porosity, fracture half length, hydraulic fracture permeability, hydraulic fracture porosity, number of fractures, and flowing bottom hole pressure, each vertical and horizontal well is historically matched. In this part of the project reservoir simulation is used to create 9 models for vertical wells and 3 models for horizontal wells based on the base model parameters illustrated in Table 1. Various parameters need to be altered in each specific model in order to historically match the real field production data for vertical and horizontal wells. More than 500 runs have been performed using Eclipse in order to match each and every well as accurately as possible. In this step the impact of each mentioned parameter on the production curve is recorded to have a better understanding of the dual porosity system and shale formations.

\subsection{Creation of final vertical and horizontal models:}

Various parameters are used for each vertical and horizontal model. This step is one of the most important steps of the thesis because the final models for both vertical and horizontal wells are going to be built based on all of the designed vertical and horizontal models. For instance, each vertical model created has a different natural fracture permeability. After arranging all of the natural fracture permeabilities and formatting them as a table, the most commonly used 
natural fracture permeability is identified and used for the vertical model. For instance, If the most commonly used natural fracture permeability for all the 9 vertical wells is $0.002 \mathrm{md}$, then this permeability is used when creating the final vertical model. The rest of the parameters for the final vertical and horizontal models are found using the same procedure.

\subsection{Estimation of the recovery for horizontal and vertical wells:}

Finally, one vertical and one horizontal model with the most frequently repeated parameters

is run in Eclipse to yield the final results for this thesis and to distinguish the future behavior of the reservoir for the next thirty years. These results include the recoverable reserves and recovery factor for both horizontal and vertical wells after thirty years. In addition, the results can be used to compare the productivity of vertical Marcellus Shale with horizontal Marcellus Shale. 


\section{Chapter 4 \\ Results and Discussions}

There are 9 vertical and 3 horizontal wells studied in this thesis. I have illustrated 1 vertical and 1 horizontal well that have been historically matched in this thesis. The first well illustrated below is vertical and the second well is horizontal. Both wells are located in Upshur County. The rest of the wells are illustrated in Appendix D with explanation for each history match.

\subsection{Vertical \#2:}

The second well studied in this thesis is located in Upshur County. The acreage for this well is assumed to be 80 acres and the thickness was obtained from the completion data as $47 \mathrm{ft}$. In addition, a square reservoir is assumed for this reservoir with dimensions of $1867 * 1867\left(\mathrm{ft}^{\wedge} 2\right)$. Both the initial and final parameters used for getting a match are listed in Table 2.

To get a match natural fracture permeability had to be increased from 0.002 md to 0.004 md in order for the curve to shift upward. By increasing the natural fracture permeability, the entire decline curve shifts upward. In addition, natural fracture porosity had to be increased as well (from 0.005 to 0.009 ) in order to increase the numbers of natural fractures that exist in the dual porosity model and as a result increasing the initial production. It was observed that when altering the natural fracture porosity it does not have huge impact on the production decline curve and its little impact is only visible at the beginning of the production. 
Table 2. Initial and final values of the parameters for vertical \#2

\begin{tabular}{|c|c|c|}
\hline \multicolumn{3}{|c|}{ Initial values of the parameters } \\
\hline Area & 120 & acres \\
\hline Top of fracture & 7053 & $\mathrm{ft}$ \\
\hline Bottom of fracture & 7100 & $\mathrm{ft}$ \\
\hline Thickness & 47 & $\mathrm{ft}$ \\
\hline Fracture porosity & 0.005 & fraction \\
\hline Matrix porosity & 0.05 & fraction \\
\hline Fracture permeabilit & 0.002 & md \\
\hline Dimensions & $2286 * 2286$ & $\mathrm{ft}^{\wedge} \mathbf{2}$ \\
\hline Matrix permeability & 0.0002 & $\mathrm{md}$ \\
\hline Rock Density & 100 & $\mathrm{lb} / \mathrm{ft}^{\wedge} 3$ \\
\hline Pressure & 3500 & psia \\
\hline$S_{w}$ & 15 & $\%$ \\
\hline \multicolumn{3}{|c|}{ Hydraulic Fracture } \\
\hline Half length & 500 & $\mathrm{ft}$ \\
\hline permeability & 20000 & $\mathrm{md}$ \\
\hline porosity & 20 & $\%$ \\
\hline width & 0.01 & inch \\
\hline
\end{tabular}

\begin{tabular}{|c|c|c|}
\hline \multicolumn{3}{|c|}{ Final values of the parameters after the match } \\
\hline Area & 80 & acres \\
\hline Top of fracture & 7053 & $\mathrm{ft}$ \\
\hline Bottom of fracture & 7100 & $\mathrm{ft}$ \\
\hline Thickness & 47 & $\mathrm{ft}$ \\
\hline Fracture porosity & 0.009 & fraction \\
\hline Matrix porosity & 0.05 & fraction \\
\hline Fracture permeability & 0.004 & md \\
\hline Dimensions & $1867 * 1867$ & $\mathrm{ft}^{\wedge} \mathbf{2}$ \\
\hline Matrix permeability & 0.0002 & $\mathrm{md}$ \\
\hline Rock Density & 100 & $\mathrm{lb} / \mathrm{ft}^{\wedge} 3$ \\
\hline Pressure & 3500 & psia \\
\hline$S_{w}$ & 15 & $\%$ \\
\hline \multicolumn{3}{|c|}{ Hydraulic Fracture } \\
\hline Half length & 500 & $\mathrm{ft}$ \\
\hline permeability & 20000 & $\mathrm{md}$ \\
\hline porosity & 20 & $\%$ \\
\hline width & 0.01 & inch \\
\hline
\end{tabular}

The area of the squared reservoir was decreased from 120 acres to 80 acres. Since real field production data for this specific well was initially high compared with other vertical wells, a higher acreage was assumed for this reservoir to increase the recoverable reserve. However, after reducing the acreage down to 80 acres (which is a common acreage for vertical wells), it was determined that the recoverable reserves does not reduce by much compared to the 120 acres. Therefore assigning a higher drainage area for this well because of higher production data is not accurate. By reducing the acreage the recoverable reserve does not change much, which means assigning 80 acres would be sufficient for the reservoir to be drained. Furthermore, if 120 acres is chosen for this particular well it will decrease the recovery factor by a huge amount since the initial gas in place will be drastically increased. This change in recovery factor is not accurate 
and cannot be done. Figure 14 illustrates the procedure that caused a match for the second vertical well.

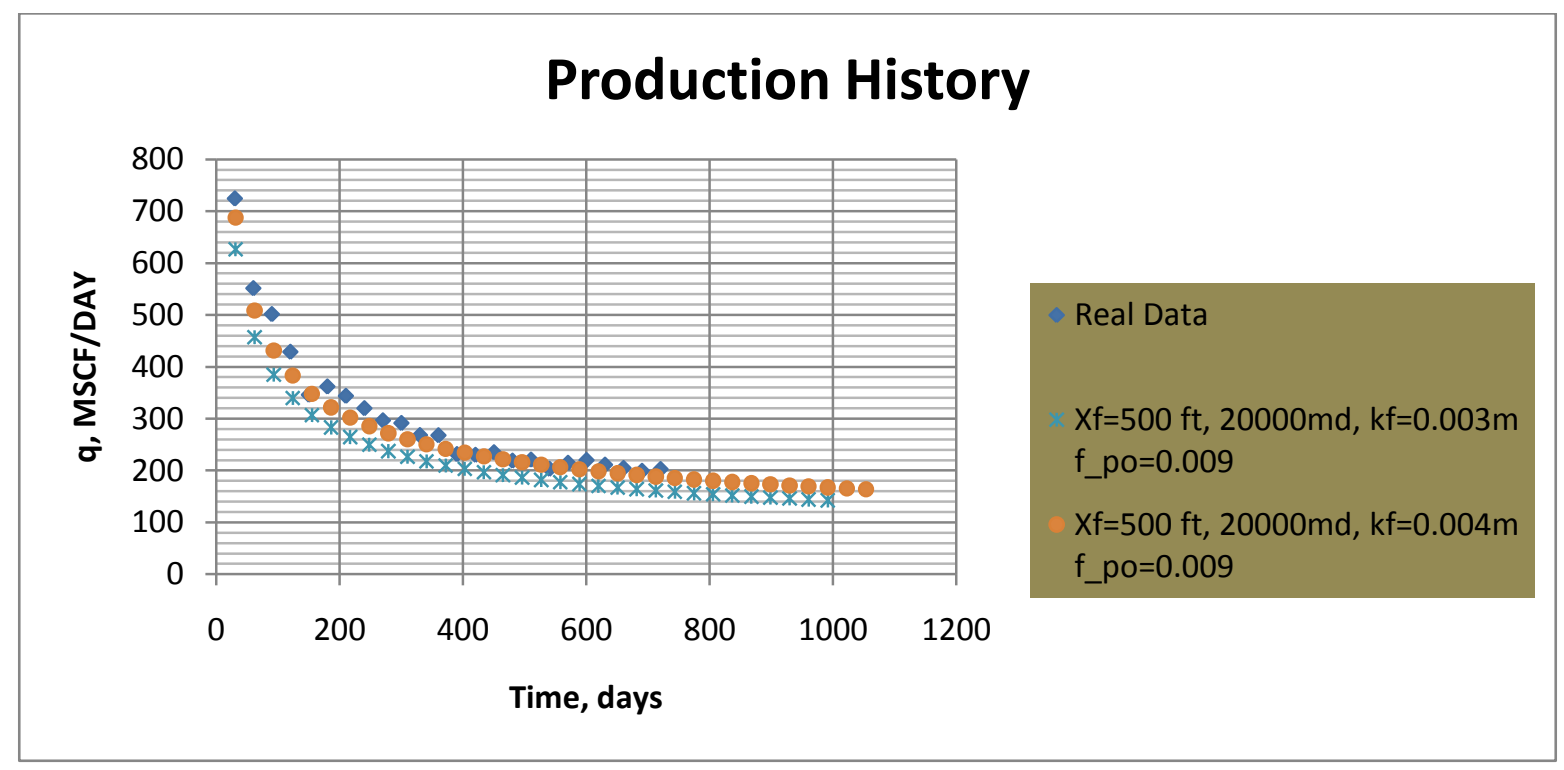

Figure 13. History Matching for Vertical \#2

Please note that performing other runs and changing parameters could be used to come up with a match. However, the above match is only one way of getting the match with approximate parameters from the Marcellus Shale in West Virginia. After running different simulation runs Figure 14 is the match for the second vertical well.

\subsection{Horizontal \#1:}

The first horizontal well studied for this thesis is located in Upshur County. The acreage for this well is assumed to be 220 acres and the thickness was obtained from the thickness map of Upshur County as $75 \mathrm{ft}$. In addition, a rectangular reservoir is assumed for this reservoir with dimensions of $4800 * 2000\left(\mathrm{ft}^{\wedge} 2\right)$. The length of the horizontal segment of this reservoir is $3499 \mathrm{ft}$ is provided in the well data section of West Virginia Geological Survey website. Both initial and final parameters used for getting a match are listed in Table 3. 


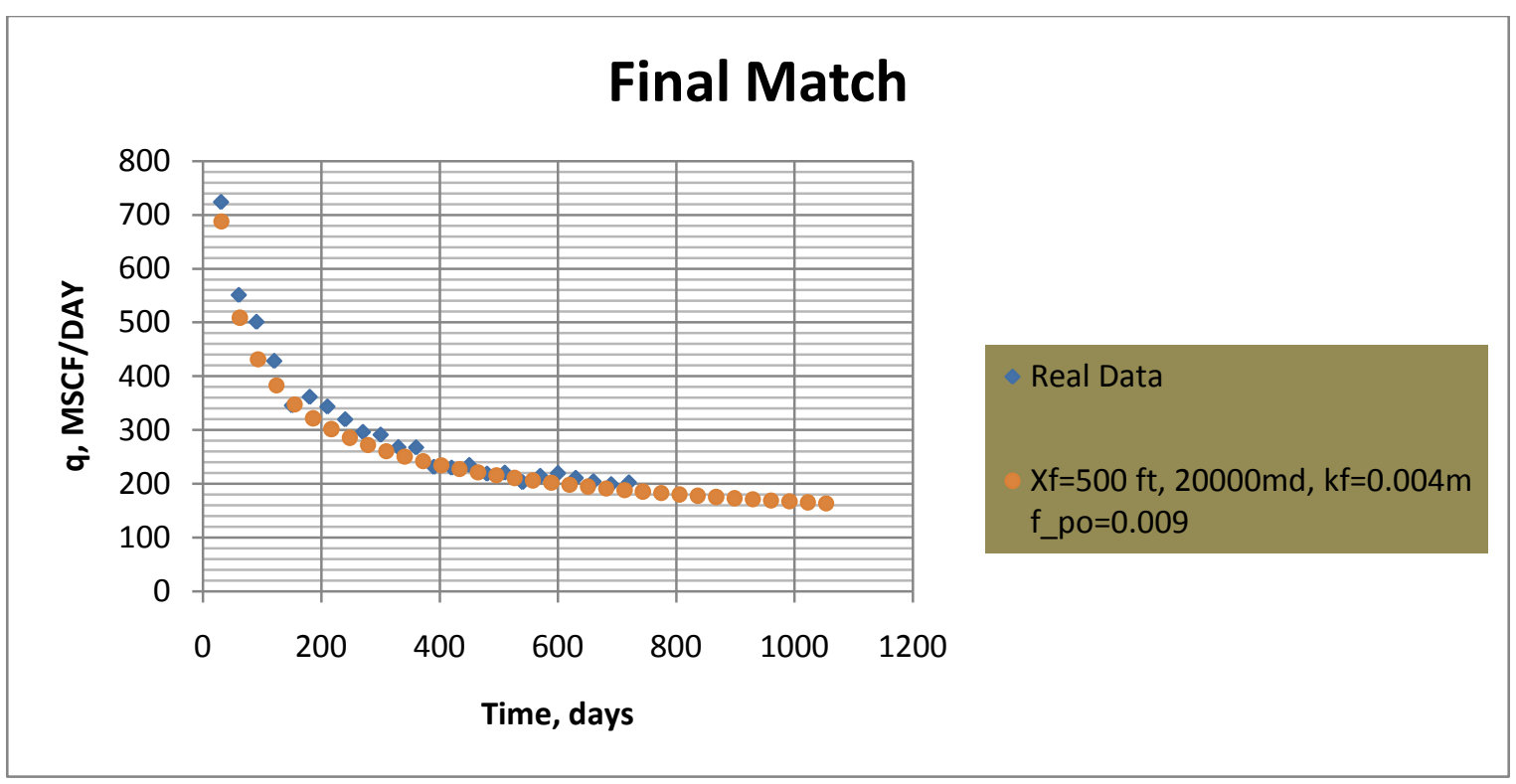

Figure 14. Final Match for Vertical \#2

As can be seen in Table 3, the fracture permeability is reduced to $0.001 \mathrm{md}$ compared to the base model which was $0.002 \mathrm{md}$. Also, numbers of stages (numbers of hydraulic fractures) have increased to meet the criteria. $500 \mathrm{ft}$ equally fractured spacing is assumed for this reservoir. Fracture half length is reduced from $500 \mathrm{ft}$ to $300 \mathrm{ft}$ in order for the production decline curve to go down. In addition, the model assumes an extraordinary amount of hydrocarbon in the natural fracture when having multiple numbers of hydraulic fractures. Thus in order for the model to adjust accurately it is imperative to reduce the hydraulic fracture permeability and porosity to $10,000 \mathrm{md}$ and $10 \%$. In this scenario the model assumes reasonable amount of gas in the natural fractures and the initial production curve goes down after changing the hydraulic fracture permeability and porosity.

Finally, for this specific well the production decline trend has increased after 7 months of production instead of having a normal decline trend. This indicates a change in minimum bottom hole pressure, which can cause this increase in production. As a result to adjust for this change 
minimum bottom hole pressure is assumed to be 800 psia for 7 months and after that it has been reduced to 400 psia to account for an increase in production.

Table 3. Initial and final values of the parameters for horizontal \#1

\begin{tabular}{|c|c|c|}
\hline \multicolumn{3}{|c|}{ Initial values of the parameters } \\
\hline Horizontal length & 3499 & $\mathrm{ft}$ \\
\hline acreage & 220 & acres \\
\hline Top of fracture & 7000 & $\mathrm{ft}$ \\
\hline Bottom of fracture & 7075 & $\mathrm{ft}$ \\
\hline Thickness & 75 & $\mathrm{ft}$ \\
\hline Fracture por & 0.005 & \\
\hline Matrix por & 0.05 & \\
\hline Fracture perm & 0.002 & md \\
\hline Dimensions & $4800 * 2000$ & $\mathrm{ft}^{\wedge} 2$ \\
\hline Matrix perm & 0.0002 & $\mathrm{md}$ \\
\hline Rock Density & 100 & $\mathrm{lb} / \mathrm{ft}^{\wedge} 3$ \\
\hline Pressure & 3500 & psia \\
\hline Sw & 15 & $\%$ \\
\hline Hydraulic Fracture & Seven & Stages \\
\hline Half length & 500 & $\mathrm{ft}$ \\
\hline permeability & 20,000 & md \\
\hline porosity & 20 & $\%$ \\
\hline width & 0.01 & inch \\
\hline \multicolumn{3}{|l|}{ Bottom Hole Pressure } \\
\hline $\mathbf{P}_{\mathrm{wf}}$ & 500 & psia \\
\hline
\end{tabular}

\begin{tabular}{|c|c|c|}
\hline \multicolumn{3}{|c|}{ Final values of the parameters after the match } \\
\hline Horizontal length & 3499 & $\mathrm{ft}$ \\
\hline acreage & 220 & acres \\
\hline Top of fracture & 7000 & $\mathrm{ft}$ \\
\hline Bottom of fracture & 7075 & $\mathrm{ft}$ \\
\hline Thickness & 75 & $\mathrm{ft}$ \\
\hline Fracture por & 0.005 & \\
\hline Matrix por & 0.05 & \\
\hline Fracture perm & 0.001 & md \\
\hline Dimensions & $4800 * 2000$ & $\mathrm{ft}^{\wedge} 2$ \\
\hline Matrix perm & 0.0002 & md \\
\hline Rock Density & 100 & $\mathrm{Ib} / \mathrm{ft}^{\wedge} 3$ \\
\hline Pressure & 3500 & psia \\
\hline Sw & 15 & $\%$ \\
\hline Hydraulic Fracture & Seven & Stages \\
\hline Half length & 300 & $\mathrm{ft}$ \\
\hline permeability & 10,000 & md \\
\hline porosity & 10 & $\%$ \\
\hline width & 0.01 & inch \\
\hline \multicolumn{3}{|l|}{ Bottom Hole Pressure } \\
\hline$P_{w f}(01 / 01 / 1981)$ & 800 & psia \\
\hline$P_{w f}(07 / 01 / 1981)$ & 400 & psia \\
\hline
\end{tabular}

Figure 15 is a visual illustration of having different reservoir and hydraulic fracture parameters. Figure 15 demonstrates that using incremental pressure is essential to get a match for this case since after about 210 days the production decline increases. In addition, natural fracture permeability is reduced to 0.001 md to meet the real field data requirements. 


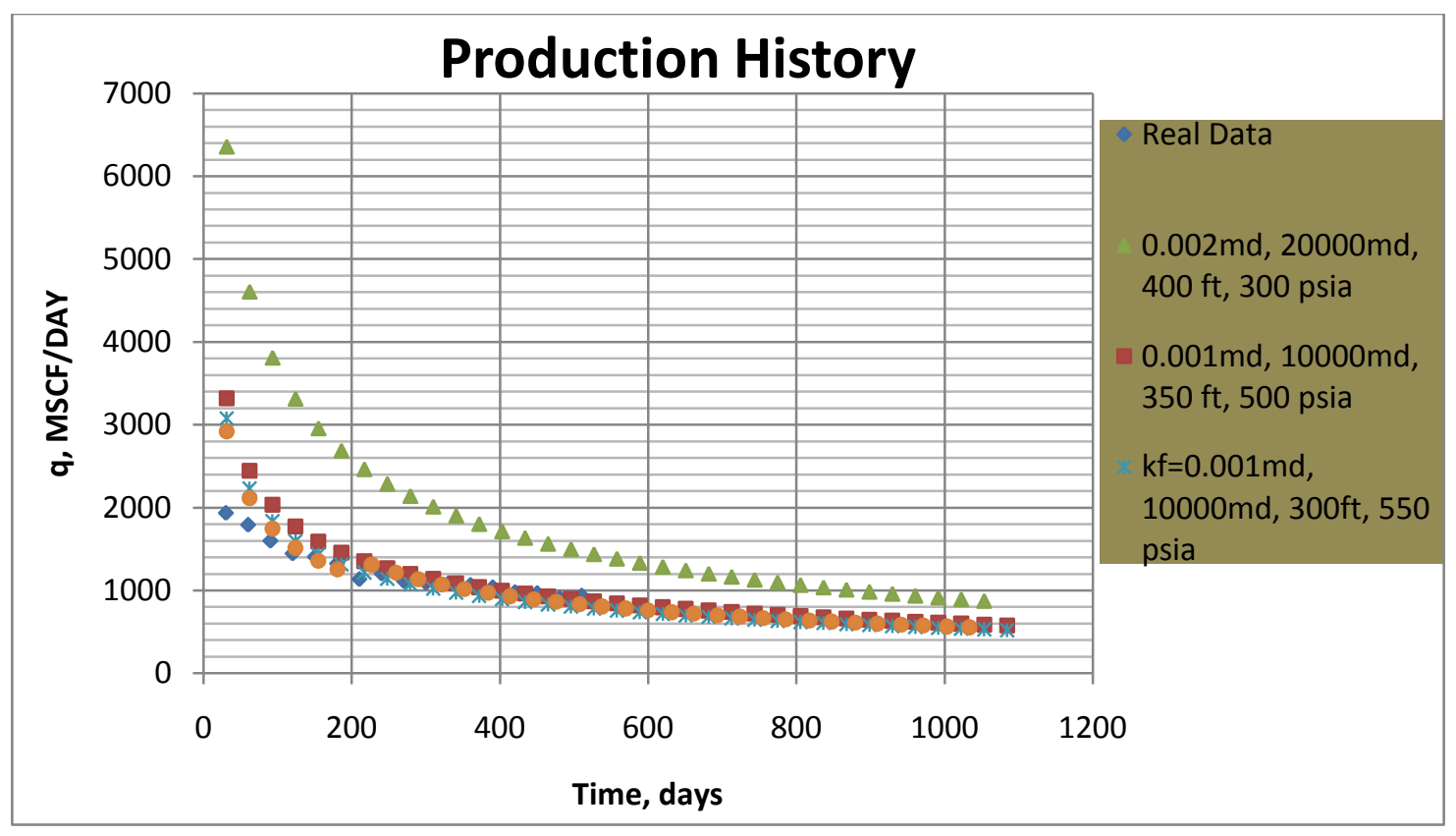

Figure 15. History Matching for Horizontal \#1

Figure 16 is the match that was obtained for the first horizontal well.

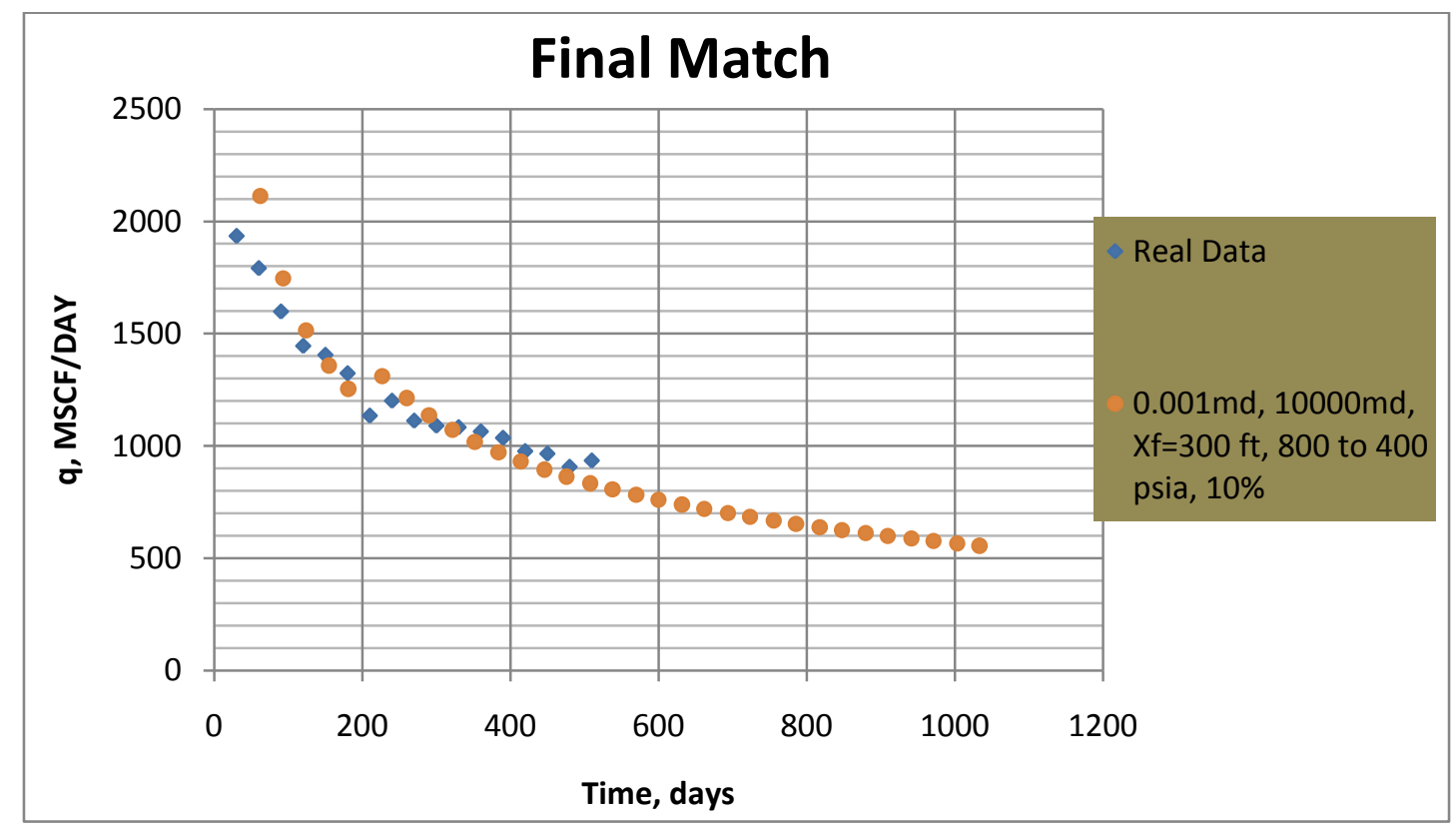

Figure 16. Final Match for Horizontal \#1 
As can be seen in Figure 17 the model is assumed to be horizontal with seven stages of hydraulic fracturing. The horizontal well is assumed to be in the middle of reservoir which means it was placed in the y-direction and half of the reservoir width. The green color in the model indicates that it was successfully perforated and hydraulically fractured.

Figure 18 is a visual representation of the model.

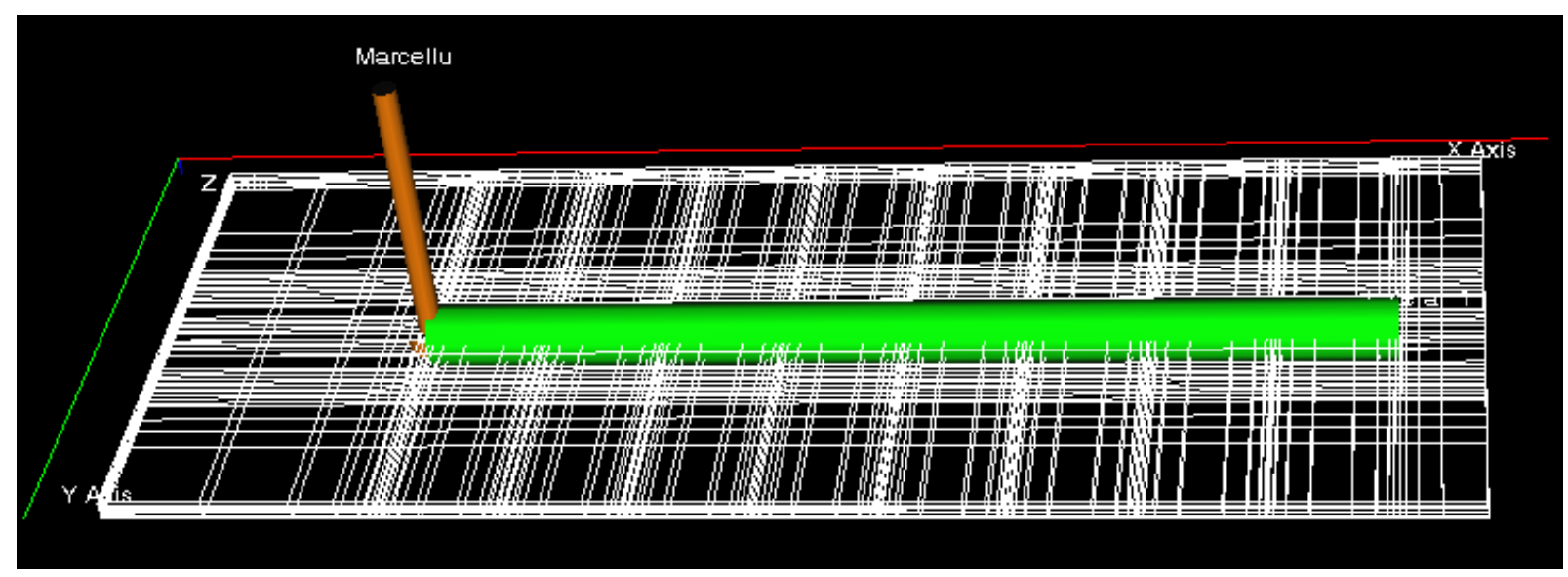

Figure 17. Horizontal Model \#1 Illustration

\subsection{Final Vertical and Horizontal Model Selection:}

One of the objectives of this thesis is to come up with a final model for one vertical and one horizontal well based on the previous studied vertical and horizontal wells. The vertical and horizontal well parameters developed can be used for real field application. After building the new vertical and horizontal models these two models can be run in order to understand the recovery factor and reserves for both the vertical and horizontal wells after 30 years.

Table 4 shows the final parameters for all of the vertical and horizontal wells used to history match. 


\begin{tabular}{|c|c|c|c|c|}
\hline Well \# & Horizontal L (ft) & County & Area (acres) & Dimensions (ft^2) \\
\hline Vertical \# 1 & None & Upshur & 80 & $1867^{*} 1867$ \\
\hline Vertical \#2 & None & Upshur & 80 & $1867^{*} 1867$ \\
\hline Vertical \#3 & None & Upshur & 80 & $1867^{*} 1867$ \\
\hline Vertical \#4 & None & Doddridge & 80 & $1867^{*} 1867$ \\
\hline Vertical \#5 & None & Harrison & 80 & $1867^{*} 1867$ \\
\hline Vertical \#6 & None & Upshur & 40 & $1320^{*} 1320$ \\
\hline Vertical \#7 & None & Doddridge & 80 & $1867^{*} 1867$ \\
\hline Vertical \#8 & None & Doddridge & 40 & $1320^{*} 1320$ \\
\hline Vertical \#9 & None & Doddridge & 80 & $1867^{*} 1867$ \\
\hline Horizontal \#1 & 3500 & Upshur & 220 & $4800^{*} 2000$ \\
\hline Horizontal \#2 & 1812 & Upshur & 151 & $3624 * 1812$ \\
\hline Horizontal \#3 & 2727 & Marshall & 216 & $4700^{*} 2000$ \\
\hline
\end{tabular}

\begin{tabular}{|c|c|c|c|c|}
\hline Well \# & Thickness (ft) & Natural fracture por & Natural fracture K (md) & Pwf (psia) \\
\hline Vertical \# 1 & 50 & 0.005 & 0.002 & 500 \\
\hline Vertical \#2 & 47 & 0.009 & 0.004 & 500 \\
\hline Vertical \#3 & 57 & 0.005 & 0.002 & 500 \\
\hline Vertical \#4 & 38 & 0.005 & 0.002 & 500 \\
\hline Vertical \#5 & 80 & 0.005 & 0.001 & 500 \\
\hline Vertical \#6 & 80 & 0.005 & 0.0006 & 500 \\
\hline Vertical \#7 & 50 & 0.005 & 0.001 & 500 \\
\hline Vertical \#8 & 47 & 0.003 & 0.002 & 700 \\
\hline Vertical \#9 & 50 & 0.005 & 0.003 & 500 \\
\hline Horizontal \#1 & 75 & 0.005 & 0.001 & 800 to 400 \\
\hline Horizontal \#2 & 75 & 0.005 & 0.002 & 800 to 600 \\
\hline Horizontal \#3 & 60 & 0.005 & 0.004 & 400 \\
\hline
\end{tabular}

\begin{tabular}{|c|c|c|c|c|c|}
\cline { 2 - 6 } \multicolumn{1}{c|}{} & \multicolumn{5}{c|}{ Hydraulic Fracture Properties } \\
\hline Well \# & K (md) & Porosity (\%) & width (in) & half length (ft) & \# of fracs \\
\hline Vertical \# 1 & 20000 & 20 & 0.01 & 500 & 1 \\
\hline Vertical \#2 & 20000 & 20 & 0.01 & 500 & 1 \\
\hline Vertical \#3 & 20000 & 20 & 0.01 & 500 & 1 \\
\hline Vertical \#4 & 12000 & 20 & 0.01 & 500 & 1 \\
\hline Vertical \#5 & 13000 & 20 & 0.01 & 500 & 1 \\
\hline Vertical \#6 & 15000 & 20 & 0.01 & 500 & 1 \\
\hline Vertical \#7 & 10000 & 20 & 0.01 & 500 & 1 \\
\hline Vertical \#8 & 10000 & 20 & 0.01 & 200 & 1 \\
\hline Vertical \#9 & 20000 & 20 & 0.01 & 500 & 1 \\
\hline Horizontal \#1 & 10000 & 10 & 0.01 & 300 & 7 \\
\hline Horizontal \#2 & 10000 & 10 & 0.01 & 350 & 4 \\
\hline Horizontal \#3 & 20000 & 20 & 0.01 & 500 & 6 \\
\hline
\end{tabular}

Table 4. Final Parameters for Horizontal and Vertical Wells 


\subsection{Final Vertical Model:}

Using carefully selected parameters from the 9 vertical wells and 3 horizontal wells (Table 4) two models have been created. The first final model is a vertical well. It is based on the most repetitive parameters used for each of the 9 vertical wells. For example, an 80 acre reservoir has been used most frequently for the 9 vertical wells studied in this thesis. As a result an 80 acre reservoir parameter has been used to create for this final vertical model. All the parameters for the final vertical model have been selected using the same selection process. Table 5 illustrates the parameters for the final vertical model.

Table 5. Final Vertical Parameters

\begin{tabular}{|c|c|c|}
\hline \multicolumn{3}{|c|}{ Final Vertical Model } \\
\hline Area & 80 & acres \\
\hline Top of fracture & 7000 & $\mathrm{ft}$ \\
\hline Bottom of fracture & 7055 & $\mathrm{ft}$ \\
\hline Thickness & 55 & $\mathrm{ft}$ \\
\hline Fracture porosity & 0.005 & \\
\hline Matrix porosity & 0.05 & \\
\hline Fracture permeability & 0.002 & $\mathrm{md}$ \\
\hline Dimensions & $1867 * 1867$ & $\mathrm{ft}^{\wedge} 2$ \\
\hline Matrix permeability & 0.0002 & $\mathrm{md}$ \\
\hline Rock Density & 100 & $\mathrm{lb} / \mathrm{ft}^{\wedge} 3$ \\
\hline Initial Pressure & 3500 & psia \\
\hline Sw & 15 & $\%$ \\
\hline \multicolumn{3}{|c|}{ Hydraulic Fracture } \\
\hline Half length & 500 & $\mathrm{ft}$ \\
\hline permeability & 10,000 & $\mathrm{md}$ \\
\hline porosity & 20 & $\%$ \\
\hline width & 0.01 & inch \\
\hline Minimum Pwf & 500 & psia \\
\hline
\end{tabular}


After running the above vertical model, decline curve, cumulative production, and initial gas in place can be obtained.

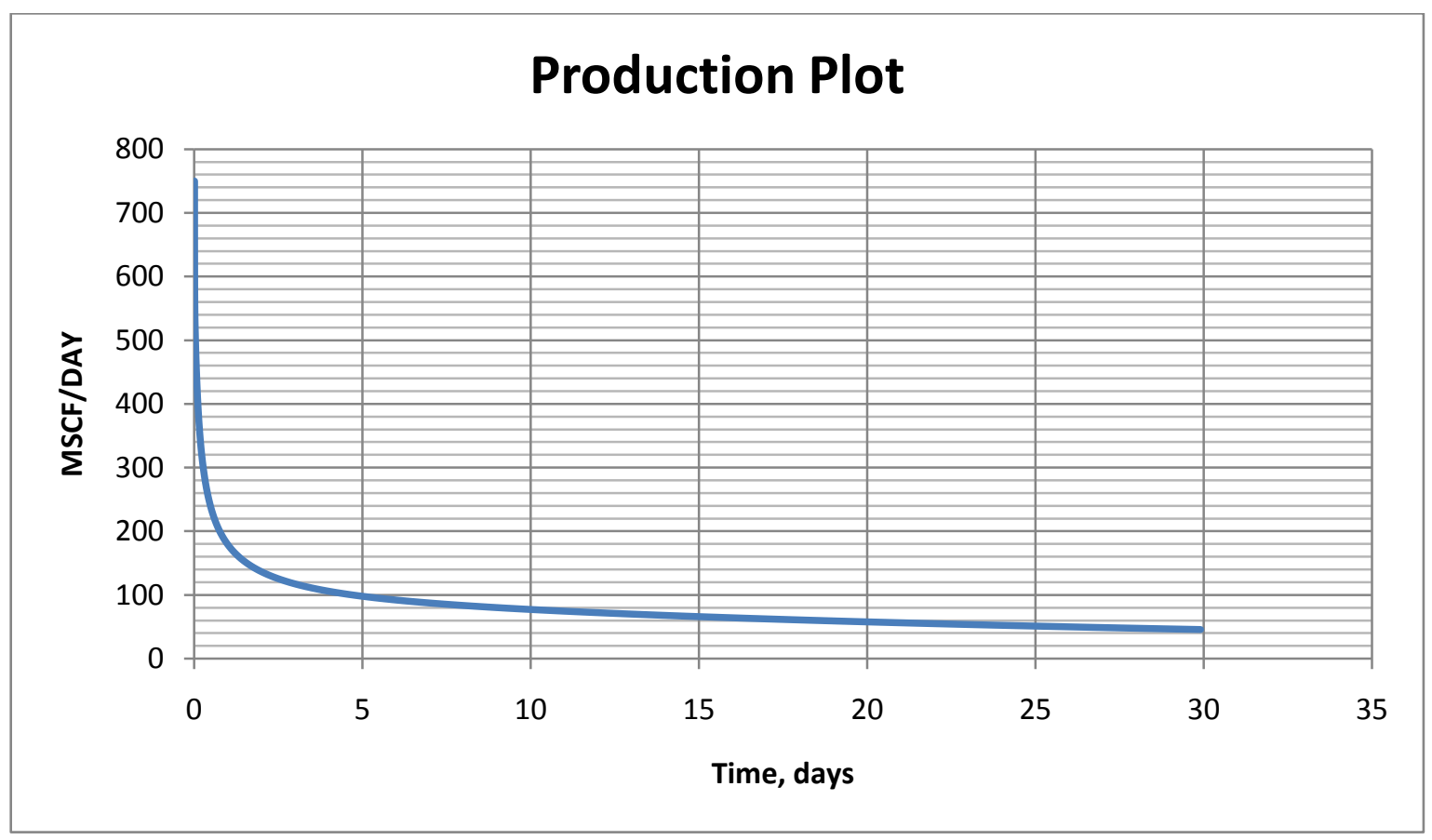

Figure 18. Final Production Rate Behavior for Vertical Model

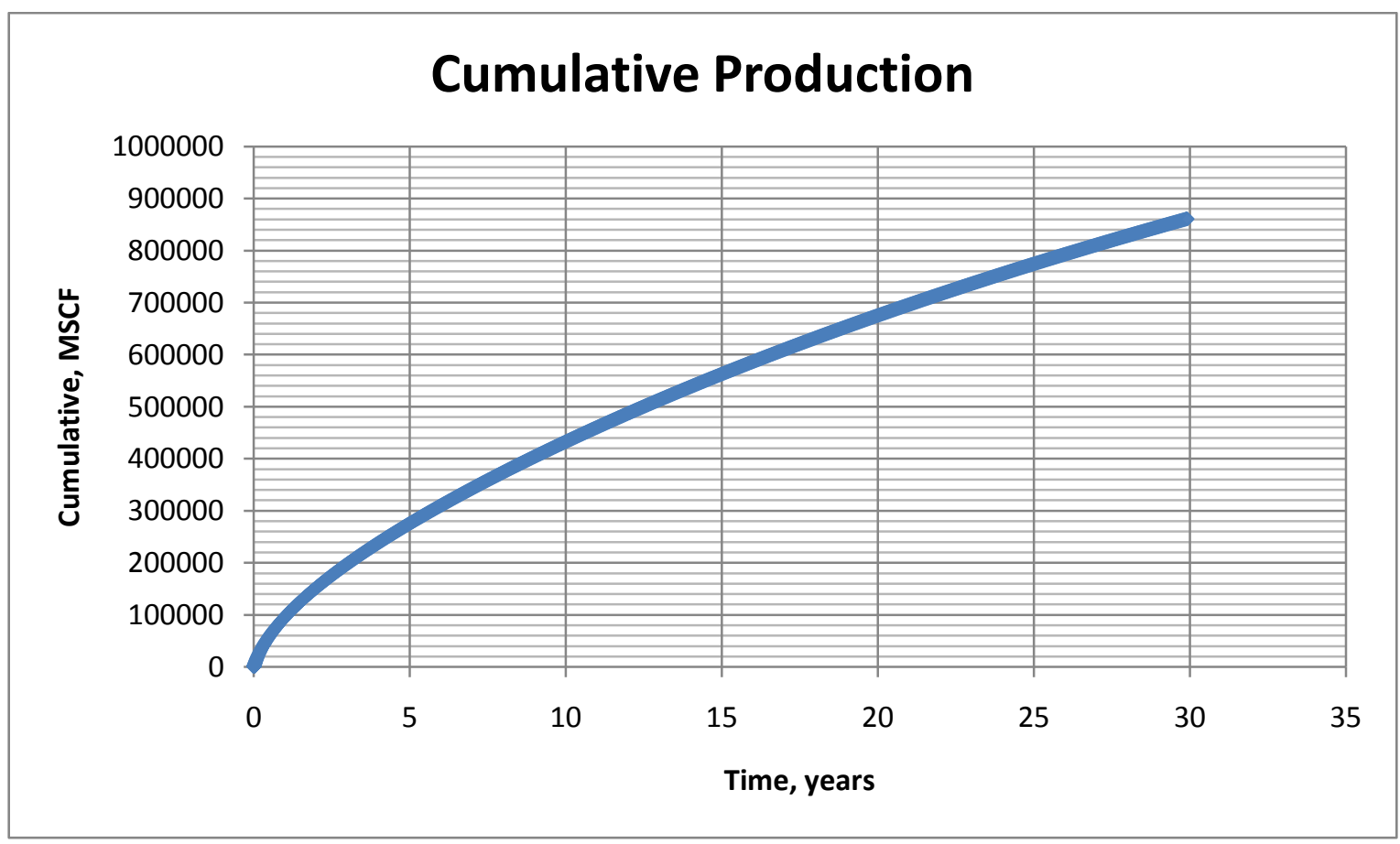

Figure 19. Final Cumulative Production Behavior for Vertical Model 
In addition, recovery factor after 10, 20, and 30 years can be calculated and is shown in Table 6.

\section{Table 6. Recovery Factor for Final Vertical Model}

\begin{tabular}{|c|c|c|c|}
\hline $\begin{array}{c}\text { Time } \\
\text { (years) }\end{array}$ & $\begin{array}{c}\text { EUR } \\
\text { (MSCF) }\end{array}$ & IGIP (MSCF) & RF \\
\hline 10.02 & $433,171.25$ & $2,101,226.80$ & 20.62 \\
\hline 20.00 & $675,268.69$ & $2,101,226.80$ & 32.14 \\
\hline 29.91 & $860,898.88$ & $2,101,226.80$ & 40.97 \\
\hline
\end{tabular}

Therefore, after 30 years on average, vertical wells produce 860,898.88 MSCF with about $41 \%$ recovery.

\subsection{Final Horizontal Model:}

The same analysis can be done for horizontal wells. After reviewing all of the horizontal wells studied in this thesis, the parameters in Table 7 have been chosen to be run in Eclipse.

After running the parameters shown in Table 7, the production curve and cumulative production in Figure 20 and 21 are obtained. 
Table 7. Final Horizontal Parameters

\begin{tabular}{|c|c|c|}
\hline \multicolumn{3}{|c|}{ Horizontal Model } \\
\hline Horizontal length & 3500 & $\mathrm{ft}$ \\
\hline Area & 216 & acres \\
\hline Top of fracture & 7000 & $\mathrm{ft}$ \\
\hline Bottom of fracture & 7075 & $\mathrm{ft}$ \\
\hline Thickness & 75 & $\mathrm{ft}$ \\
\hline Fracture porosity & 0.005 & \\
\hline Matrix porosity & 0.05 & \\
\hline Fracture perm & 0.002 & $\mathrm{md}$ \\
\hline Dimensions & $4700 * 2000$ & $\mathrm{ft}^{\wedge} 2$ \\
\hline Matrix perm & 0.0002 & $\mathrm{md}$ \\
\hline Rock Density & 100 & $\mathrm{Ib} / \mathrm{ft} \wedge 3$ \\
\hline Pressure & 3500 & psia \\
\hline Sw & 15 & $\%$ \\
\hline \multicolumn{3}{|c|}{ Hydraulic Fracture } \\
\hline Half length & 500 & $\mathrm{ft}$ \\
\hline permeability & 10,000 & $\mathrm{md}$ \\
\hline porosity & 20 & $\%$ \\
\hline width & 0.01 & inch \\
\hline \# of stages & 7 & stages \\
\hline
\end{tabular}

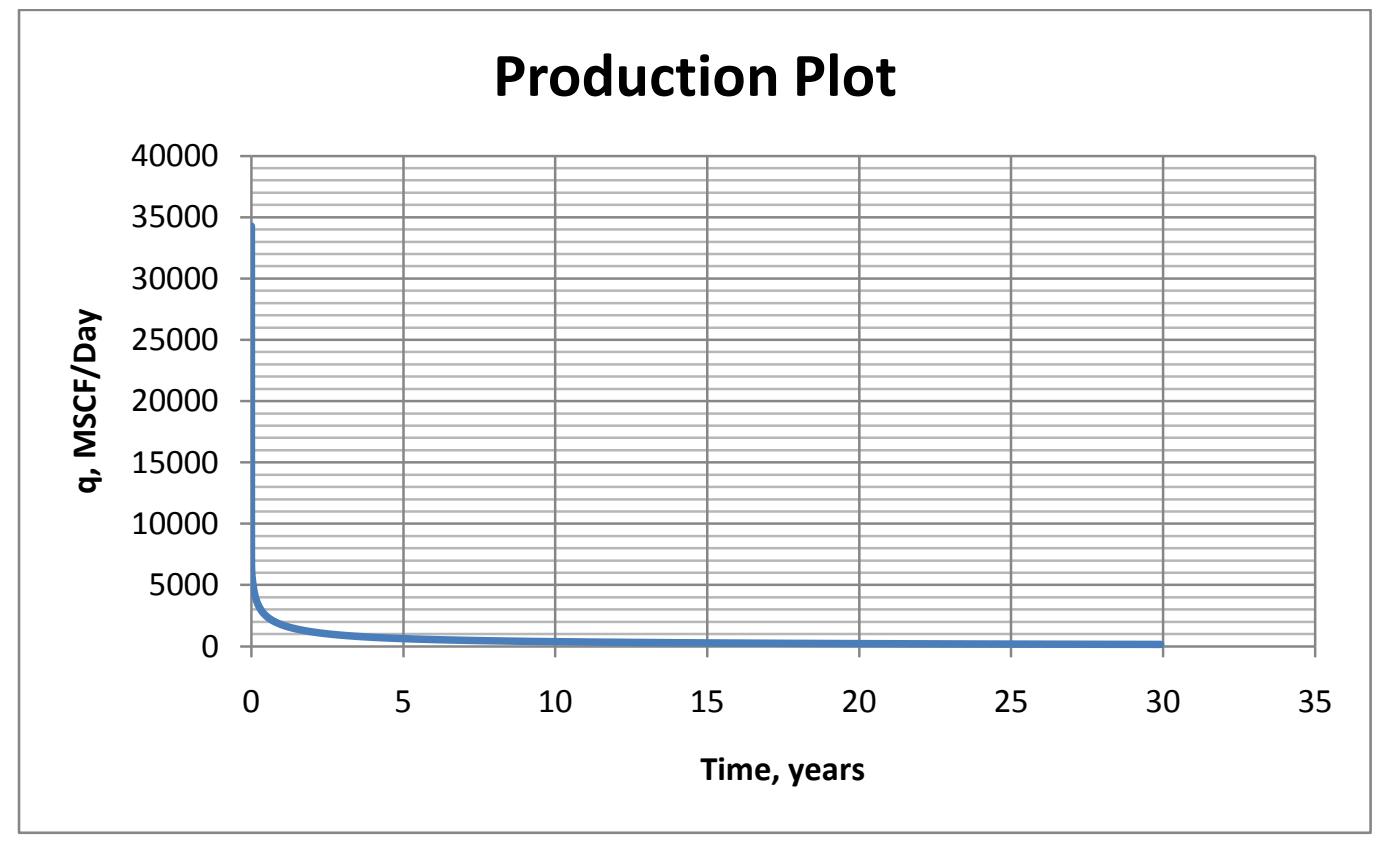

Figure 20. Final Production Rate Behavior for Horizontal Model 


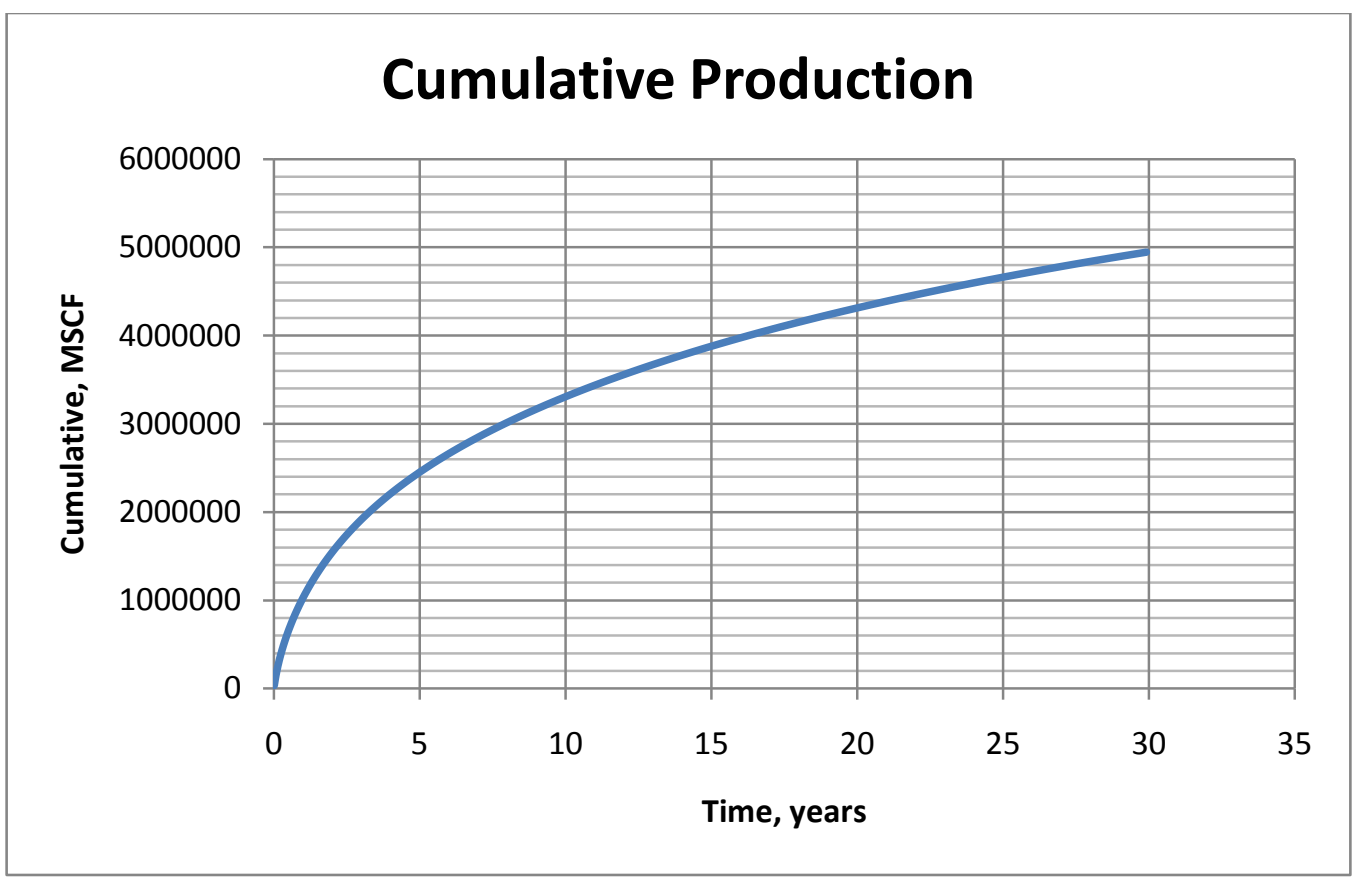

Figure 21. Final Cumulative Production Behavior for Horizontal Model

In addition, recovery factor after 10, 20, and 30 years can be calculated,

Table 8. Recovery Factor for Final Horizontal Model

\begin{tabular}{|c|c|c|c|}
\hline Time (years) & EUR (MSCF) & IGIP (MSCF) & RF \\
\hline 10.015059 & $3,311,735.30$ & $7,722,280.00$ & 42.89 \\
\hline 20.004107 & $4,316,199.50$ & $7,722,280.00$ & 55.89 \\
\hline 29.913757 & $4,947,622.00$ & $7,722,280.00$ & 64.07 \\
\hline
\end{tabular}

So, after 30 years, on average, horizontal wells produce 4,947,622.00 MSCF with approximately $64 \%$ recovery. 


\section{Chapter 5 \\ Conclusions}

The objective of this thesis is to predict the future performance of the reservoir for both vertical and horizontal wells using the real field data. 9 vertical and 3 horizontal wells have been studied to better understand the importance of each parameter in the model generated in Eclipse. Some conclusions that can be made from this thesis are:

1) Natural fracture permeability has a significant impact on the production;

2) Natural fracture porosity has little impact on the initial production of the reservoir;

3) Hydraulic fracture properties are essential in increasing the production. First of all, the fracture half-length has a significant effect on the production. The fracture halflength primarily impacts the early production. Hydraulic fracture permeability only affects the initial production and it has no impact on the later part of the production. Finally, hydraulic fracture porosity's impact occurs during later production period as numbers of hydraulic fracturing stages increases;

4) After analyzing the production history from 9 vertical wells, the suggested parameters for vertical wells in Marcellus Shale are listed in Table 5.

5) After studying and exploring 3 horizontal wells the suggested parameters for horizontal wells in Marcellus shale are listed in Table 7.

6) When comparing the recoverable reserve per acreage horizontal wells produce approximately 22,905.66 MSCF/acre while vertical wells produce $\mathbf{1 0 , 7 6 1 . 2 4}$ MSCF/acre after 30 years;

7) The recoverable reserve for horizontal well is approximately 4.9 BCF while the recoverable reserve for vertical wells is nearly $\mathbf{0 . 8 6}$ BCF after 30 years. 


\section{References}

Aminian, K. (n.d.). Fundamental Concept of Coalbed Methane. Coalbed Methane , 15.

Aminian, K. (2011, January). Natural Gas. Morgantown, WV , U.S.A.

Aminian, K. (2011, March). Unconvetional Reservoir. Morgantown, WV, U.S.A.

Bertola, D. (2008, February 11). Retrieved May 23, 2011, from

http://www.bizjournals.com/buffalo/stories/2008/02/11/story2.html?b=1202706000\%255E15875 57

Common, W. M. (n.d.). Wiki Media Common. Retrieved from Wiki Media Common: http://www.google.com/imgres?imgurl=http://upload.wikimedia.org/wikipedia/commons/a/ac/Di ffusion.jpg\&imgrefurl=http://commons.wikimedia.org/wiki/File:Diffusion.jpg\&usg=_YQSK93 Z-

_EPbdraRhUma5VZTqhs=\&h=357\&w=791\&sz=97\&hl=en \&start=1\&um=1\&itbs=1\&tbnid=CK MGVz

DOE. (2004, June). Hydraulic Fracturing White Paper. U.S.A.

Dr.Cheng (Composer). (2010). Hydraulic Fracturing. [Dr.Cheng, Performer] Morgantown, WV, U.S.A.

EIA. (2008, November). Retrieved July 6, 2011, from

http://www.energyindustryphotos.com/shale_gas_map_shale_basins.htm

EIA. (2009, May 28). Energy Information Administartion. Retrieved July 6, 2011, from http://2.bp.blogspot.com/_4ify7vDXrDs/S7ukXorU5I/AAAAAAAAFiU/5CPKPKIQ2F8/s1600/shale_gas_us_eia_gov.jpg

Farinelli, J. (n.d.). Gas and Rock. Retrieved from Pacific Gas and Electric Company: http://www.google.com/imgres?imgurl=http://www.pgesafetyeducation.com/school/sseng/image s/gas/4-

4ai.gif\&imgrefurl=http://www.pgesafetyeducation.com/school/sseng/gas/index.html\&usg=_y6 24q8hchs9uC1S4gPlwjaVPu9E=\&h=213\&w=500\&sz=29\&hl=en\&start=3\&um=1\&itbs=1\&

Farinelli, J. (n.d.). Pacific Gas and Electric Company. Retrieved from Rock and Gas:

http://www.google.com/imgres?imgurl=http://www.pgesafetyeducation.com/school/sseng/image s/gas/4-

4ai.gif\&imgrefurl=http://www.pgesafetyeducation.com/school/sseng/gas/index.html\&usg=_y6

24q8hchs9uC1S4gPlwjaVPu9E=\&h=213\&w=500\&sz=29\&hl=en\&start=3\&um=1\&itbs $=1 \&$ 
Geology. (2008). Retrieved May 23, 2011, from http://geology.com/articles/marcellusshale.shtml

Geology. (2008). Retrieved May 23, 2011, from http://geology.com/articles/marcellusshale.shtml

Horizontal Drilling. (2008). Retrieved Jul 6, 2011, from http://www.horizontaldrilling.org/

Dr.Cheng (Performer). (2010). Hydraulic Fracture. [Dr.Cheng, Conductor] Morgantown, WV, U.S.A.

Hydraulic Fracturing. (2011). Retrieved May 23, 2011, from PROPUBLICA:

http://www.propublica.org/special/hydraulic-fracturing-national

J.Soeder, D. (1988). Porosity and Permeabilirty of Estern Devonian Gas Shale. SPE

International , 9.

jackson, J. a. (2009). Pore Networks and Fluid Flow in Gas Shales. SPE International , 8.

Jackson, J. a. (2009). Pore Networks and Fluid Flow in Gas Shales. SPE International , 8.

Jackson, J. a. (2009). Pore Networks and Fluid Flow in Gas Shales. SPE International , 8.

K.Aminian. (n.d.). Petroleum and Natural Gas Engineering. Coalbed Methane- Fundamental Concepts , 15.

Master, N. (n.d.). Nation Master. Retrieved from Nation Master:

http://www.statemaster.com/encyclopedia/Buoyancy

Mohaghegh, S. (2010, November). Basic Reservoir Simulation. Morgantown, WV, U.S.A .

NETL. (2010). Projection of Economic Impact of Marcellus Shale Gas Development in West Virginia. Anthony M. Zammerilli.

Root, W. a. (1963). Fekete. Retrieved May 30, 2011, from Dual Porosity:

http://www.fekete.com/software/welltest/media/webhelp/Dual_Porosity.htm

Root, W. a. (1963). The behavior of naturally fractured reservoirs. SPE, 11.

Schlumberegr. (2011). Retrieved June 10, 2011, from slb:

http://www.glossary.oilfield.slb.com/search.cfm

Schlumberger . (2011). Retrieved 19 May, 2011, from Schlumberger Oilfied Glossary:

http://www.glossary.oilfield.slb.com/Display.cfm?Term=gravity\%20drainage

Schlumberger. (2009). U.S.A. 
Schlumberger. (2011). Retrieved May 19, 2011, from

http://www.glossary.oilfield.slb.com/Display.cfm?Term=diffusion

Schlumberger. (2011). Retrieved June 10, 2011, from slb:

http://www.glossary.oilfield.slb.com/Display.cfm?Term=free\%20gas

Schlumberger. (n.d.). Oilfield Glossary. Retrieved from Schlumberger:

http://www.glossary.oilfield.slb.com/search.cfm

Schlumberger. (n.d.). Oilfield Glossary. Retrieved from Schlumberger:

http://www.glossary.oilfield.slb.com/Display.cfm?Term=reservoir\%20pressure

SLB. (2011). Schlumberger. Retrieved June 13, 2011, from

http://www.glossary.oilfield.slb.com/DisplayImage.cfm?ID=663

T.Schweizer, R. (2009). A study of the effects of well and fracture design in a typical Marcellus shale well. West Virginia University's Journal , 109.

toro, J. (n.d.). Petroleum System. Retrieved from Toro's Page:

http://www.geo.wvu.edu/ jtoro/Petroleum/03_Petroleum\%20System.pdf

toro, J. (n.d.). Petroleum System. Retrieved from Toro's page:

http://www.geo.wvu.edu/ jtoro/Petroleum/03_Petroleum\%20System.pdf

Toro, J. (n.d.). Petroleum System. Retrieved from Toro's Page:

http://www.geo.wvu.edu/ jtoro/Petroleum/03_Petroleum\%20System.pdf 


\section{Appendix A}

Appendix A demonstrates the Schlumberger Eclipse software used to Model the Marcellus shale. To achieve this goal, a coal bed methane template was used to enter the shale properties for all the cases that have been shown throughout this thesis. A sequential procedure to run the software is shown below.

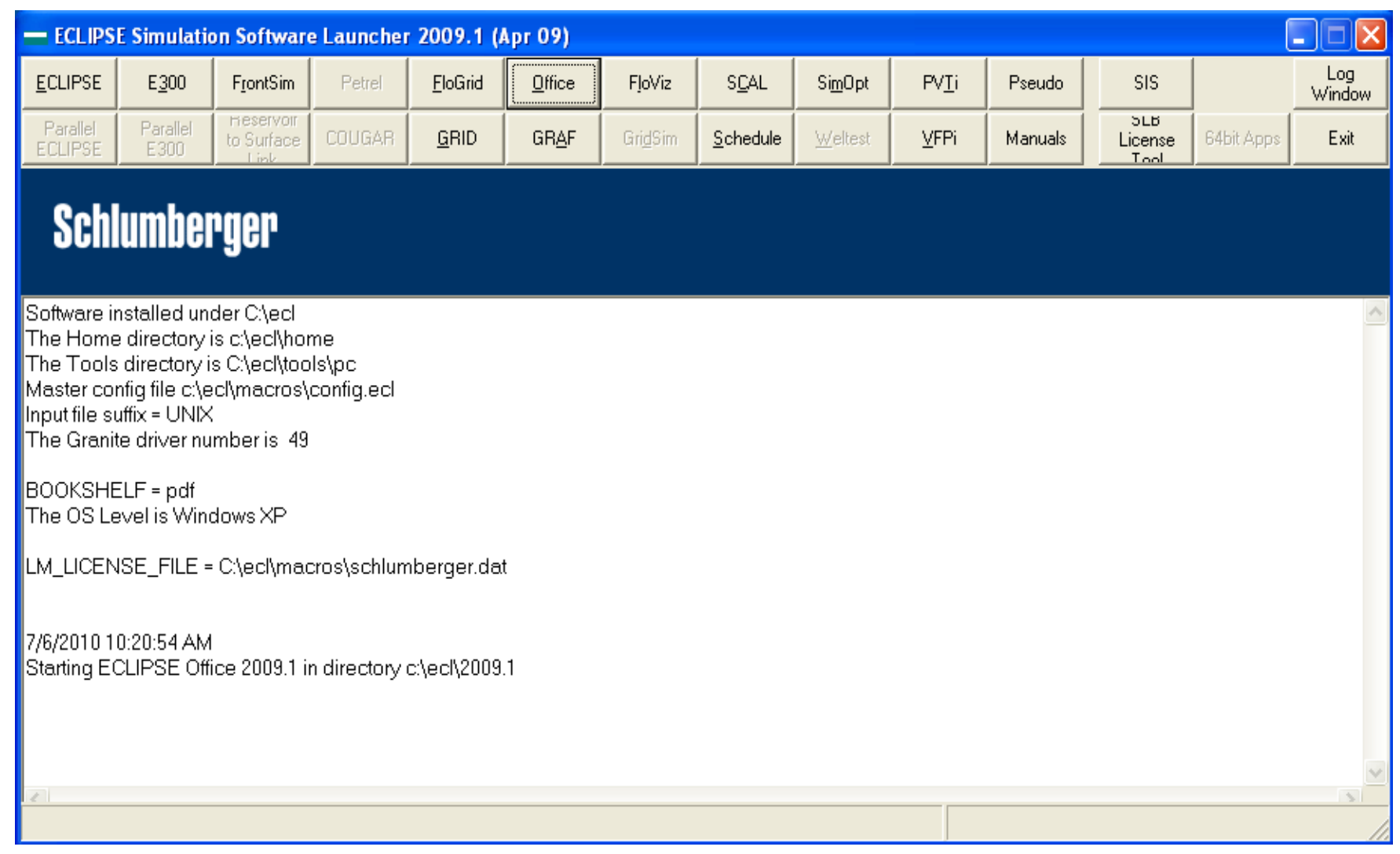

(Figure A-1. Eclipse launcher main screen)

Figure A-1 is the Eclipse Launcher which is used in order to open the template tab. Once here, the "office" tab should be selected. Then "Startup Directory" would appear and the user can choose the location of files to be saved. As shown in the below image, in this example, 2009.1 version of the software is used to run the model. All the runs were made in 2009.1 Model. 


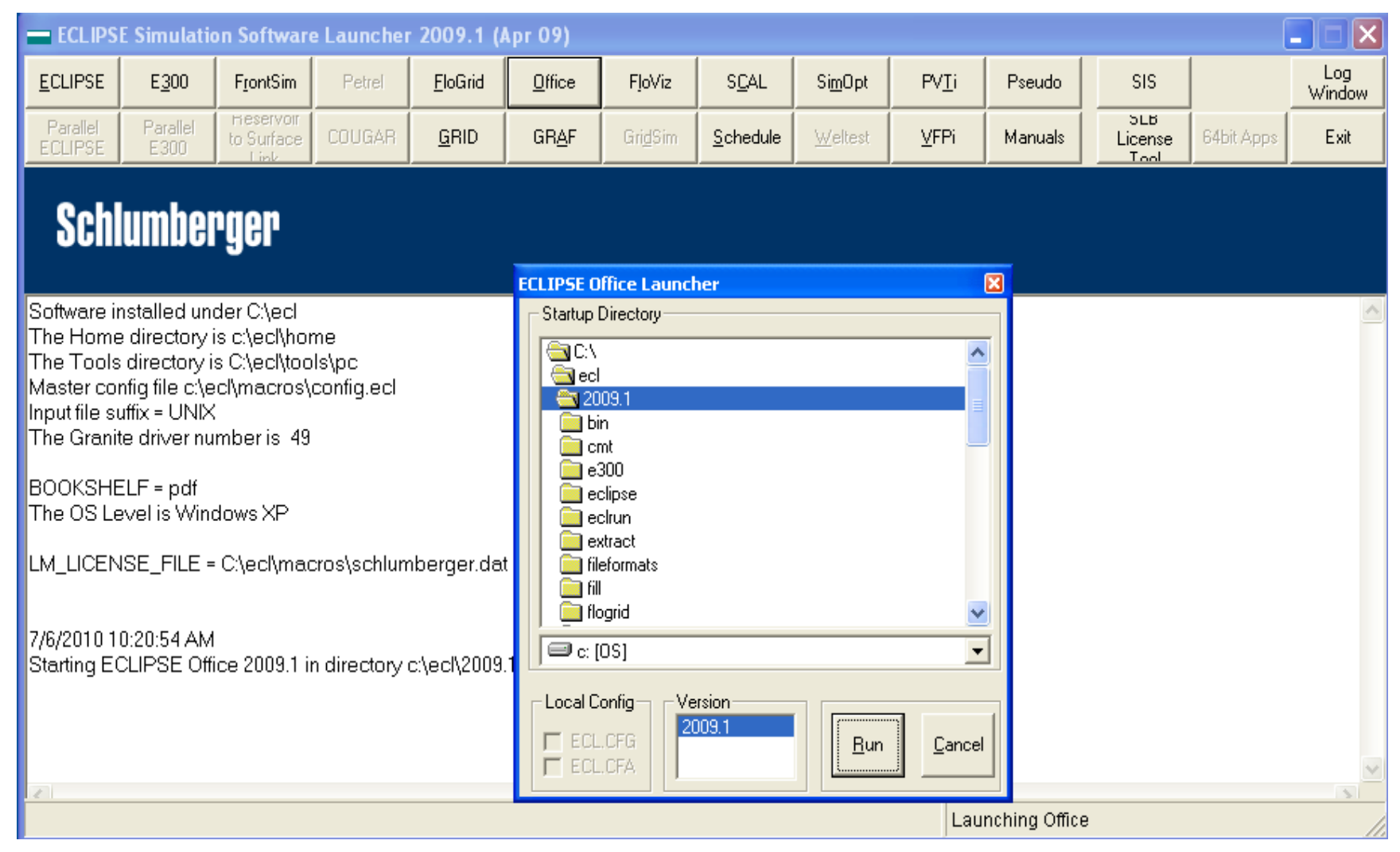

(Figure A-2. Eclipse launcher main screen)

Once office window is open, the user must select "File" and then "New Project." If the file has been saved before, then "Open Project" tab can be used instead (Figure A-3). 


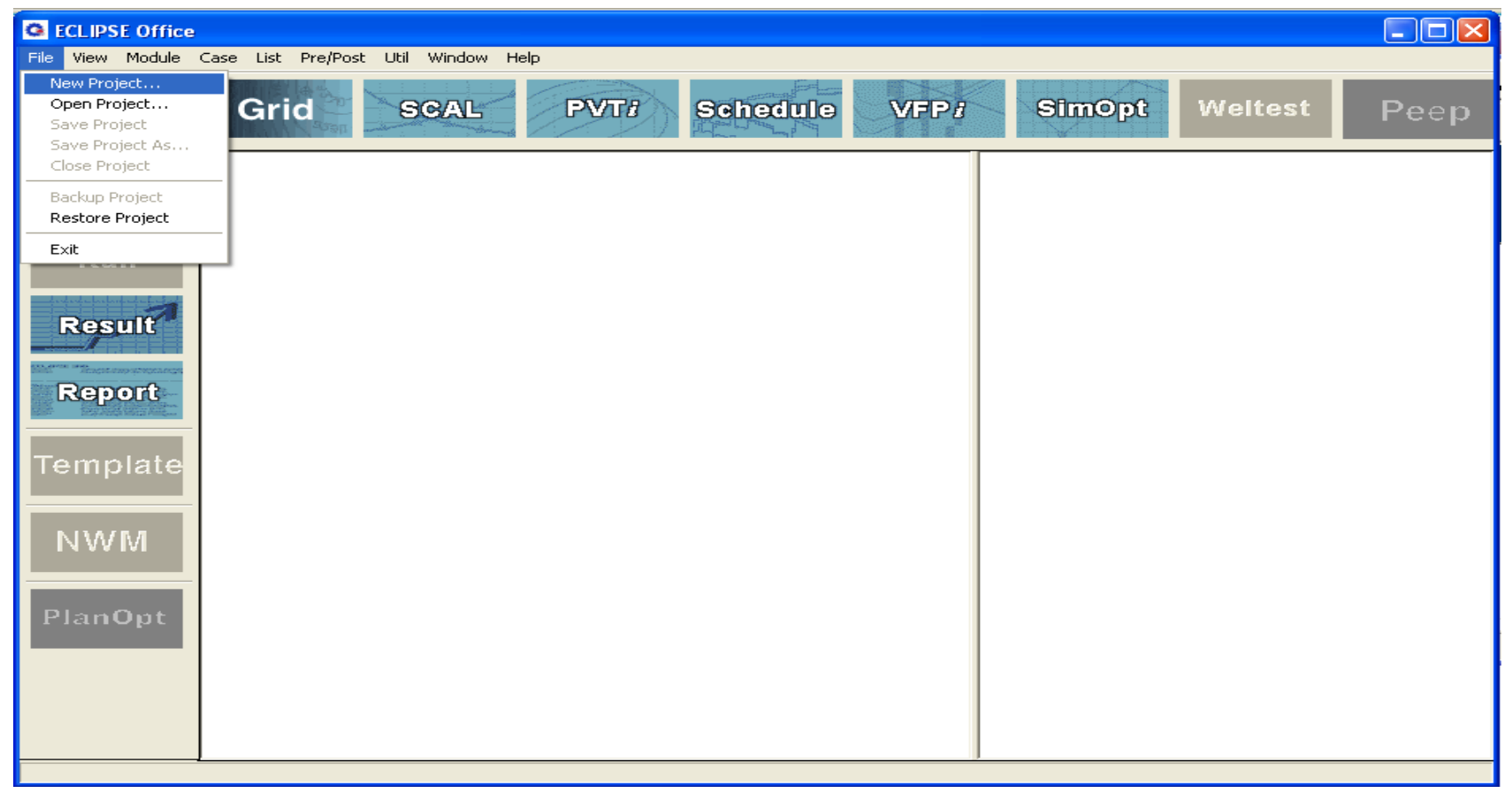

(Figure A-3. Eclipse office screen)

Once the new project is selected, the file name is entered and saved in the directory. Please notice that the file name has a default extension type of ".off" for the office program (Figure A-4) 


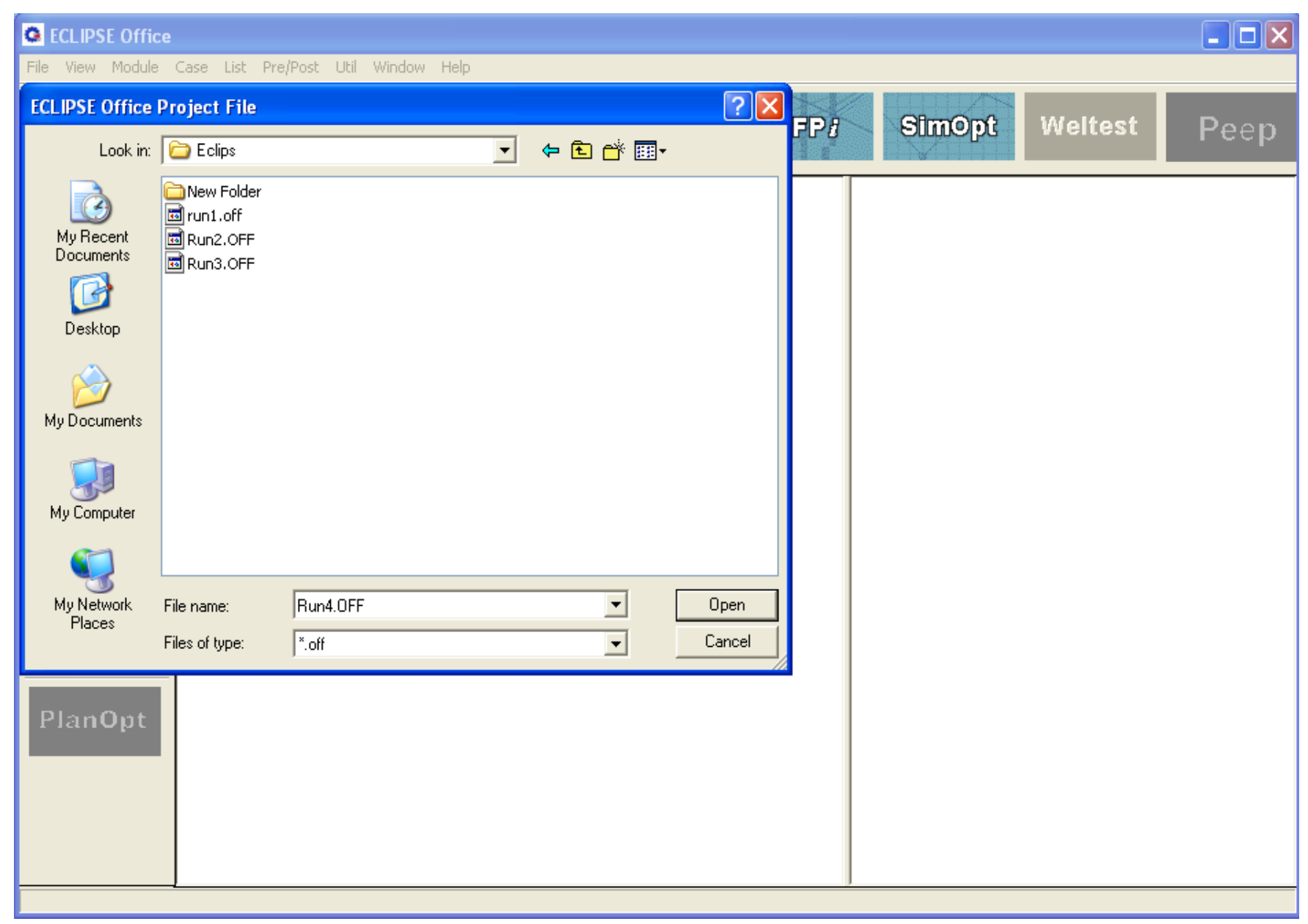

(Figure A-4. Eclipse file directory screen)

Once eclipse office is launched and the specific file is selected, a template case can be added. This feature will allow the user to select from different types of reservoirs and casing. Then "Add Template Case" is selected and that will let the user select "Template Model" (Figure A-5). 


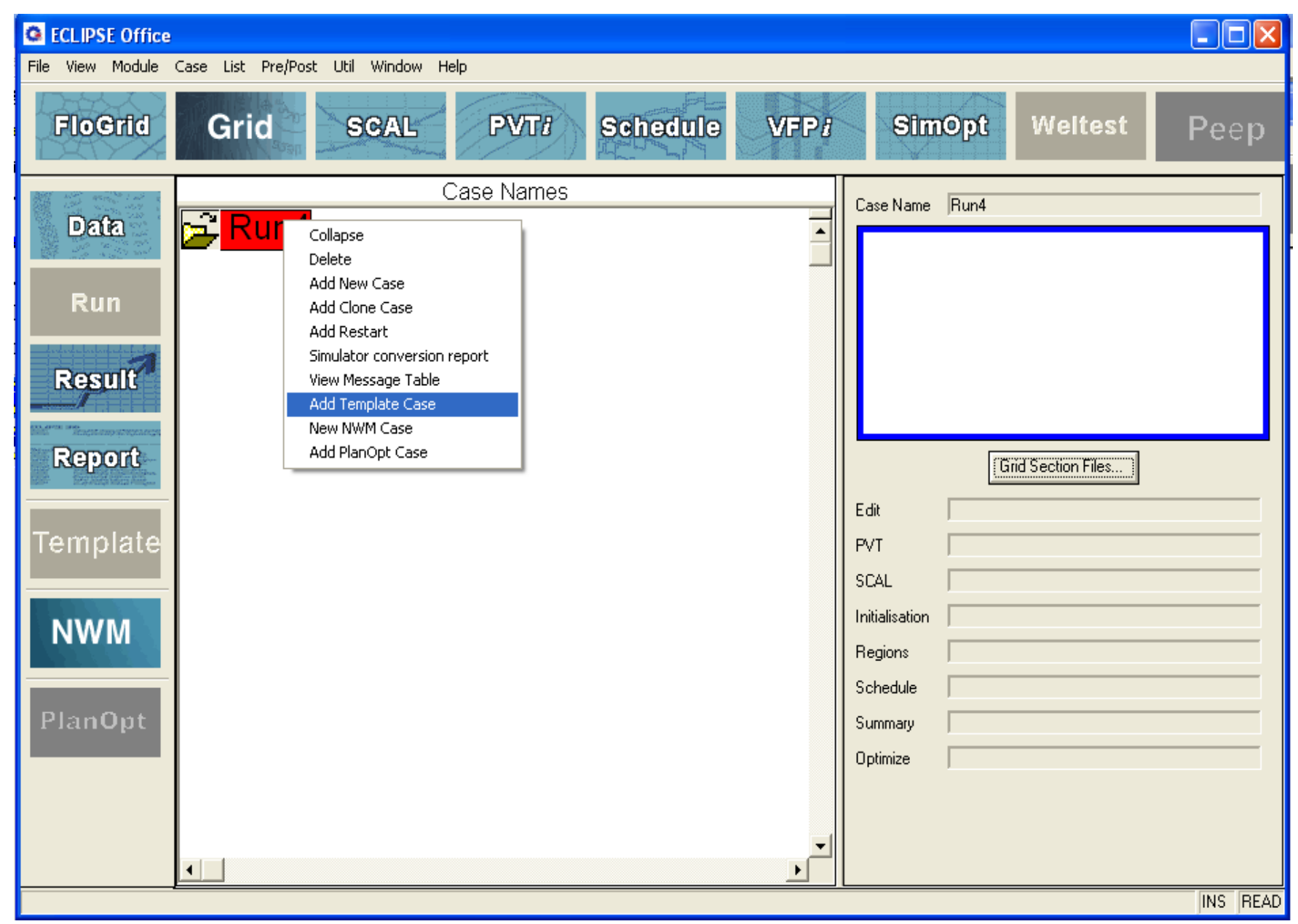

(Figure A-5. Eclipse add template case screen)

Figure A-6 shows four template cases available in the program. These cases contain "Single Well Radial"," Completion Modeling Tool", "Coal Bed Methane", and" CO2 Sequestration." In addition to the "Template Model", name and unit of the case can be selected as well.

Based on discussions with programming experts, the use of parameters in the coal bed methane template was recommended to correctly model shale gas reservoir. This is because shale has the two forms of flow, both the conventional "free" gas and as adsorbed gas. Field units and the coal bed methane template were selected from this project. (T.Schweizer, 2009) 


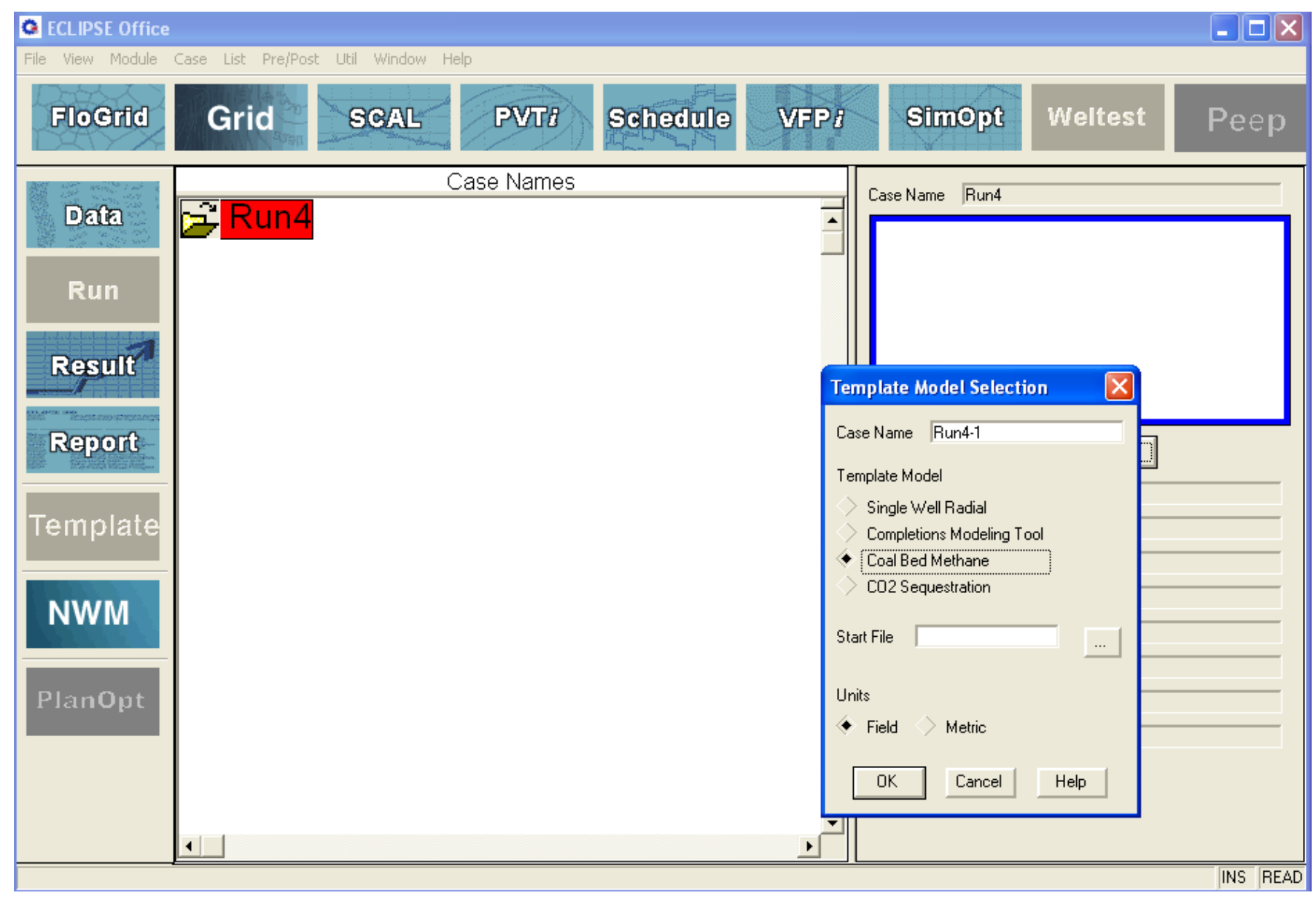

(Figure A-6. Eclipse template model selection screen)

Once the coal bed methane template is chosen, the model can be edited after completing each required data. If there is any missing data in any section of the template, it would not let the user continue to the next page until the mentioned data is corrected. It is very important to enter the stimulation and reporting data. For all the runs, the starting time is entered to be January 1 , 1981, and the ending time is entered to be January 1, 2010. Furthermore, the report interval is 31 days for the total stimulation time of 29 years. For the model parameters section, "Dry Gas" phase has been selected for the "Single Porosity Model" and "Dry Gas" and "Water" for the "Dual Porosity Model." In addition, for the "Dual Porosity Model" the following parameters have been chosen: 
1) Model employs non-equilibrium initialization

2) Coal defined on unit weight basis with ash and moisture content

3) Include Shale Properties

4) Instant Adsorption Model

5) Use Compositional Model

\section{Dual Porosity Model:}

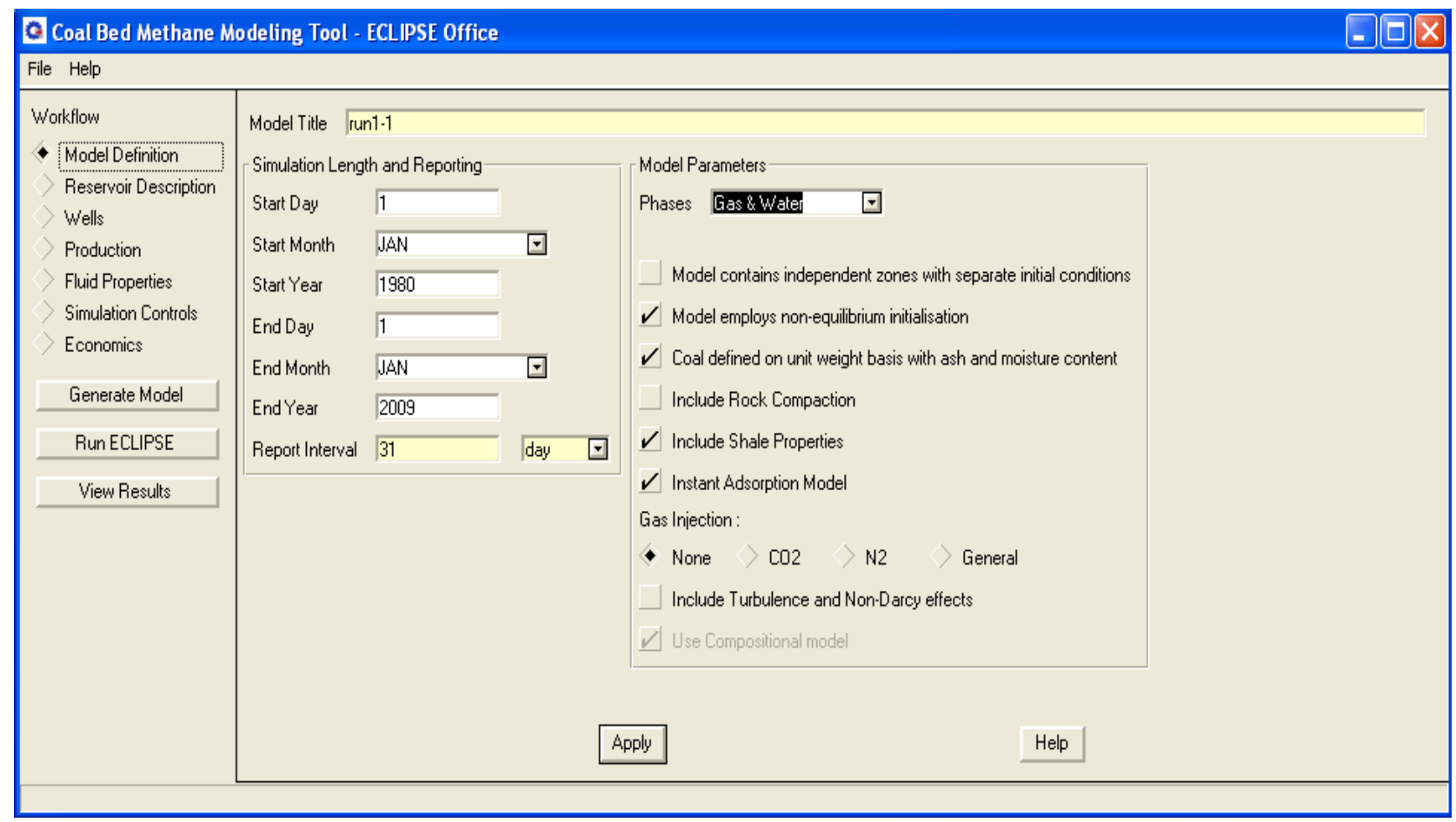

(Figure A-7. Eclipse model definition screen)

After completing "Model Definition" section, the next section that should be competed is called "Reservoir Description." There are five different taps in this section and in sequence they 
are called, "Layer”, “Rock Properties”, "Non-Equilibrium Initial Condition”, “Aquifer”, and "Fractures."

Under the layer name, each layer is called Layer+ number of the layer. Each Run that has been generated used certain amount of layers. For the most part, there is either 1 layer of $75 \mathrm{ft}$ or 5 layers of $15 \mathrm{ft}$ which adds up to $75 \mathrm{ft}$. The rock name is simply called reservoir. For "Top Depth Left Face" and "Top Depth Right Face" values in feet were taken from specific location with an approximate depth of $7000 \mathrm{ft}$ and zero horizontal displacement due to the small size of the modeled reservoir. Different types of reservoir acreages have been chosen depending on the location and drainage area of each specific horizontal or vertical well. For horizontal wells, a rectangular reservoir is assumed whereas for vertical wells, a square reservoir is generated.

Below is just a visual illustration for the value imputed for one random well. In the below example, the drainage area is assumed to be $4000 * 1000 / 43560=92$ acres and as previously mentioned, this drainage area can be different depending on location and lithology of each specific well. 


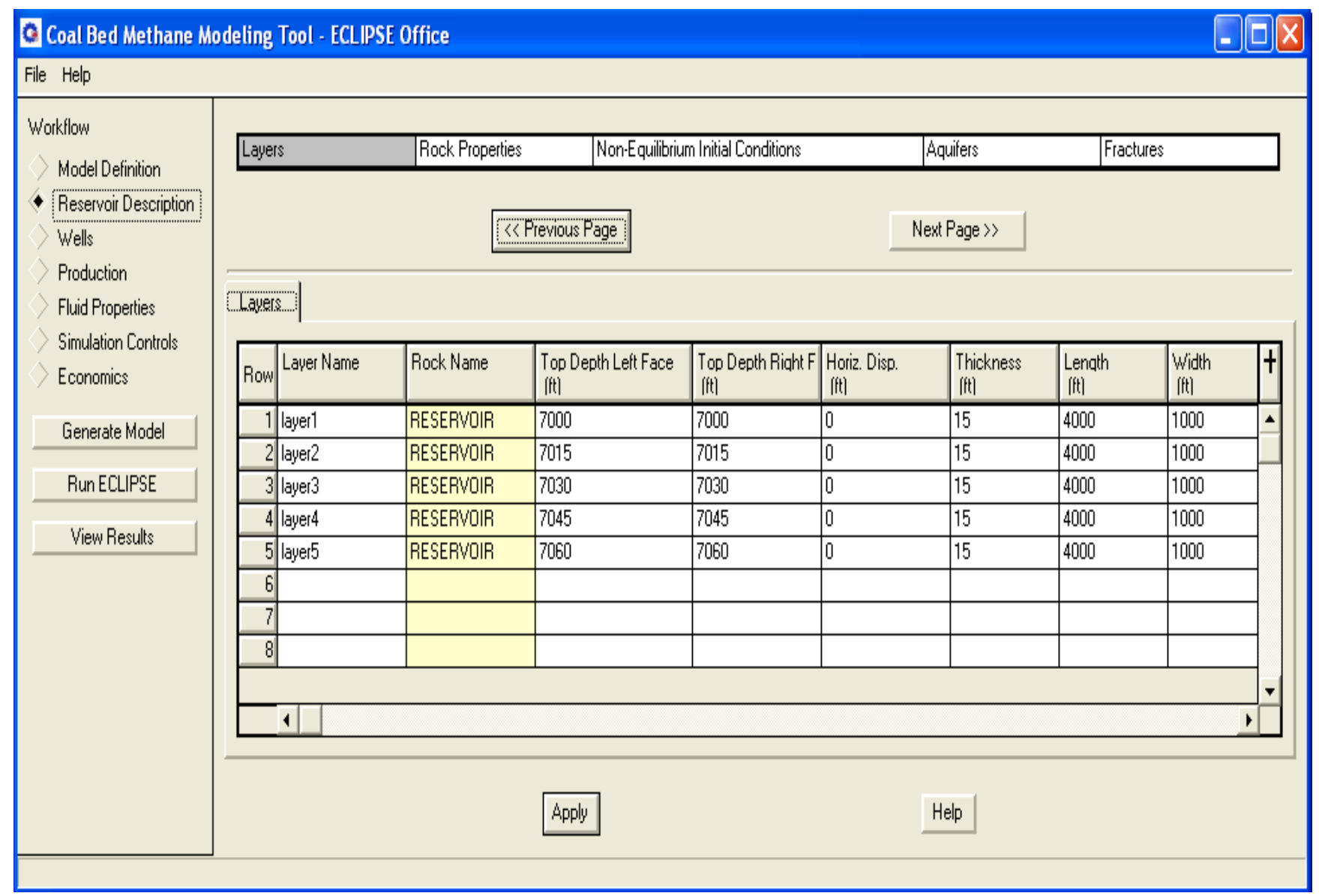

(Figure A-8. Reservoir description for layers screen)

The "Layers" tab is followed by the "Rock Properties" on the reservoir description workflow.

For "Single Porosity Model," specific porosity is entered and by default the $\mathrm{z}$ direction porosity is $1 / 10^{\text {th }}$ of the $\mathrm{x}$ and $\mathrm{y}$ direction because of overburden pressure and compaction stress in the $\mathrm{z}$ direction which causes the porosity to be less in that direction.

For "Dual Porosity Model," since matrix porosity is bigger than fracture porosity, the matrix porosity is entered as 0.05 and fracture porosity is 0.005 . In addition, fracture permeability varies for each well and does not stay constant for all the runs. 


\section{Single Porosity Model:}

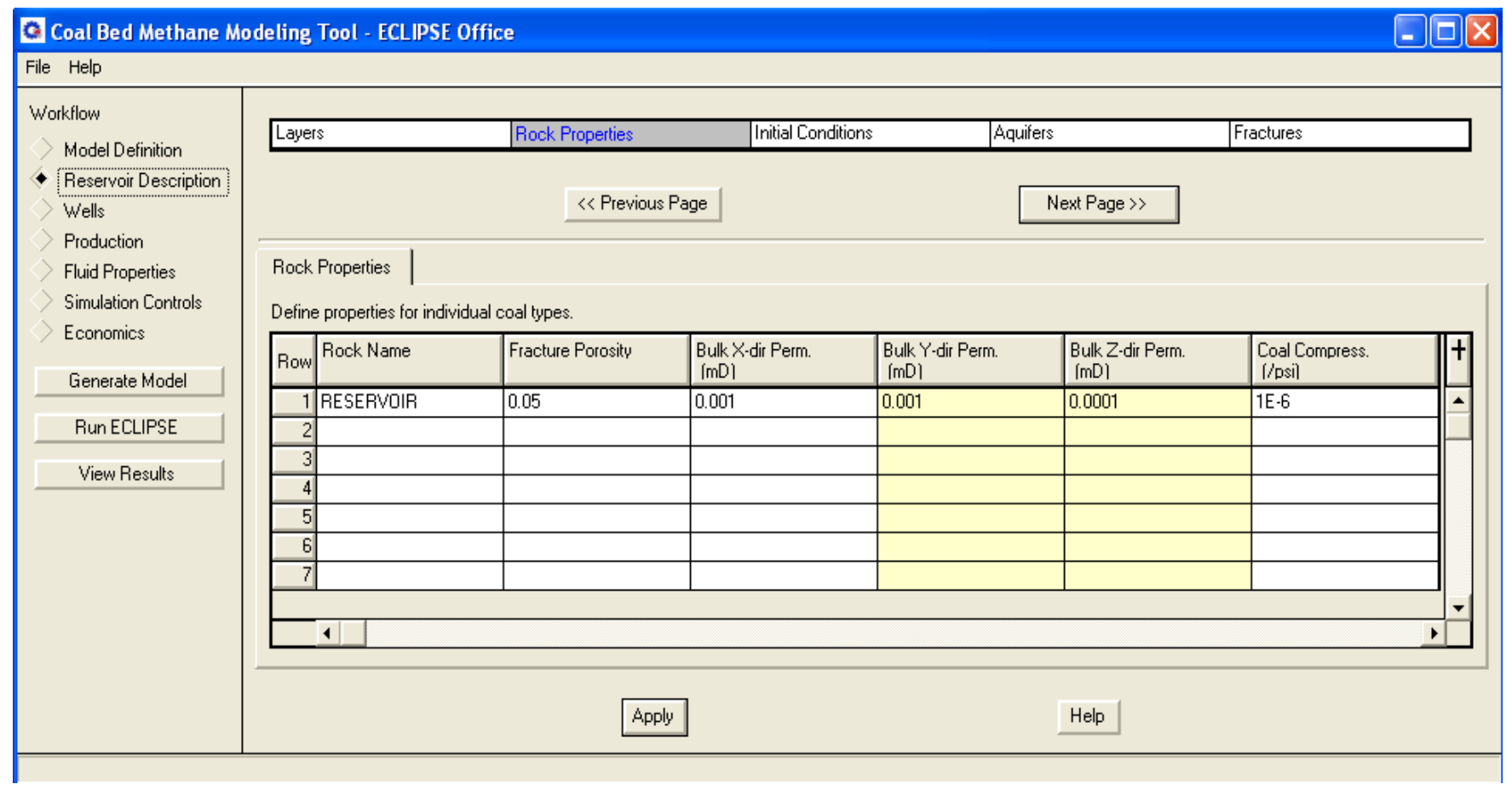

(Figure A-9. Reservoir description for rock properties screen) 


\section{Dual Porosity Model:}

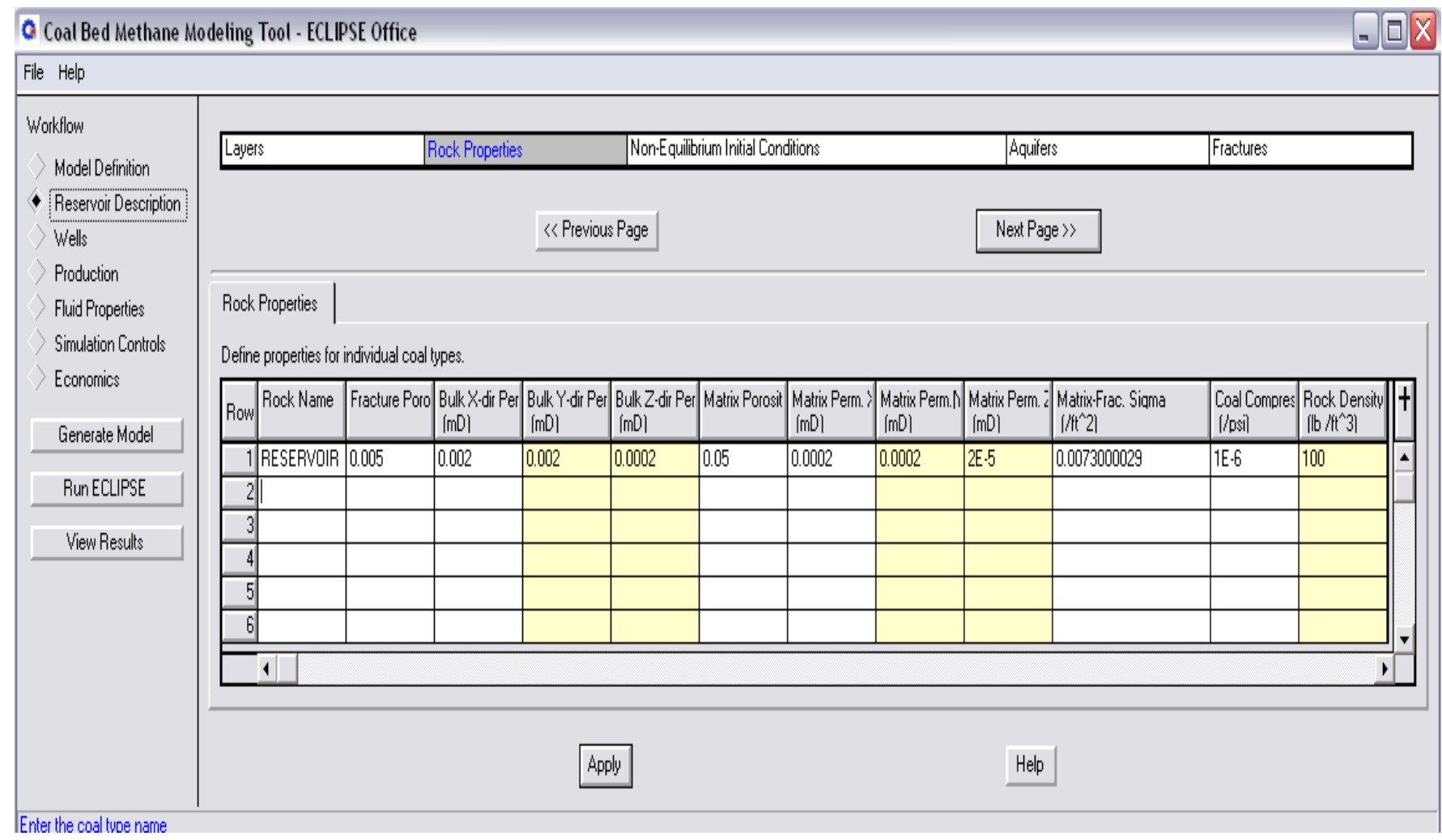

(Figure A-9. Reservoir description for rock properties screen)

Figure A-10 shows the non-equilibrium initial conditions section of the reservoir description. Only two data values are inputted for the initial reservoir pressure and water saturation. 


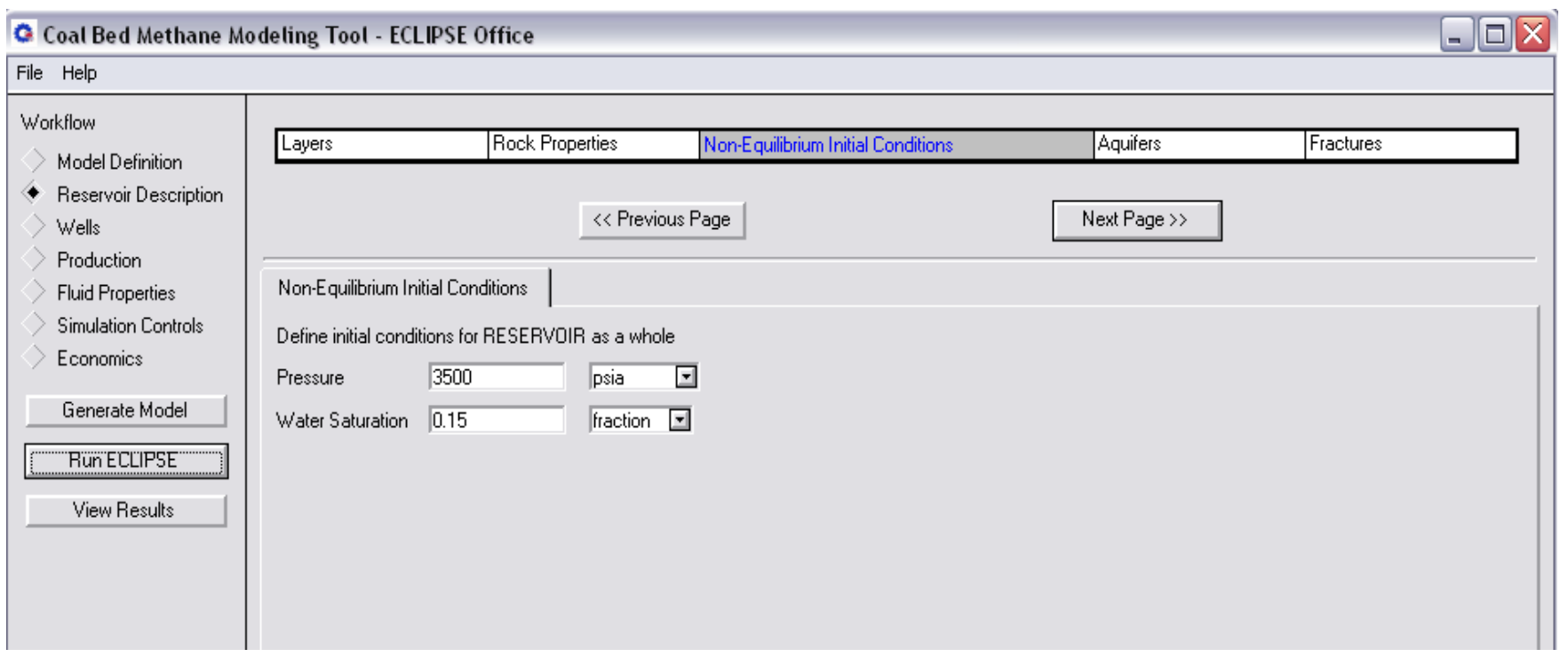

(Figure A-10. Reservoir description for initial condition screen)

The next section of the reservoir description is called aquifer has not been used in this thesis but it is included to show a complete description of properties in the reservoir.

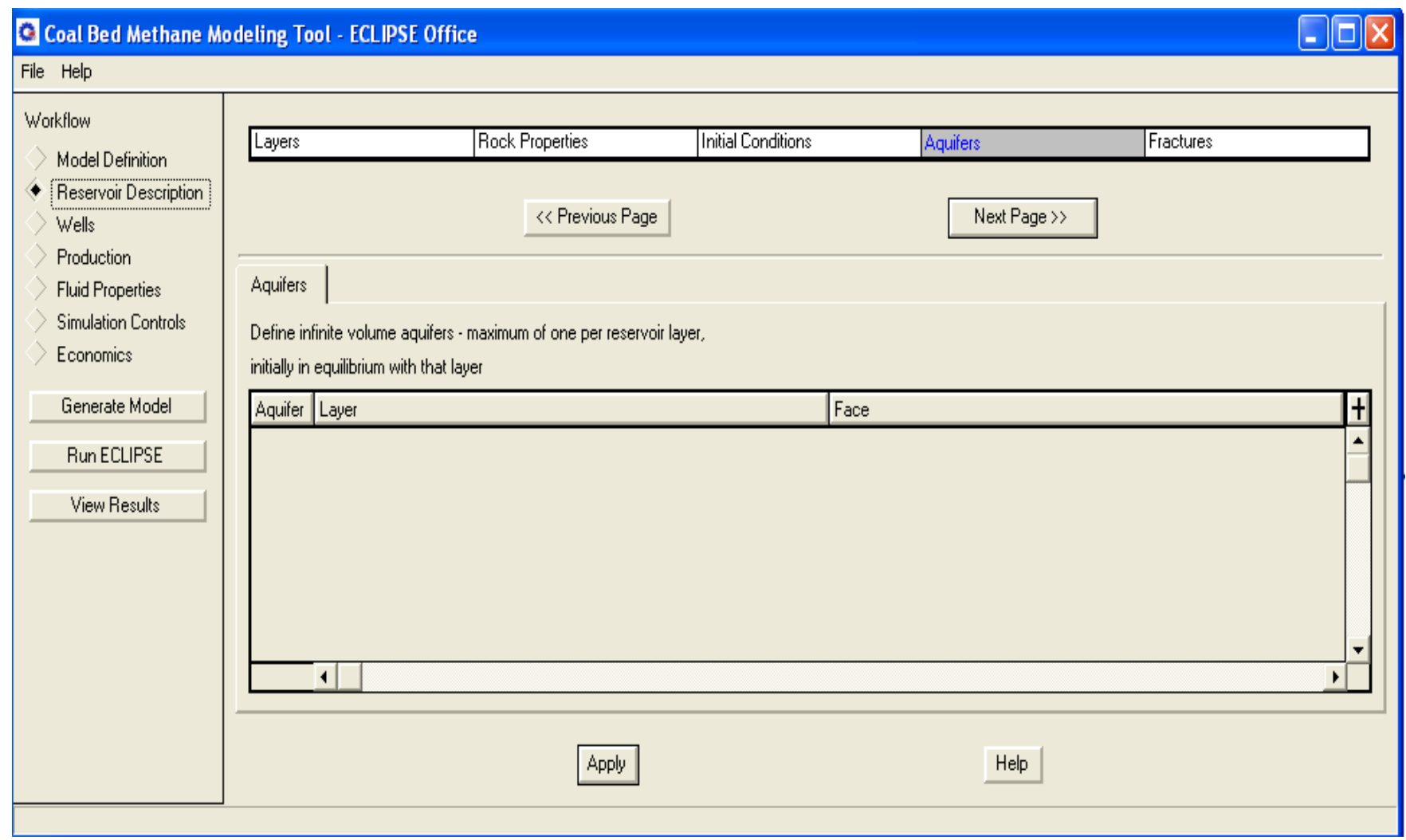




\section{(Figure A-11. Reservoir description for aquifer screen)}

Figure A-12 shows the fractures tab for reservoir description. Number of hydraulic fractures varies depending on the well. Usually for the vertical wells, one hydraulic fracture is used to generate the history matching, however for horizontal wells up to 7 fractures have been defined in the model to see the their impact on the initial production data.

$\mathrm{X}$ center refers to the segment of the horizontal section that needs to be fractured and $\mathrm{Y}$ center is the location of the horizontal well which is the in the middle of the specific formation. For example, if the width of the reservoir (which was defined in the layers section) is $2000 \mathrm{ft}, \mathrm{Y}$ center will be $1000 \mathrm{ft}$. Half length, fracture width, fracture porosity, and fracture permeability can be defined for any particular well. 


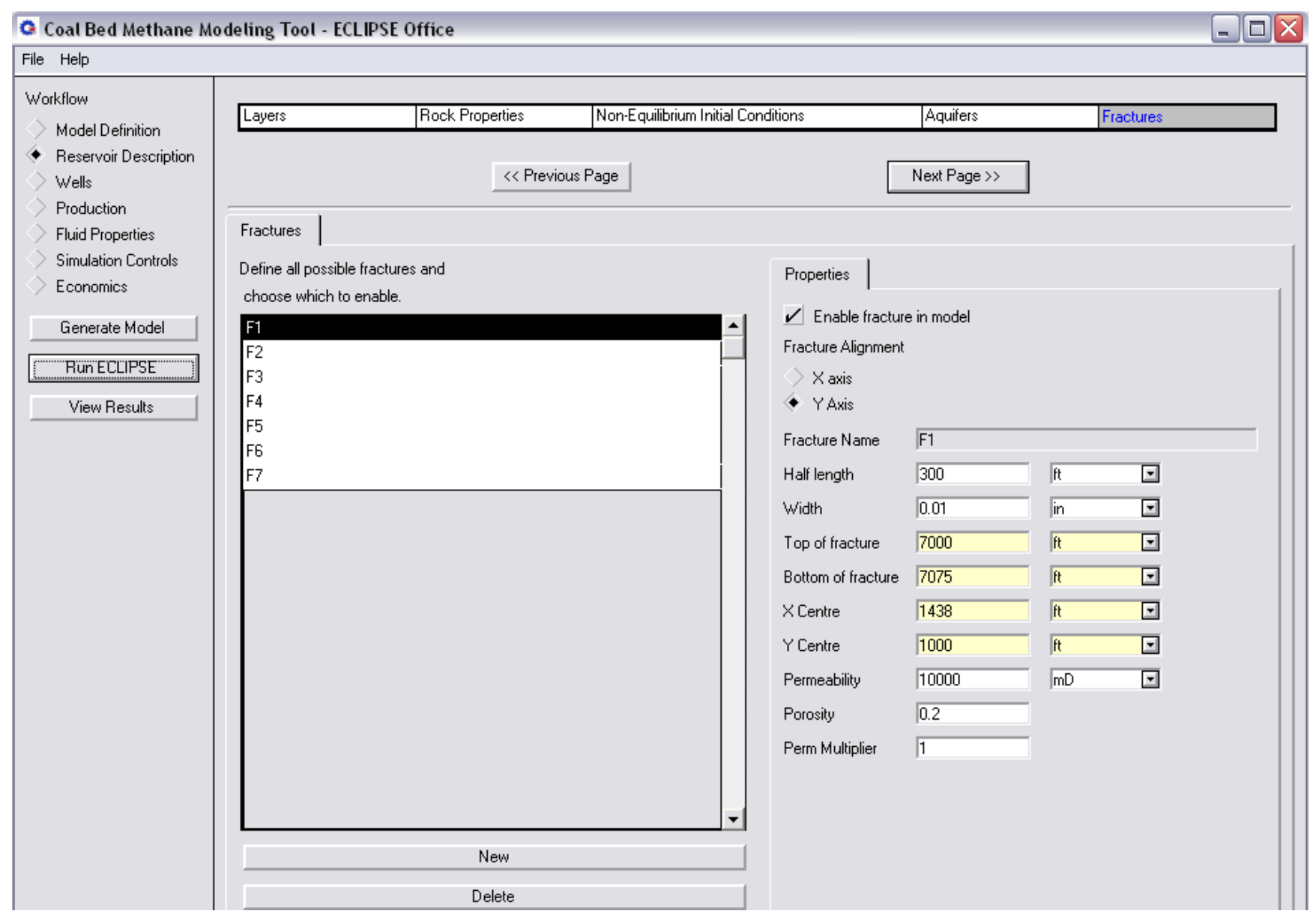

(Figure A-12. Reservoir description for fractures screen)

Next section is to place the vertical and horizontal well and define a hole diameter. In this particular horizontal case, the vertical well starts from $1000 \mathrm{ft}$ and it extends up to the middle of the reservoir's width (which is $1000 \mathrm{ft}$ since the reservoir width is $2000 \mathrm{ft}$ ). In addition the productive formation starts from 7000 and goes up to $7075 \mathrm{ft}$ since the thickness of the reservoir for this particular well is $75 \mathrm{ft}$. 


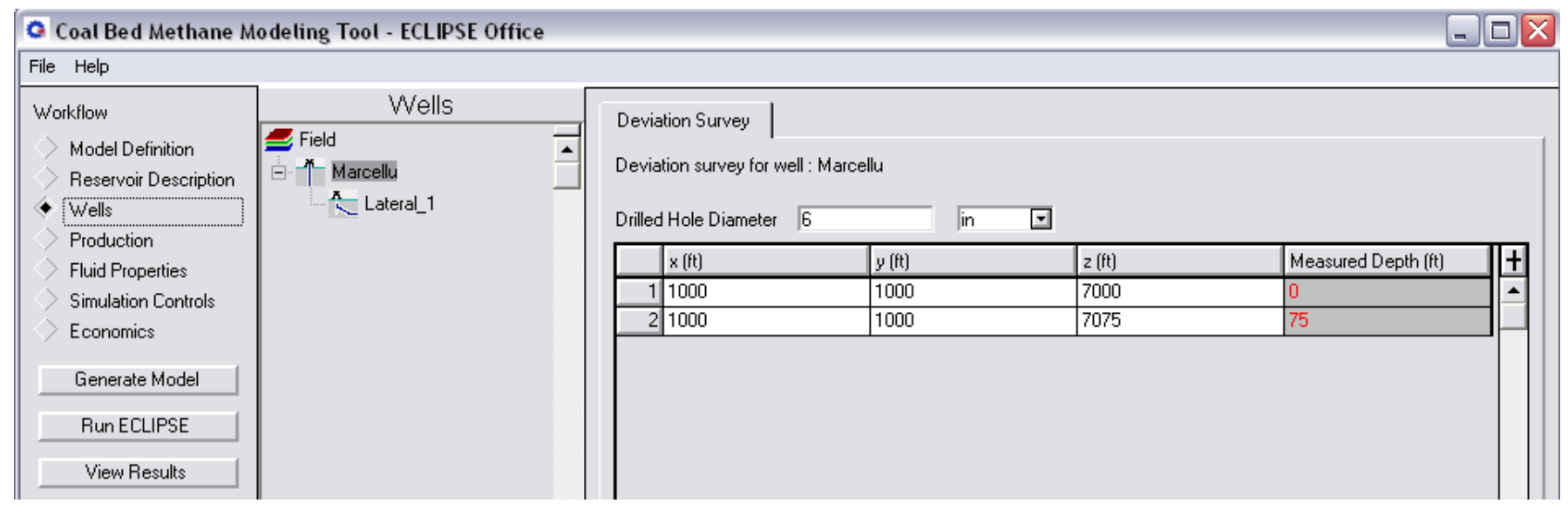

(Figure A-13. Wells for deviation survey screen)

Now to add the horizontal well to this model, right click on the Marcellus and then add lateral

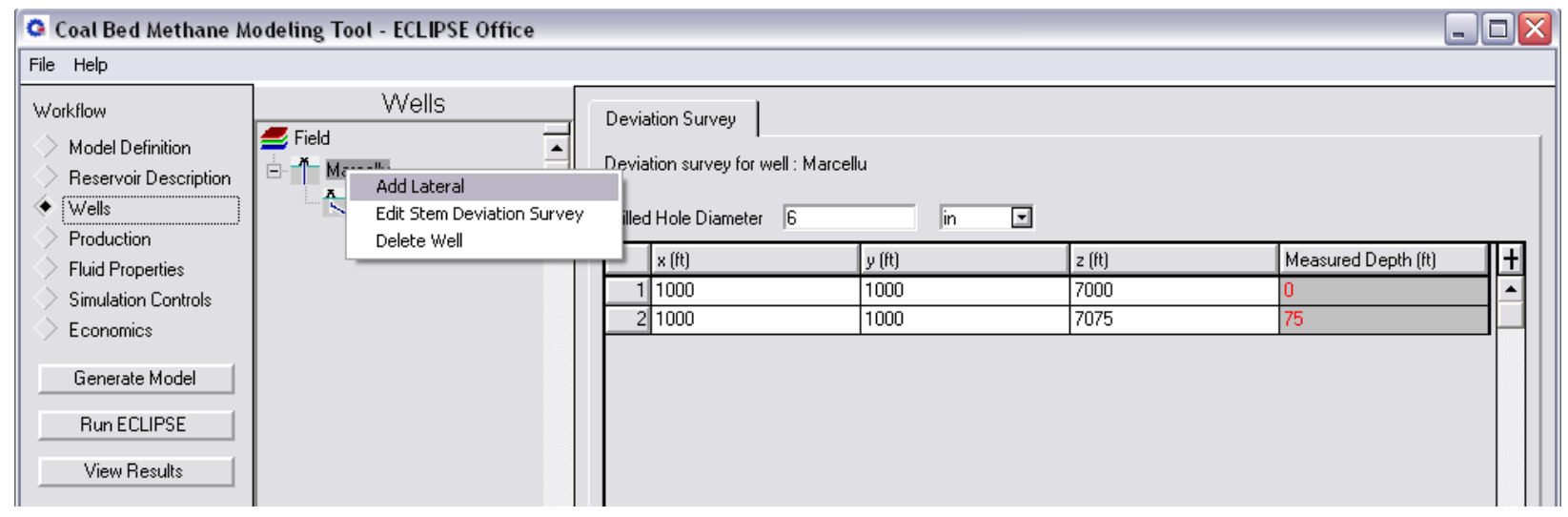

(Figure A-14. Wells for deviation survey screen)

At the stage, the midpoint of the horizontal can be entered as thickness $/ 2=75 / 2=37.5 \mathrm{ft}$.

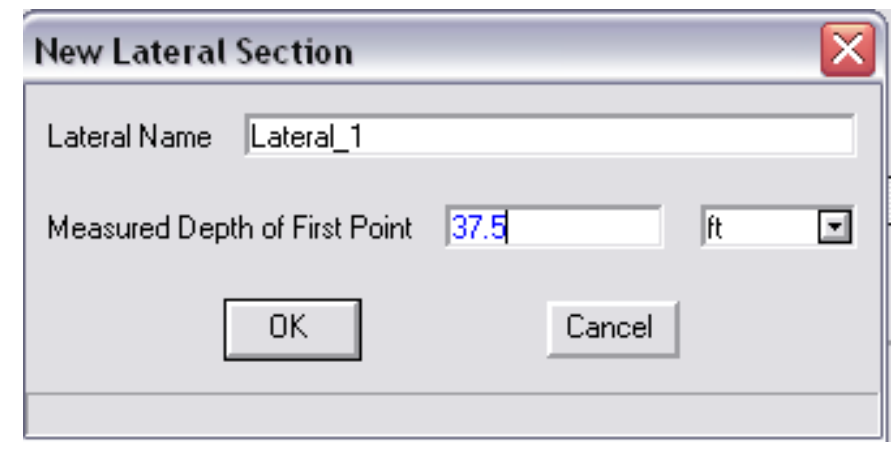




\section{(Figure A-15. Wells for deviation survey of lateral well screen)}

After defining measured depth of first point of the lateral section, it is possible to build the horizontal segment of the model. An x-axis show where the horizontal well stats and up to what point it extends. For example, in this case since the length of the horizontal segment is about $3500 \mathrm{ft}$, we would like to start the horizontal well from $1000 \mathrm{ft}$ from the reservoir and extend it all the way to $4500 \mathrm{ft}(1000+3500)$. In addition $y$-axis indicates the location of the horizontal well along the y-axis. For instance, if the location is chosen to be in the center of the reservoir, since the width of this particular reservoir is $2000 \mathrm{ft}$, half of this width can be chosen as the y-axis. So, the y-axis in this particular case is defined as $1000 \mathrm{ft}$. The below figure illustrates the horizontal segment of the reservoir,

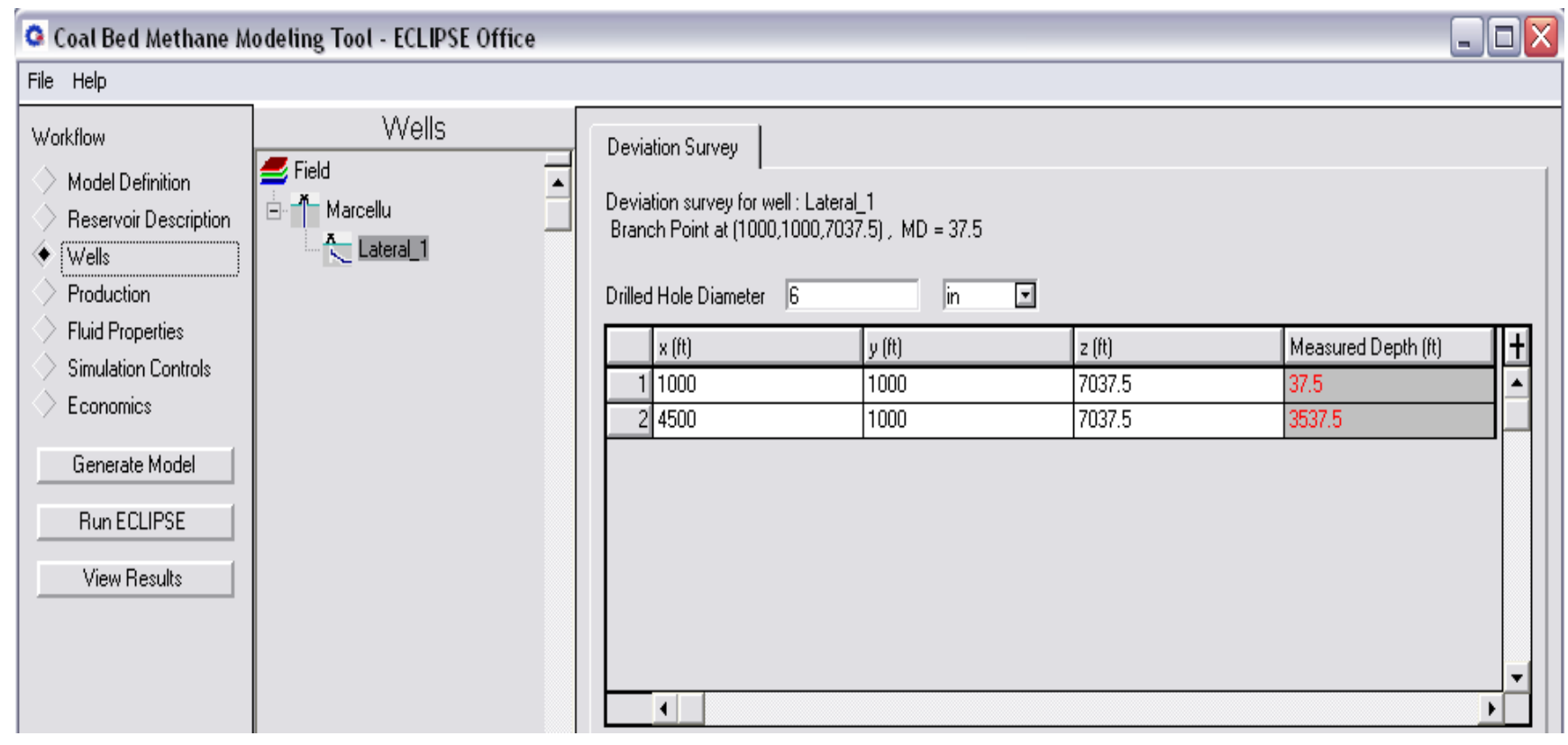

(Figure A-16. Wells for deviation survey of lateral well screen)

Now it is time to define a minimum bottom hole pressure for the reservoir. Different reservoirs behave differently and it is a subjective topic to decide where to stop all the simulation 
run. For majority of vertical and horizontal wells in this thesis, the minimum bottom hole pressure is defined as 500 psia and this number can vary. For this particular well, the minimum bottom hole pressure is assumed to be 500 as well. The below figure shows the control mode as BHP (bottom hole pressure) and the target as previously mentioned is set to be 500 psia.

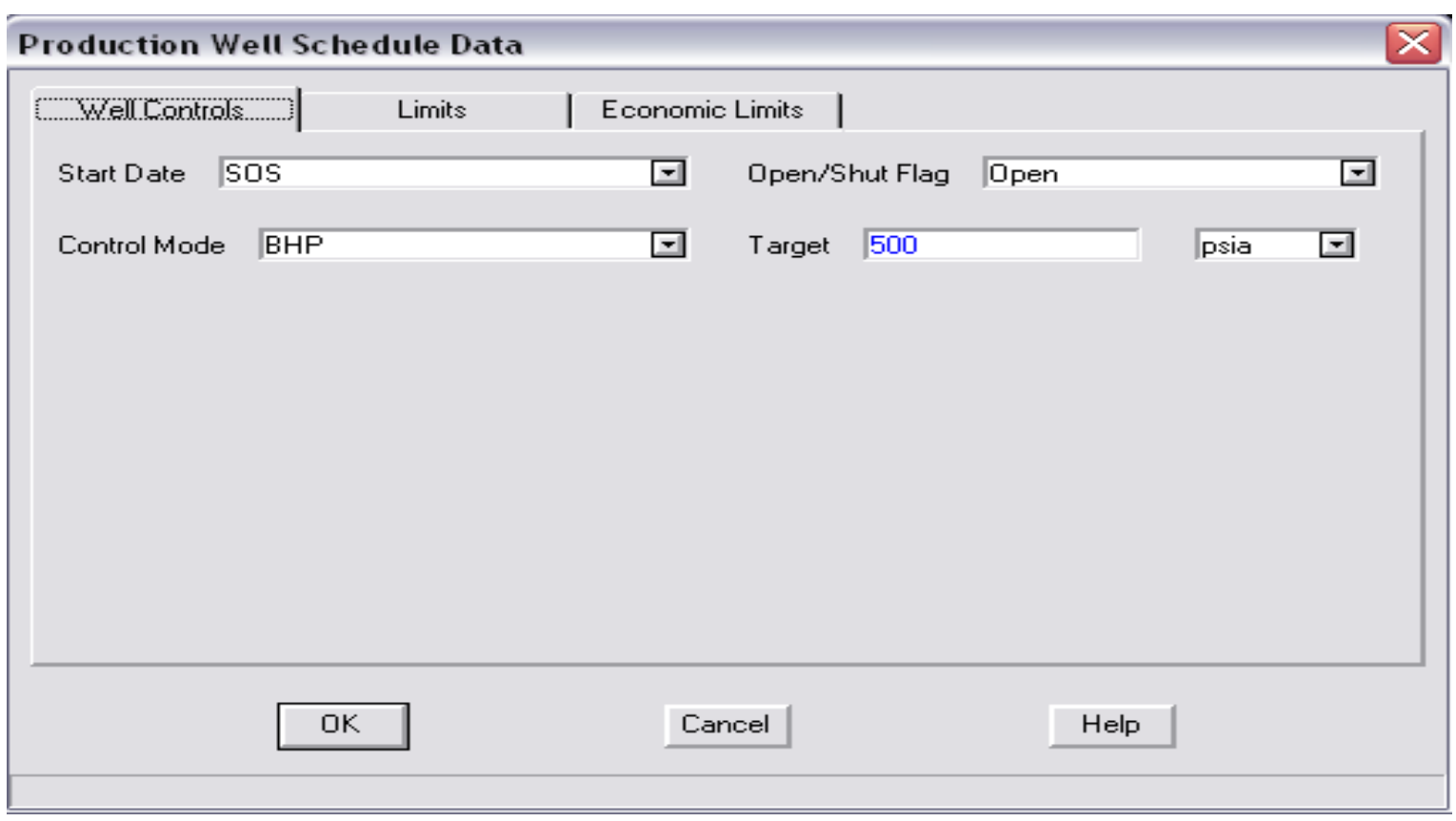

(Figure A-17. Production for well control screen)

Now the lateral section of the Marcellus shale needs to be perforated in order to produce from the well. If this stage is not defined in the model, the model will not run and it will give error. Figures A-18 and A-19 illustrates the steps that need to be taken to perforate the lateral section,

Coal Bed Methane Modeling Tool - ECLIPSE Office

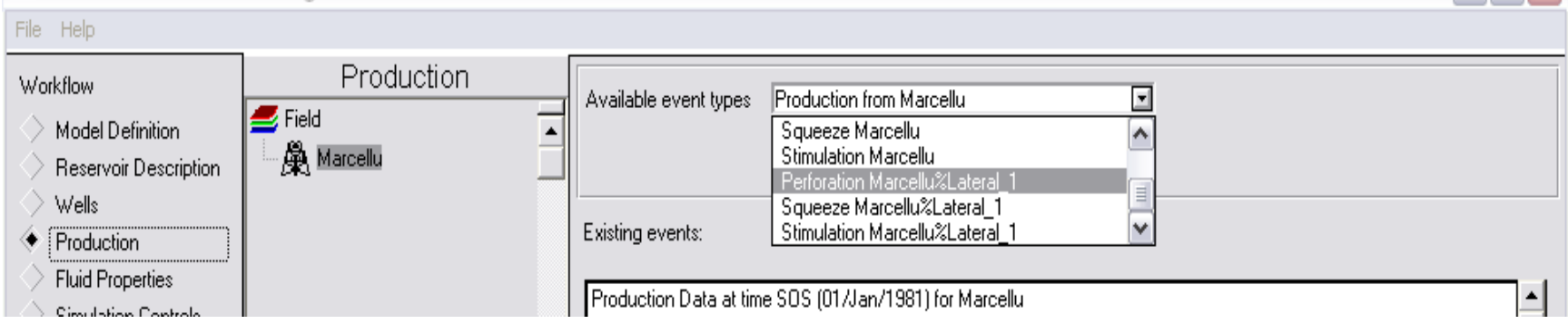


(Figure A-18. Production for Marcellus perforation screen)

\begin{tabular}{|c|c|c|c|}
\hline \multicolumn{2}{|l|}{ Perforation } & & $x$ \\
\hline \multicolumn{2}{|c|}{ Perforation Name Perforation_1 } & & \\
\hline \multicolumn{4}{|l|}{ Perforation properties } \\
\hline Start Date & SOS & & $\nabla$ \\
\hline Start MD & 37.5 & $\mathrm{ft}$ & $\nabla$ \\
\hline Stop MD & 3537.5 & fit & $\nabla$ \\
\hline Skin Factor & 0 & & \\
\hline Well Bore Diameter & 0.5 & & $\nabla$ \\
\hline OK & Cancel & Help & \\
\hline
\end{tabular}

(Figure A-19. Production for Marcellus perforation screen)

Fluid properties need to be entered into the model for the model to have a good understand of how the fluid movies within the porous media. Since this model is assumed to be 100 methane, 1 is imputed for $\mathrm{C} 1$ in the model. In addition, standard pressure, reference pressure, and reference temperature are defined in the model as well, 


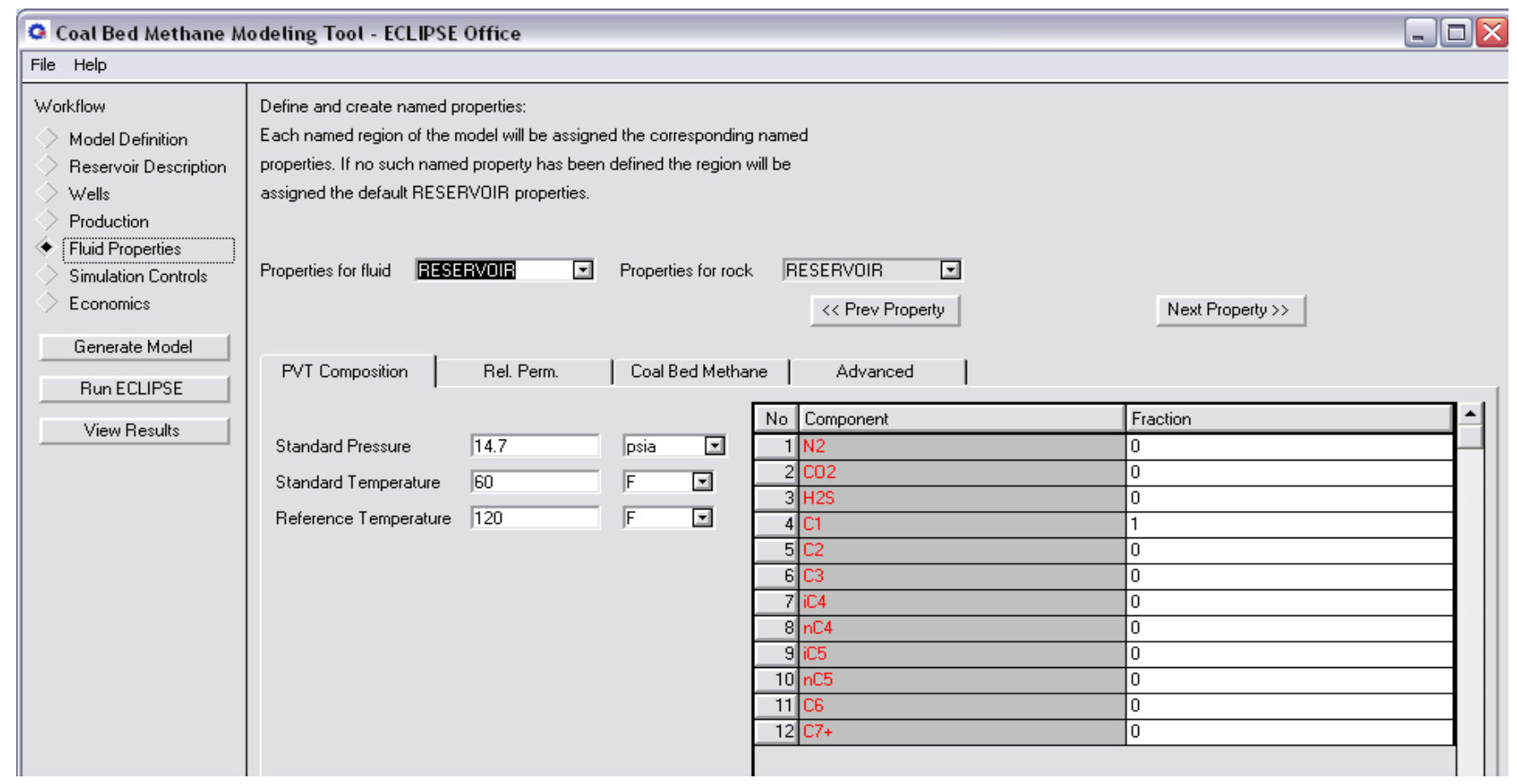

(Figure A-20. Fluid properties for PVT composition screen)

Since shale reservoir has both free and sobbed gas, Langmuir data needs to be entered for the model to be valid. The below parameters have been defined for all vertical and horizontal wells, 


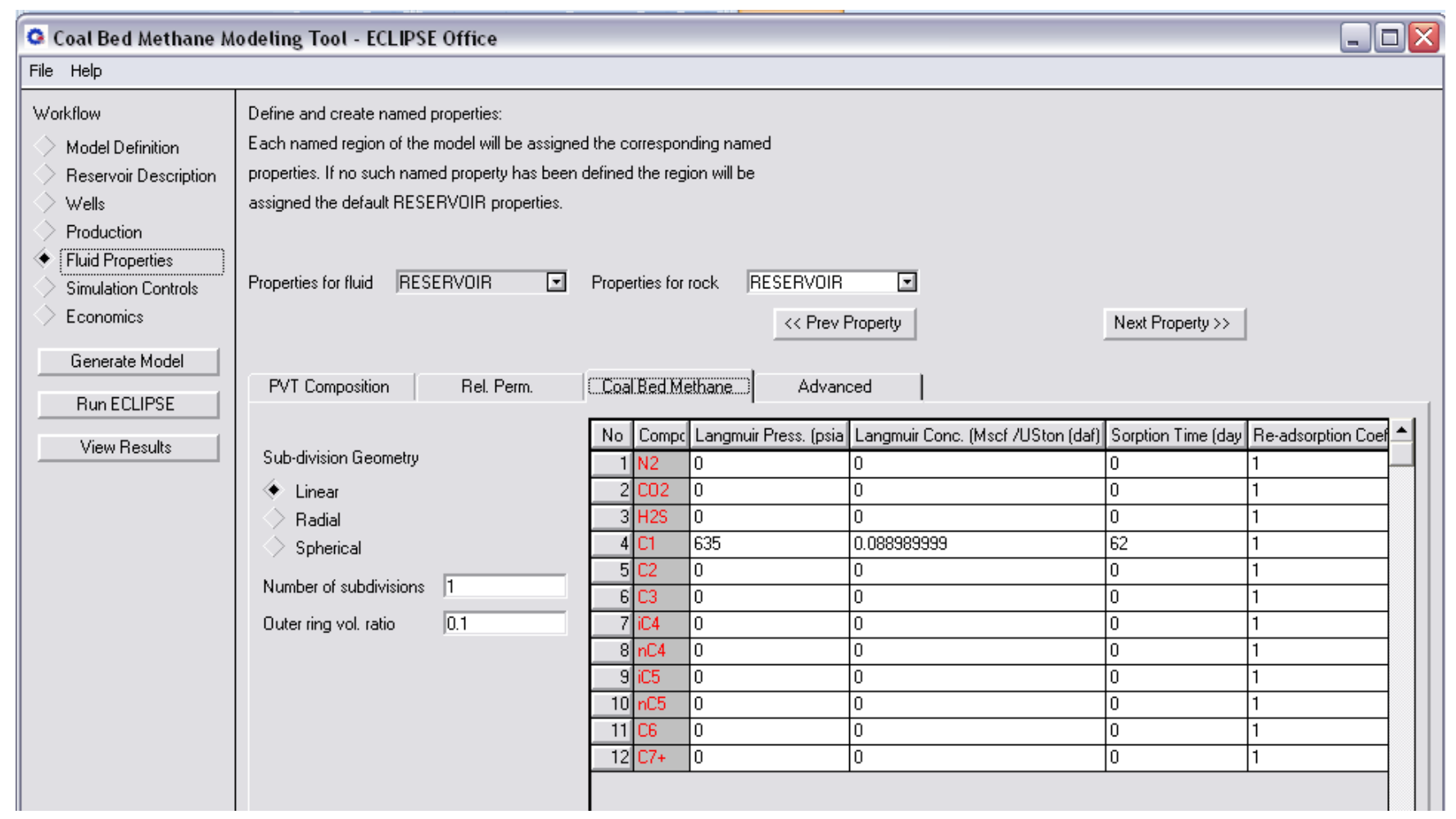

(Figure A-21. Fluid properties for coal bed methane screen)

Finally, the model in Eclipse can be run by clicking on "RUN ECLIPSE". Depending on the PC speed, the model may take up to days for complicated horizontal wells with different numbers of stages. After the model is run successfully, "View Results" can be selected to analyze the model. 


\section{Appendix B}

\section{Vertical wells:}

\begin{tabular}{|c|c|c|c|c|c|c|c|c|c|}
\hline Vertical 1 & & Vertical 2 & & Vertical 3 & & Vertical 4 & & Vertical 5 & \\
\hline Time(M) & $q$ (MCF/Month) & Time(M) & q (MCF/Month) & Time(M) & $q$ (MCF/Month) & Time(M) & $q$ (MCF/Month) & Time(M) & $q$ (MCF/Month) \\
\hline 1 & 16982 & 1 & 21724 & 1 & 18793 & 1 & 10693 & 1 & 18674 \\
\hline 2 & 11873 & 2 & 16537 & 2 & 14983 & 2 & 7925 & 2 & 14996 \\
\hline 3 & 9935 & 3 & 15038 & 3 & 12148 & 3 & 7177 & 3 & 13800 \\
\hline 4 & 8199 & 4 & 12858 & 4 & 10053 & 4 & 7076 & 4 & 12728 \\
\hline 5 & 8617 & 5 & 10376 & 5 & 9935 & 5 & 5267 & 5 & 10121 \\
\hline 6 & 7537 & 6 & 10853 & 6 & 8917 & 6 & 5543 & 6 & 8731 \\
\hline 7 & 6622 & 7 & 10311 & 7 & 7744 & 7 & 4500 & 7 & 9117 \\
\hline 8 & 6702 & 8 & 9597 & 8 & 7437 & 8 & 4133 & 8 & 7498 \\
\hline 9 & 6338 & 9 & 8894 & 9 & 6688 & 9 & 4273 & 9 & 3345 \\
\hline 10 & 5853 & 10 & 8741 & 10 & 6437 & 10 & 3960 & 10 & 12193 \\
\hline 11 & 5190 & 11 & 8043 & 11 & 6783 & 11 & 3903 & 11 & 3054 \\
\hline 12 & 5662 & 12 & 8032 & 12 & 5624 & 12 & 4369 & 12 & 9900 \\
\hline 13 & 5564 & 13 & 6945 & 13 & 6014 & 13 & 2953 & 13 & 5000 \\
\hline 14 & 5236 & 14 & 6901 & 14 & 5733 & 14 & 3367 & 14 & 5024 \\
\hline 15 & 4904 & 15 & 7049 & 15 & 5565 & 15 & 3458 & 15 & 5174 \\
\hline 16 & 5182 & 16 & 6564 & 16 & 4617 & 16 & 2517 & 16 & 5983 \\
\hline 17 & 5121 & 17 & 6623 & 17 & 5087 & 17 & 3086 & 17 & 5834 \\
\hline 18 & 4619 & 18 & 6092 & 18 & 5637 & 18 & 2985 & 18 & 5184 \\
\hline 19 & 4416 & 19 & 6441 & 19 & 5453 & & & 19 & 4154 \\
\hline 20 & 4792 & 20 & 6596 & 20 & 5325 & & & 20 & 5197 \\
\hline 21 & 4668 & 21 & 6332 & 21 & 4831 & & & 21 & 5040 \\
\hline 22 & 4778 & 22 & 6139 & 22 & 4659 & & & 22 & 4876 \\
\hline 23 & 4260 & 23 & 5977 & & & & & 23 & 5076 \\
\hline 24 & 4599 & 24 & 6078 & & & & & 24 & 4806 \\
\hline 25 & 4464 & & & & & & & 25 & 4869 \\
\hline 26 & 4272 & & & & & & & & \\
\hline 27 & 4350 & & & & & & & & \\
\hline 28 & 4071 & & & & & & & & \\
\hline 29 & 4056 & & & & & & & & \\
\hline
\end{tabular}

Table B-1. Production data for vertical wells 


\begin{tabular}{|c|c|c|c|c|c|c|c|}
\hline Vertical 6 & & Vertical 7 & & Vertical 8 & & Vertical 9 & \\
\hline Time(M) & q (MCF/Month) & Time(M) & q (MCF/Month) & Time(M) & q (MCF/Month) & Time(M) & $q$ (MCF/Month) \\
\hline 1 & 17650 & 1 & 11046 & 1 & 4322 & 1 & 14187 \\
\hline 2 & 11955 & 2 & 7641 & 2 & 3980 & 2 & 14892 \\
\hline 3 & 8880 & 3 & 6009 & 3 & 3766 & 3 & 13217 \\
\hline 4 & 7468 & 4 & 6083 & 4 & 2314 & 4 & 11888 \\
\hline 5 & 6233 & 5 & 8918 & 5 & 3388 & 5 & 13308 \\
\hline 6 & 5683 & 6 & 6410 & 6 & 2770 & 6 & 8286 \\
\hline 7 & 4991 & 7 & 6305 & 7 & 3097 & 7 & 9436 \\
\hline 8 & 5008 & 8 & 5114 & 8 & 2700 & 8 & 8792 \\
\hline 9 & 4771 & 9 & 4669 & 9 & 2183 & 9 & 9721 \\
\hline 10 & 4236 & 10 & 5011 & 10 & 2689 & 10 & 8711 \\
\hline 11 & 4547 & 11 & 4288 & 11 & 2718 & 11 & 7866 \\
\hline 12 & 4150 & 12 & 3884 & 12 & 2757 & 12 & 8135 \\
\hline 13 & 4059 & 13 & 3979 & 13 & 2209 & 13 & 7056 \\
\hline 14 & 3573 & 14 & 2917 & 14 & 2589 & 14 & 8357 \\
\hline 15 & 3771 & 15 & 3205 & 15 & 2582 & & \\
\hline 16 & 3902 & 16 & 3320 & 16 & 2489 & & \\
\hline 17 & 3720 & 17 & 2523 & 17 & 2464 & & \\
\hline 18 & 3768 & 18 & 2826 & 18 & 2300 & & \\
\hline 19 & 3473 & 19 & 3369 & 19 & 2311 & & \\
\hline 20 & 3552 & & & & & & \\
\hline 21 & 3497 & & & & & & \\
\hline 22 & 3028 & & & & & & \\
\hline 23 & 3318 & & & & & & \\
\hline 24 & 3140 & & & & & & \\
\hline 25 & 3192 & & & & & & \\
\hline 26 & 3061 & & & & & & \\
\hline 27 & 3109 & & & & & & \\
\hline 28 & 3099 & & & & & & \\
\hline 29 & 2816 & & & & & & \\
\hline 30 & 2794 & & & & & & \\
\hline 31 & 2441 & & & & & & \\
\hline 32 & 2574 & & & & & & \\
\hline
\end{tabular}

Table B-2. Production data for vertical wells 
Horizontal wells:

Horizontal 1
\begin{tabular}{|c|c|r|r|r|r|r|}
\hline Time (M) & q(Mscf/Month) & Time (M) & q(Mscf/Month) & Time (M) & q(Mscf/Month) \\
\hline 1 & 58056 & 1 & 44888 & 1 & 156342 \\
\hline 2 & 53757 & 2 & 38747 & 2 & 143525 \\
\hline 3 & 47962 & 3 & 36641 & 3 & 123918 \\
\hline 4 & 43370 & 4 & 32207 & 4 & 116830 \\
\hline 5 & 42172 & 5 & 30926 & 5 & 98102 \\
\hline 6 & 39718 & 6 & 28869 & 6 & 88543 \\
\hline 7 & 34057 & 7 & 24773 & 7 & 60454 \\
\hline 8 & 36048 & 8 & 26040 & 8 & 46030 \\
\hline 9 & 33385 & 9 & 23876 & 9 & 58339 \\
\hline 10 & 32712 & 10 & 24049 & 10 & 52154 \\
\hline 11 & 32507 & 11 & 22355 & 11 & 48045 \\
\hline 12 & 31938 & 12 & 22628 & 12 & 41601 \\
\hline 13 & 31091 & 13 & 21671 & 13 & 41623 \\
\hline 14 & 29312 & 14 & 20383 & 14 & 2362 \\
\hline 15 & 28978 & 15 & 20220 & 15 & 18652 \\
\hline 16 & 27224 & 16 & 18870 & 16 & 16549 \\
\hline 17 & 28059 & 17 & 19271 & 17 & 11246 \\
\hline
\end{tabular}

Table B-3. Production data for horizontal wells

Owner and Completion Information for vertical and horizontal wells:

\section{Vertical \#1:}

Owner Information:

API CMP_DT SUFFIX STATUS FARM WELL_IIUM CO_IIUM LEASE LEASE_IUMM MIIIERAL_OWII OPERATOR

4709703021 11/177/2000 Original Loc Completed Dale L Wintree etux $624326 \quad$ Dale L Wintree etux Colunbia Natural Resources, Inc. (CNR)

$47097030217 / 992007$ Worked Over Completed Dale L Wintriee et ux $\quad 624326 \quad 3055097 \quad$ Dale L Wintree et ux Chesapeake Appalachia, LLC

Completion Information:

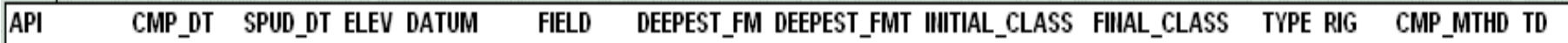

4709703021 11/17/2000 9/28/2000 1680 Ground Level Cave Run Helderberg Oriskany Development Well Development Well Gas Rotary Acid+Frac 7407

$47097030217 / 192007$ 75/2007 1680 Ground Level Cave Run Helderberg Marcellus Sh Development Well Development Well Gas Rotary Fractured 7326

\section{Vertical \#2:}

\begin{tabular}{|c|c|c|c|c|c|c|c|c|c|}
\hline API & COUITY & PERMIT & TAX_DISTRICT & QUAD_75 & QUAD_15 & LAT_DD & LOII_DD & UTME & UTMII \\
\hline 4709703444 & Upshur & 3444 & Banks & Rock Cave & Crawtord & 38.838856 & -80.328083 & 558314.5 & 4299108.9 \\
\hline
\end{tabular}


Pay/Show Water Information:

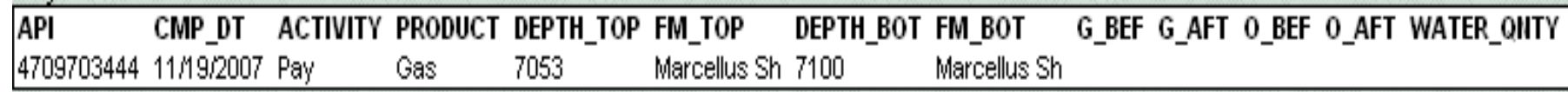

Vertical \#3:

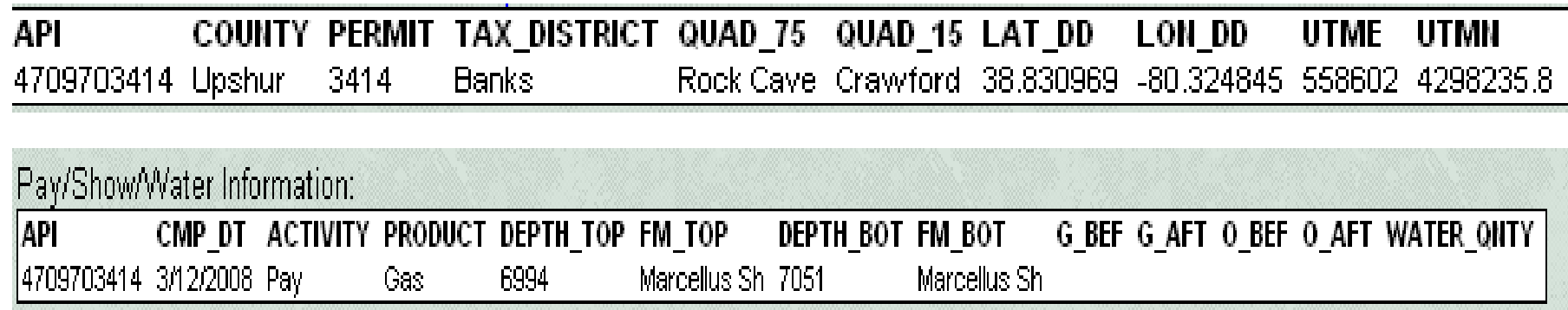

Vertical \#4:

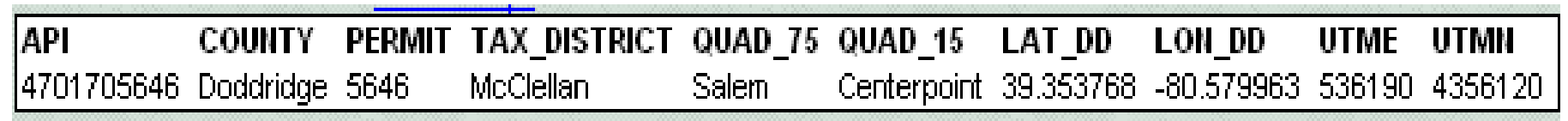

Completion Information:

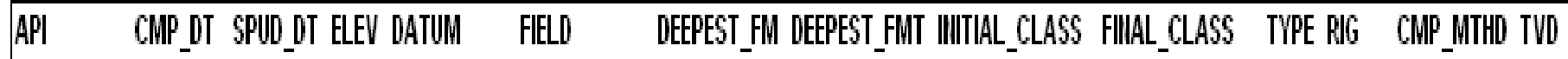

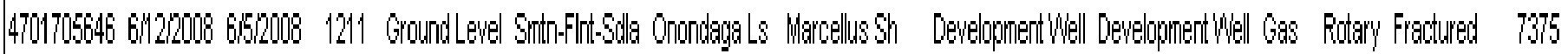

Pay/Show Water Information:

\begin{tabular}{|c|c|c|c|c|c|}
\hline API & CMP_DT ACTIVITY & PRODUCT & DEPTH_TOP FM_TOP & DEPTH_BOT FM_BOT & G_BEF G_AFT 0_BEF 0_AFT WATER_QIITY \\
\hline 4701705646 & 6/2/2008 Water & Fresh Water & & 115 & \\
\hline 4701705646 & 6/2/20008 Pay & Gas & Marcellus St & Marcellus Sh & \\
\hline
\end{tabular}

Vertical \#5:

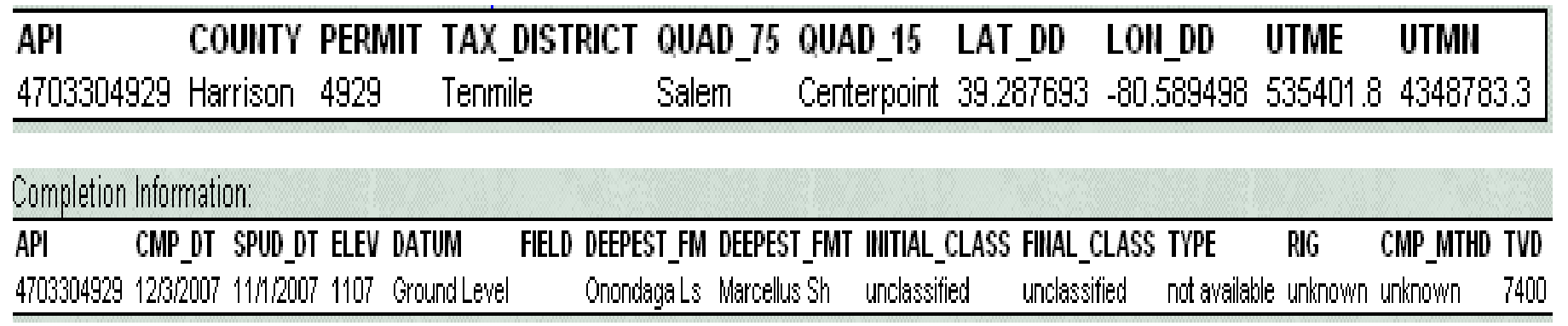

Vertical \#6:

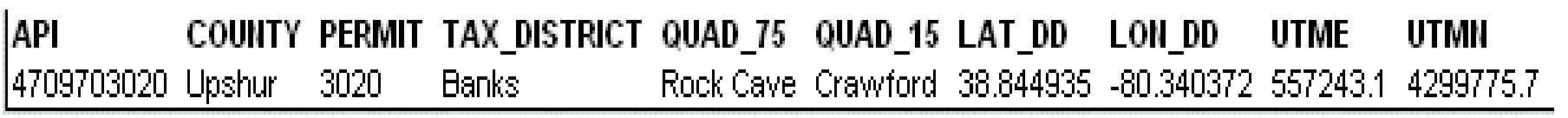


Completion Information:

\begin{tabular}{|lllllllll}
\hline API & CMP_DT & SPUD_DT ELEV DATUM & FIELD & DEEPEST_FM DEEPEST_FMT IIITIAL_CLASS & FIIIAL_CLASS & TYPE & RIG & CMP_MTHD TVD
\end{tabular} 47097030201222622000 10/9/2000 1806 Ground Level Cave Run Helderberg Oriskany Outpost (Extension) Test Outpost (Extension) Well Gas Rotary Acid+Frac 7586

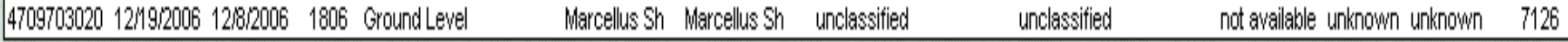

Vertical \#7:

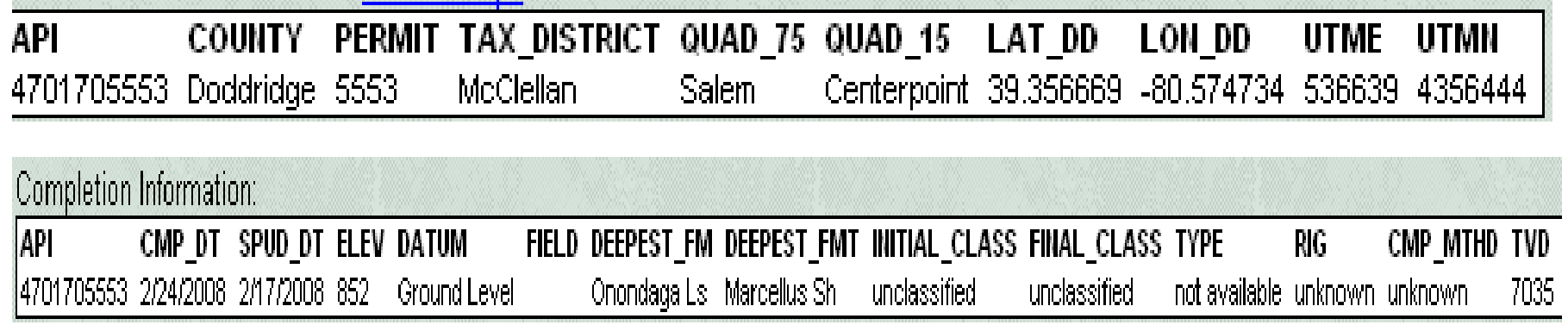

Vertical \#8:

API COUITY PERMIT TAX_DISTRICT QUAD_75 QUAD_15 LAT_DD LOII_DD UTME UTMII 4701705657 Doddridge 5657 Grant $\quad$ Smithburg Centerpoint 39.296585 -80.63322 531627.24349753 .9

Completion Information:

API CMP_DT SPUD__DT ELEV DATUM FIELD DEEPEST_FM DEEPEST_FMT IIITIAL_CLASS FIIIAL_CLASS TYPE RIG CMP_MTHD TVD

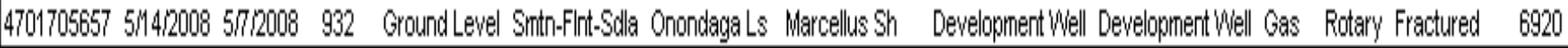

\begin{tabular}{|c|c|c|c|c|c|c|c|c|}
\hline $\begin{array}{l}\text { API } \\
4701705657\end{array}$ & $\begin{array}{l}\text { CMP_DT } \\
5 / 14 / 2008\end{array}$ & $\begin{array}{l}\text { ACTIVITY } \\
\text { Water }\end{array}$ & $\begin{array}{l}\text { PRODUCT } \\
\text { Fresh Water }\end{array}$ & DEPTH_TOP & FM_TOP & $\begin{array}{l}\text { DEPTH_BOT } \\
45\end{array}$ & FM_BOT & G_BEF G_AFT O_BEF O_AFT WATER_QIITY \\
\hline 4701705657 & $5 / 14 / 2008$ & Pay & Gas & 6870 & Marcellus Sh & 6916 & Marcellus Sh & \\
\hline
\end{tabular}

\section{Vertical \#9:}

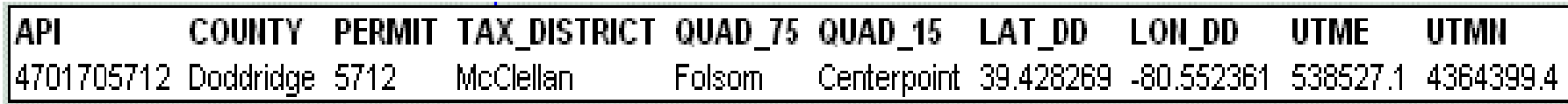

Completion Information:

API CMP_DT SPUD_DT ELEV DATUM FIELD DEEPEST_EM DEEPEST_FMT IIIITIAL_CLASS FIIIAL_CLASS TYPE RIG CMP_MTHD TVD 4701705712 82120008 8402008 1110 Ground Level Onondaga LS Marcellus Sh unclassified unclassified not avaliable unknown unknown 7233

Pay/Show Water Information:

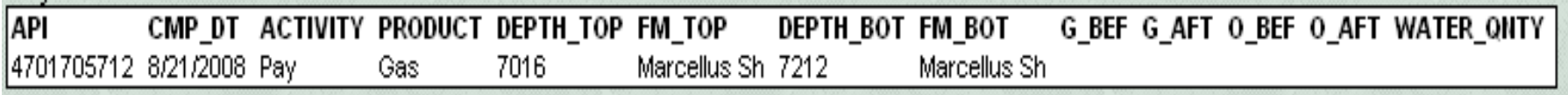

\section{Horizontal \#1:}




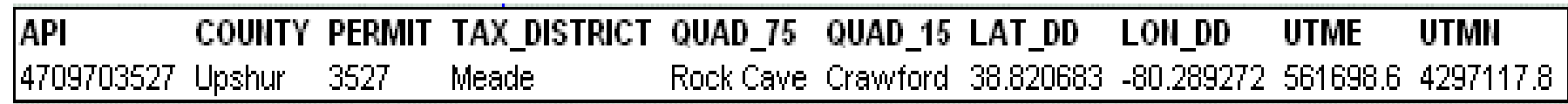

Completion Information:

API CMP_DT SPUD_DT ELEV DATUM FIELD DEEPEST_FM DEEPEST_FMT IIITIAL_CLASS FIIIAL_CLASS TYPE $\quad$ RIG CMP_MTHD TVD TMD 4709703527 731200085/2620008 1978 Ground Level Marcellus Sh Marcellus Sh unclassified unclassified not avaliable unknown unknown 7177 10676

\section{Horizontal \#2:}

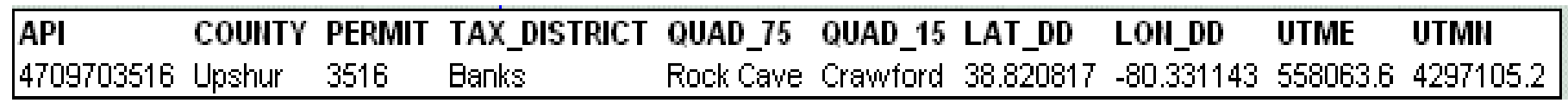

Completion Intormation:

API CMP_DT SPUD_DT ELEV DATUM FIELD DEEPEST_EM DEEPEST_EMT IIITIAL_CLASS FIIIAL_CLASS TYPE RIG CMP_MTHD TVD TMD 470970351672232008 4/29202008 1978 Ground Level Cave Run Marcellus Sh Marcellus Sh Developnent Well Developprenti Well Gas Rotary Acid+Frac 72499061

\section{Horizontal \#3:}

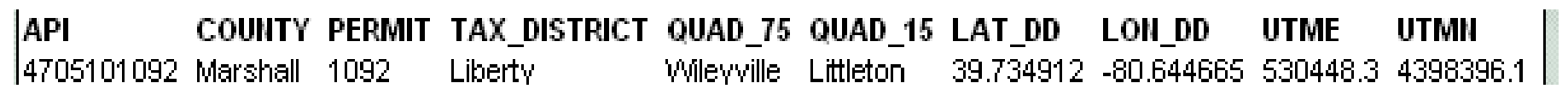
iompletion Information:

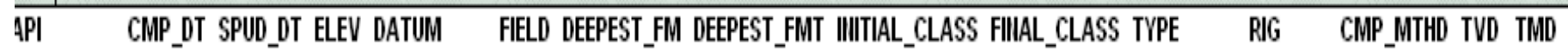
1705101092 4/620008 3/442008 1404 Ground Level Marcellus Sh Marcellus Sh unclassified unclassified not avallable unknown unknown 71789905 
Appendix C

Vertical \#1:

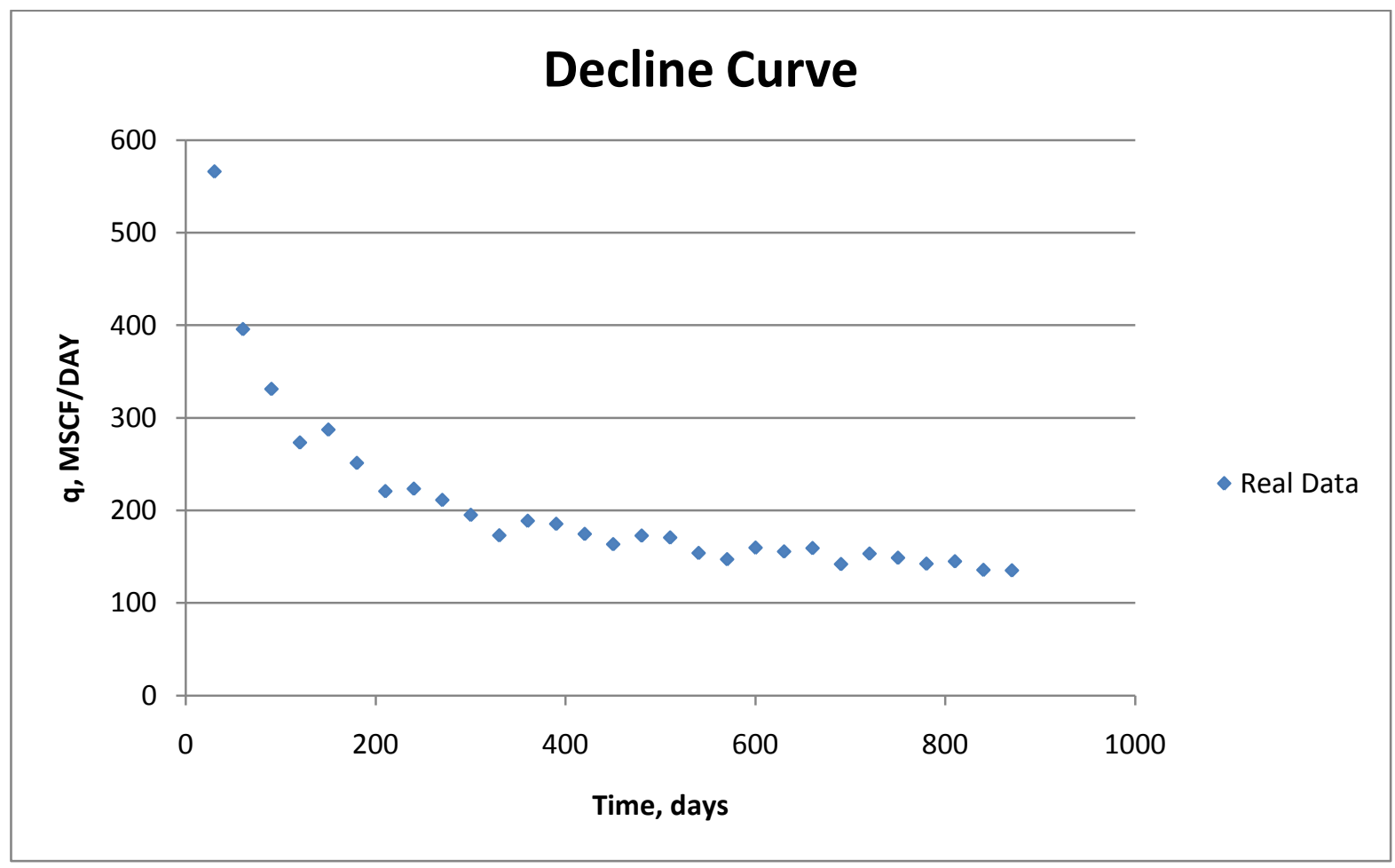

Figure C-1. Decline Curve for Vertical 1

Vertical \#2: 


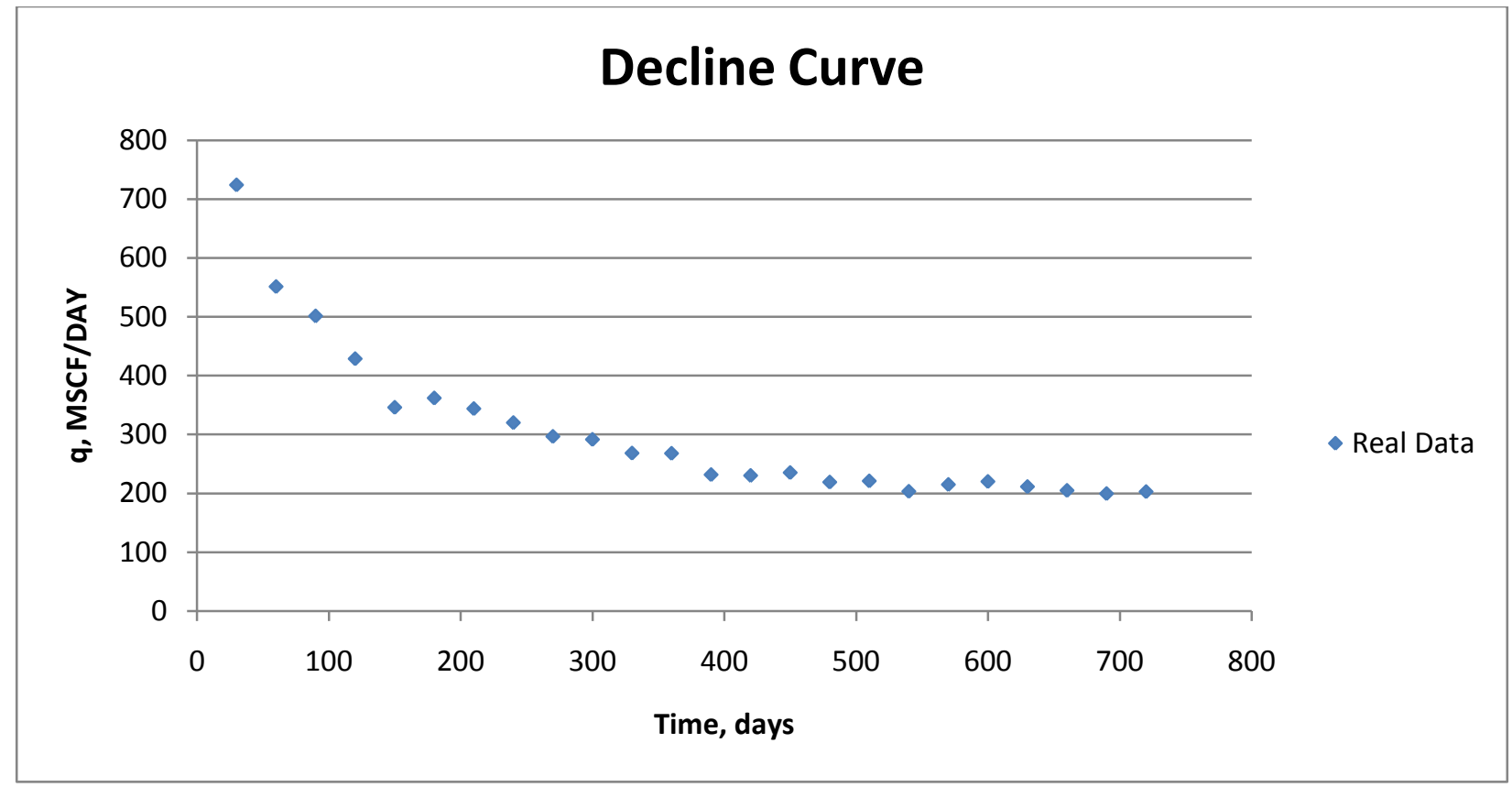

Figure C-2. Decline Curve for Vertical 2

Vertical \#3:

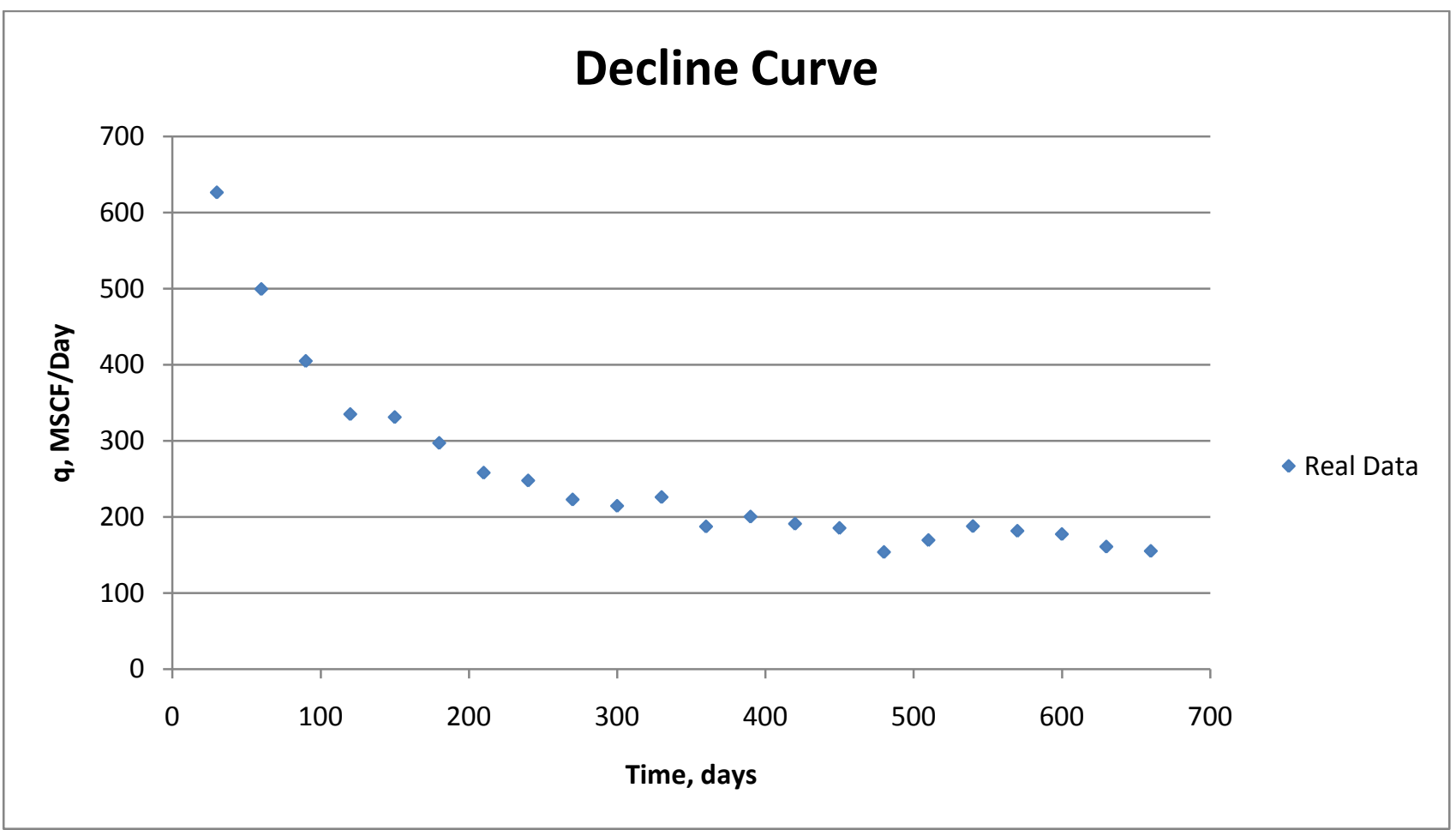

Figure C-3. Decline Curve for Vertical 3 
Vertical \#4:

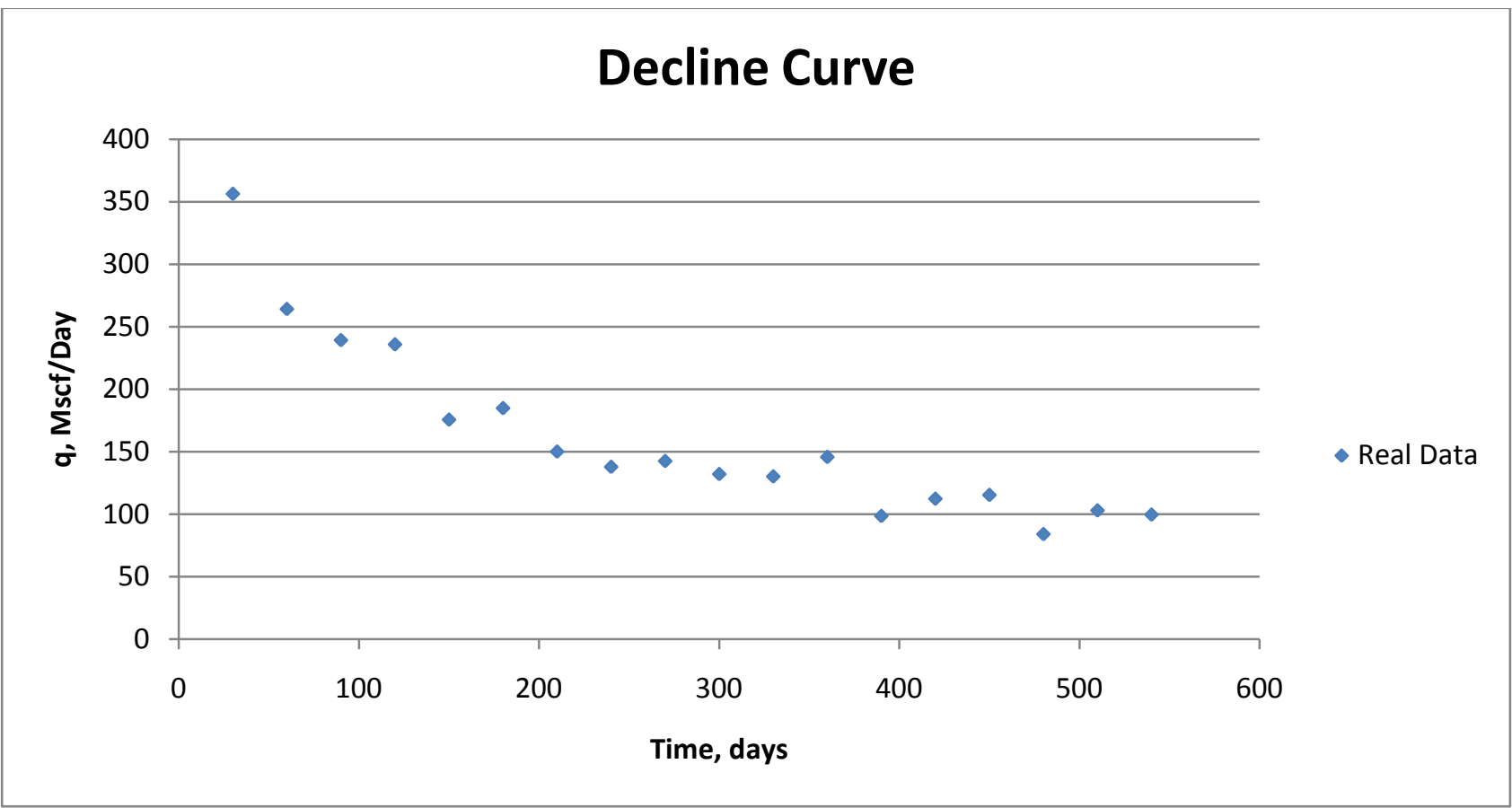

Figure C-4. Decline Curve for Vertical 4

Vertical \#5:

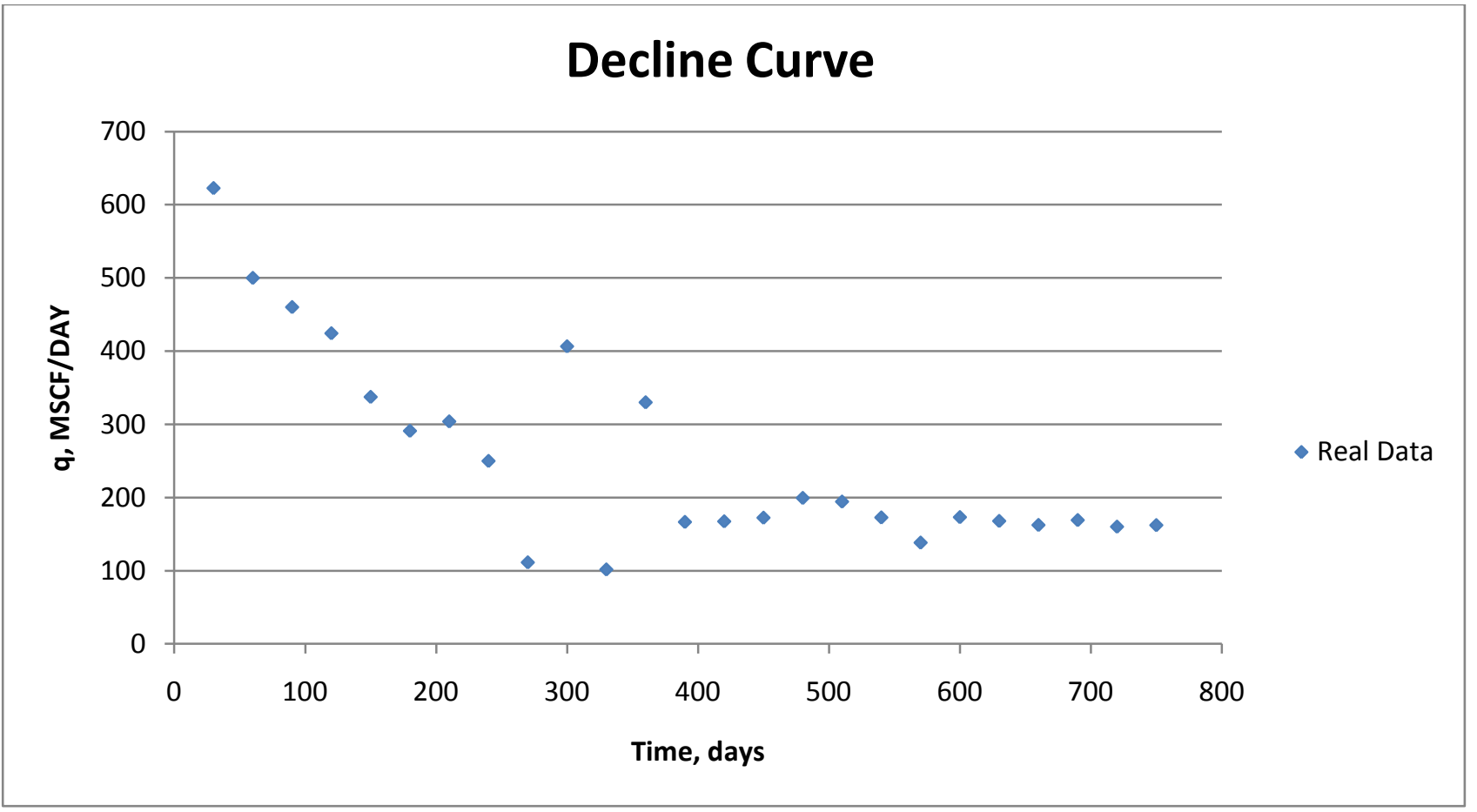

Figure C-5. Decline Curve for Vertical 5 
Vertical \#6:

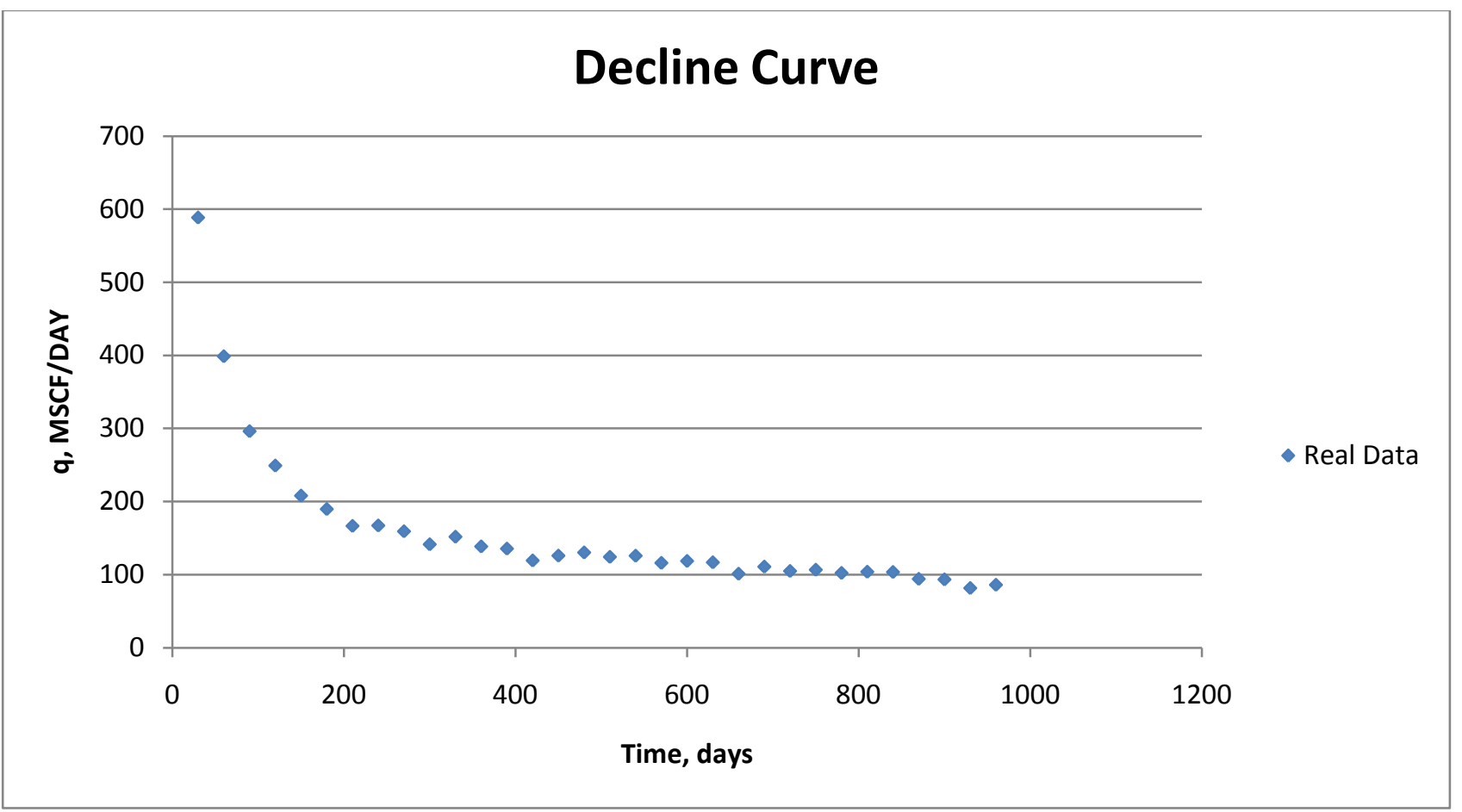

Figure C-6. Decline Curve for Vertical 6

Vertical \#7:

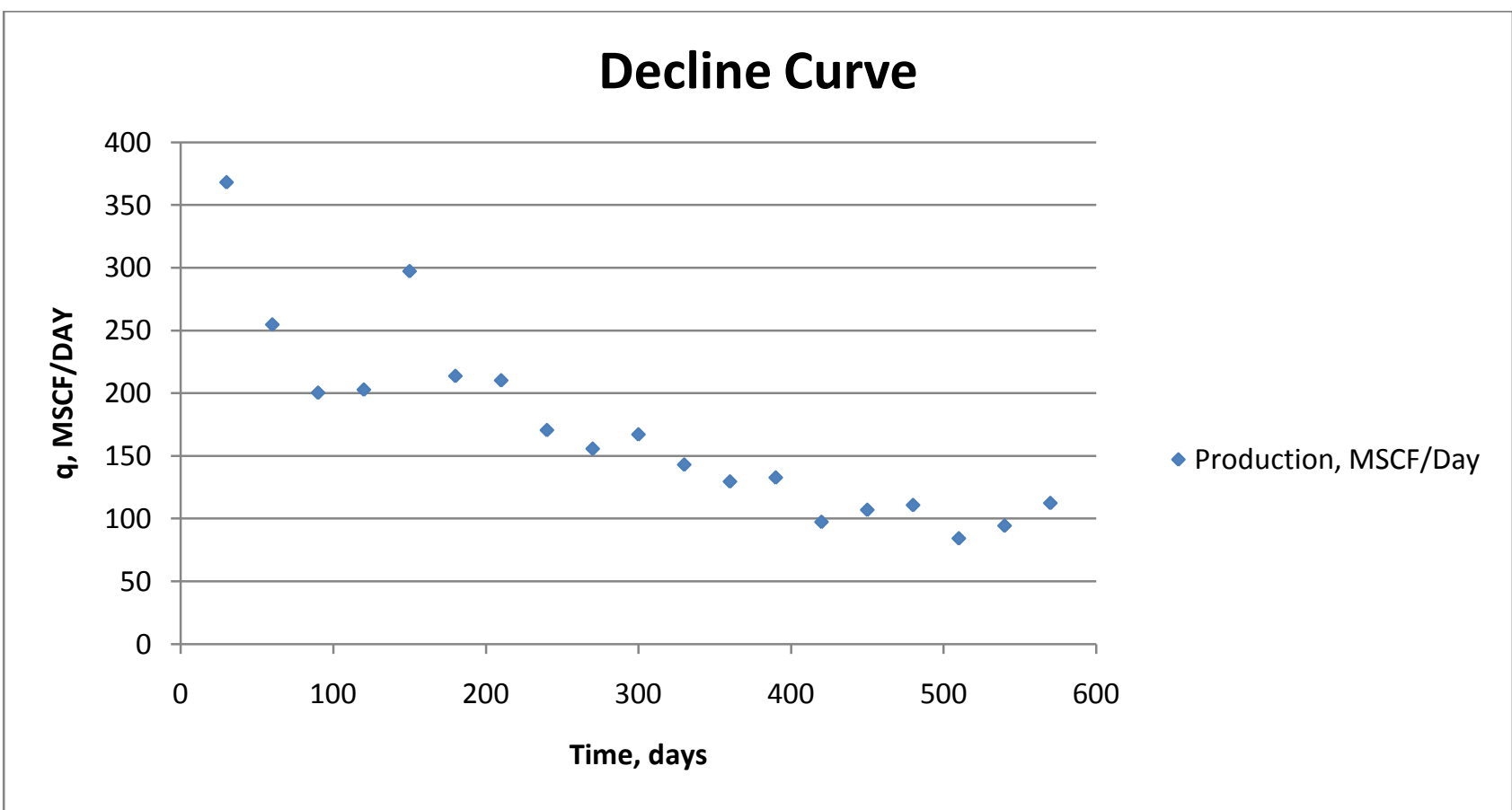

Figure C-7. Decline Curve for Vertical 7 
Vertical \#8:

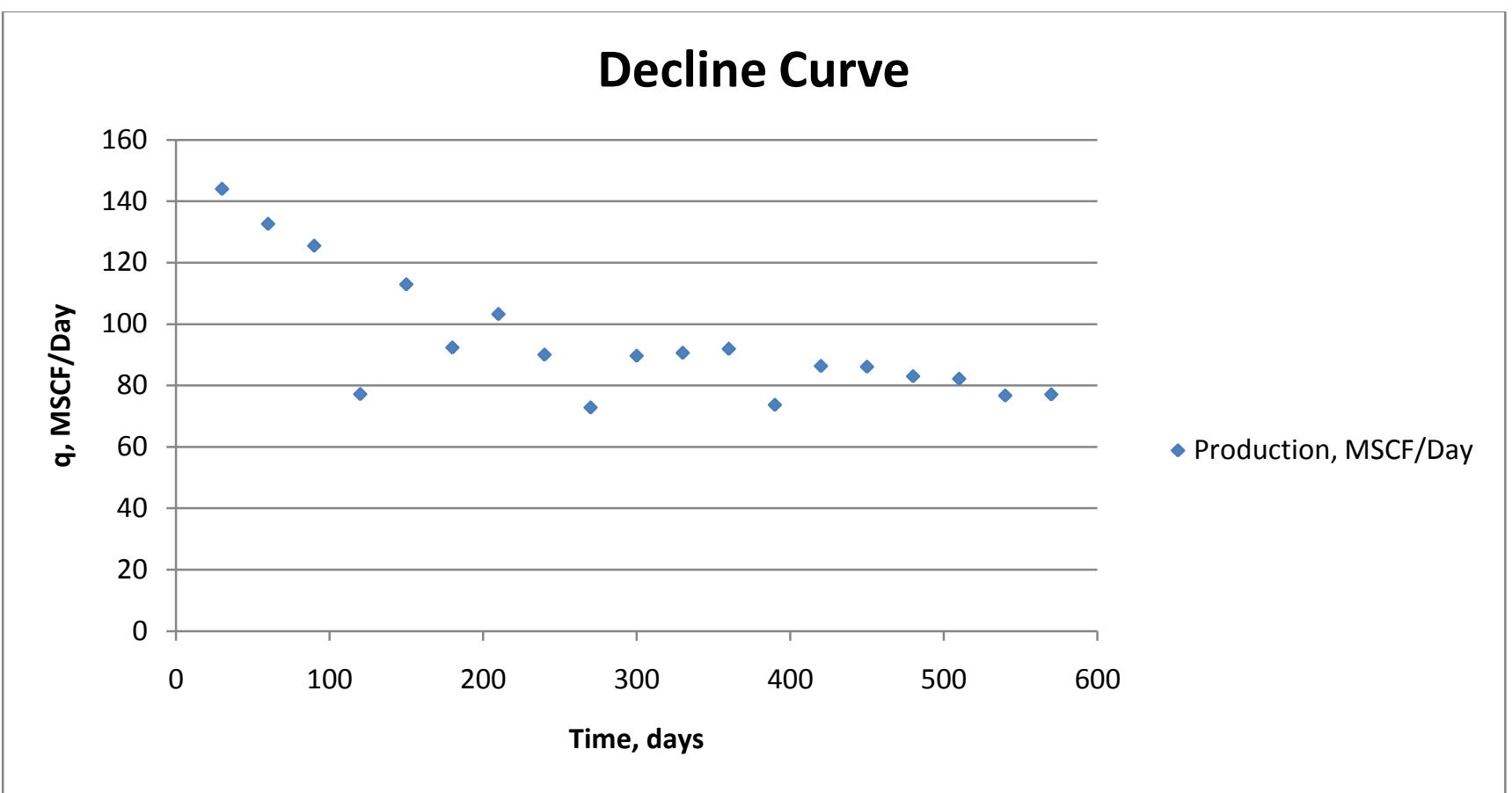

Figure C-8. Decline Curve for Vertical 8

Vertical \#9:

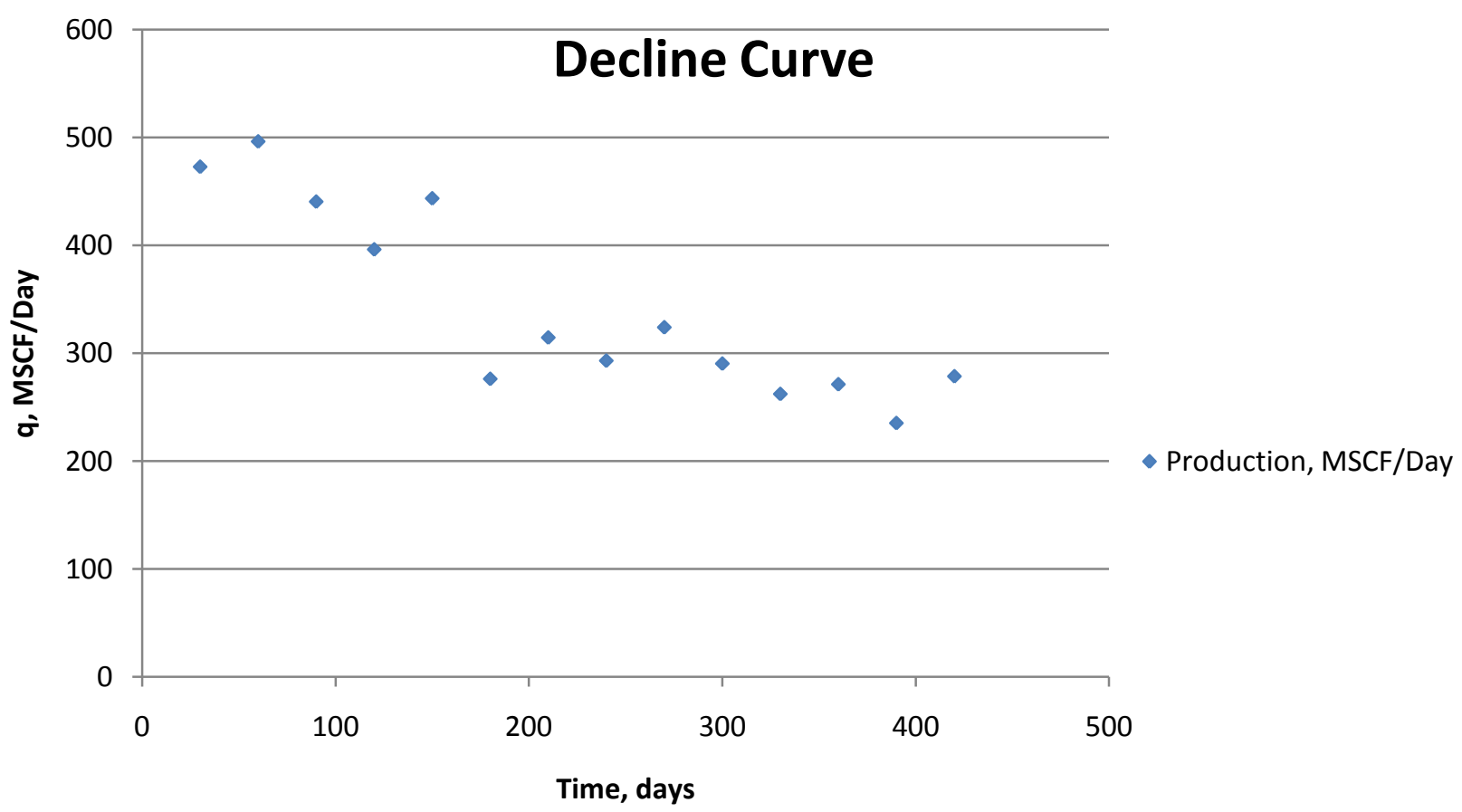

Figure C-9. Decline Curve for Vertical 9 
Horizontal \#1:

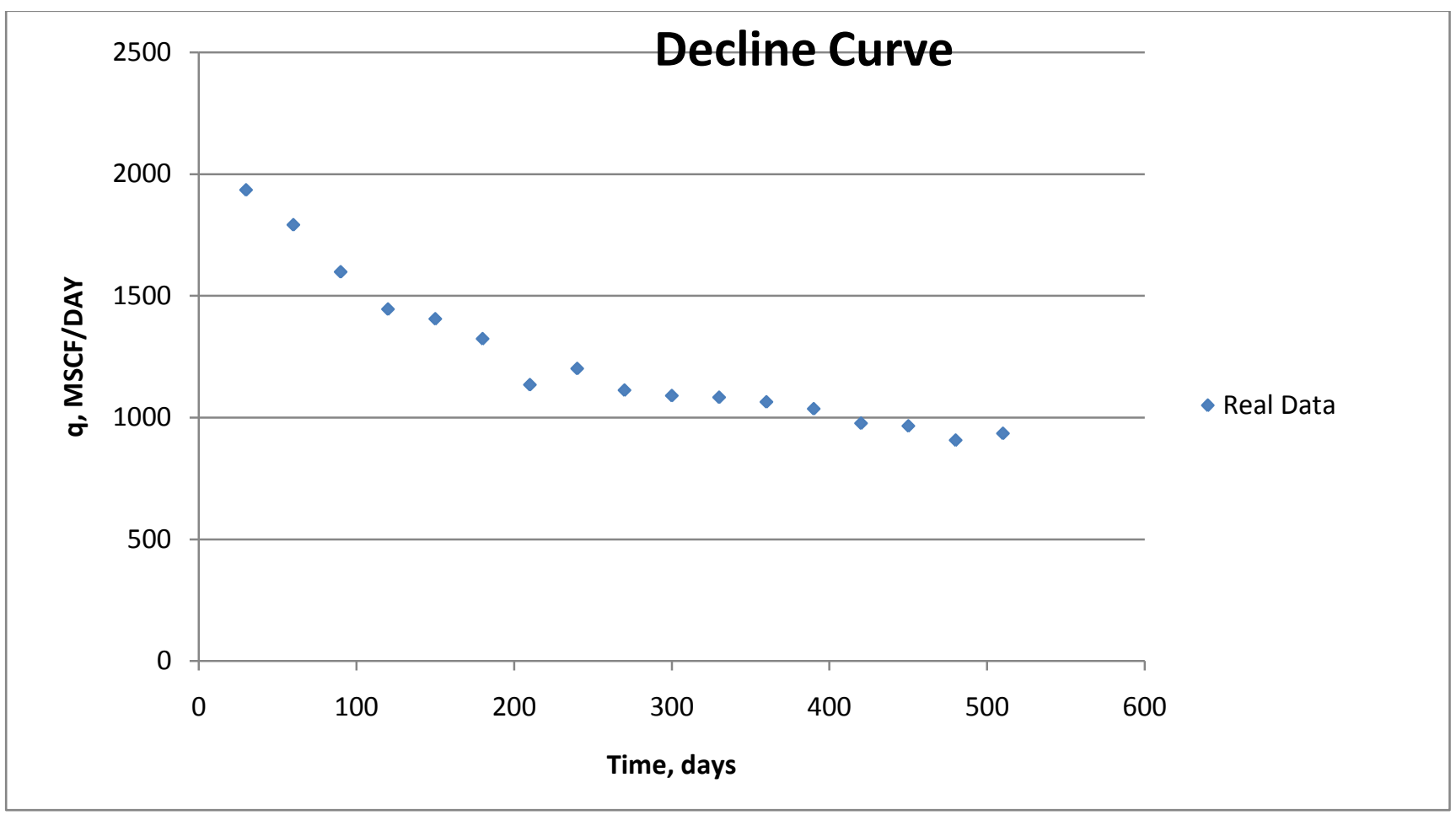

Figure C-10. Decline Curve for Horizontal \#1

\section{Horizontal \#2:}

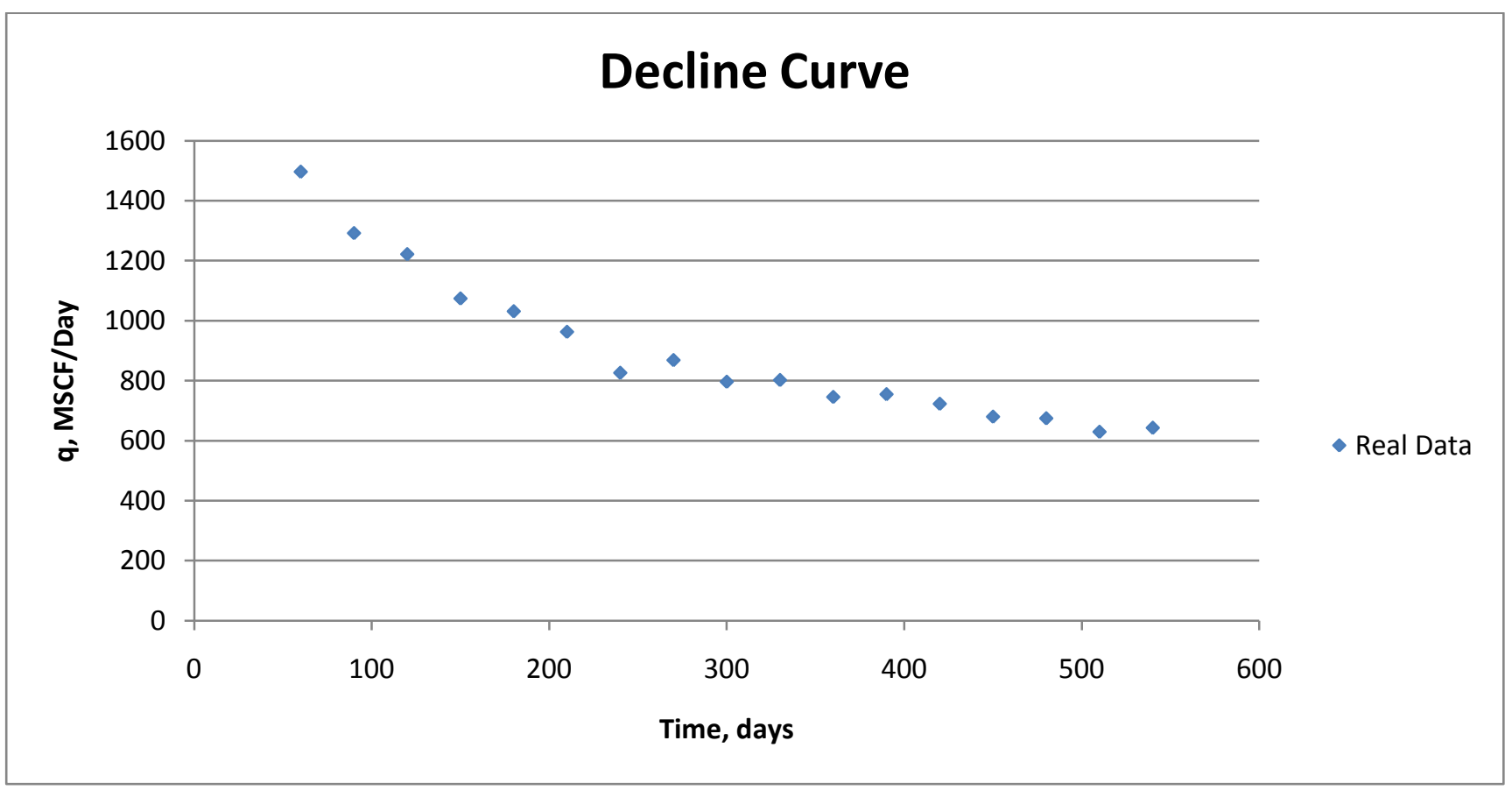

Figure C-11. Decline Curve for Horizontal \#2 


\section{Horizontal \#3:}

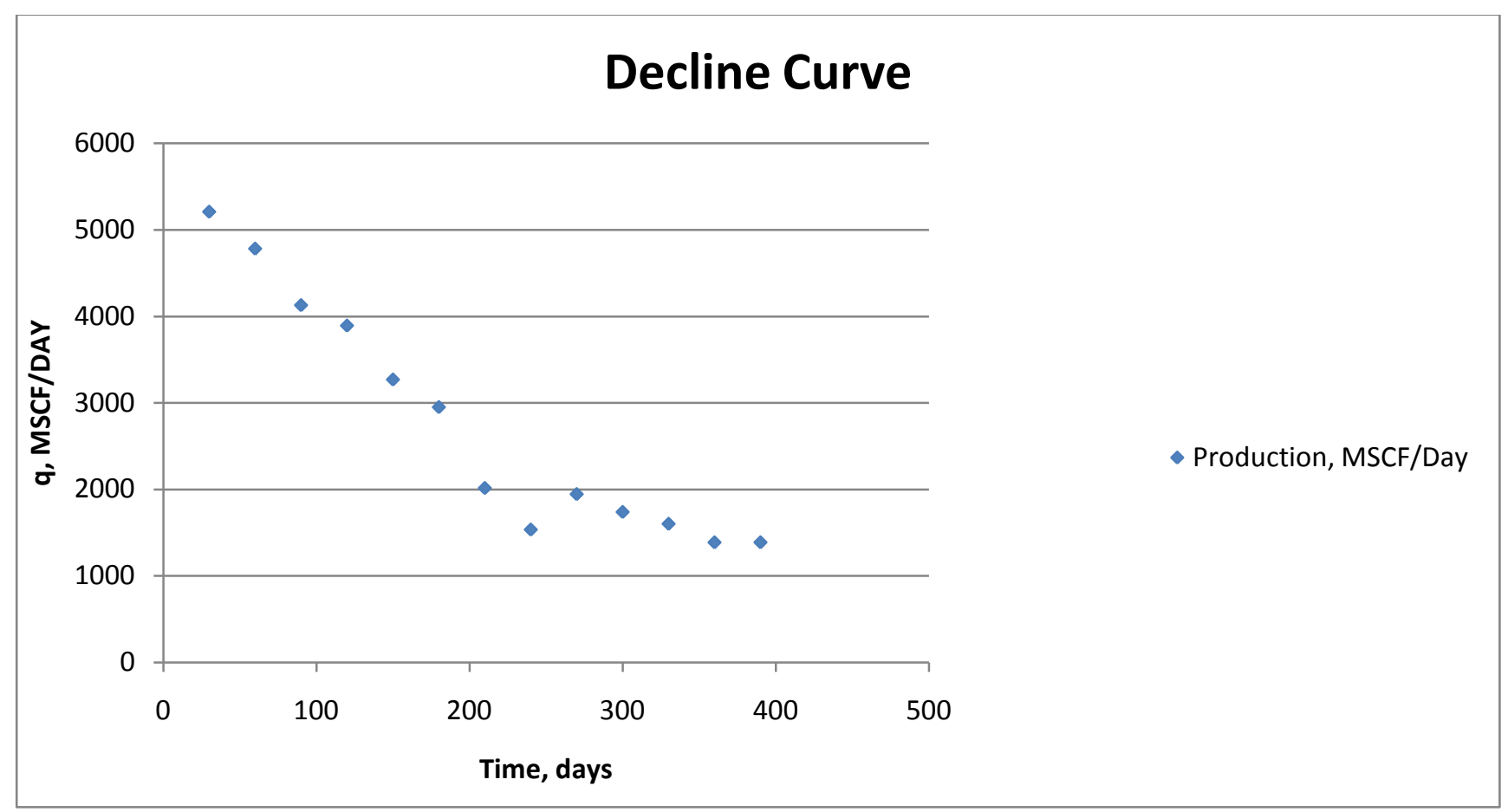

Figure C-12. Decline Curve for Horizontal \#3 


\section{Appendix D}

\section{Vertical \#1:}

First vertical well studied for this thesis is located in Upshur County. An 80 acres area was assumed for this well with the dimensions of $1867^{*} 1867\left(\mathrm{ft}^{\wedge} 2\right)$. The thickness of this well was given in the completion data as $50 \mathrm{ft}$. Both initial and final parameters used for getting a match are listed below,

\begin{tabular}{|c|c|c|}
\hline \multicolumn{3}{|c|}{ Initial parameters used } \\
\hline Thickness & 50 & $\mathrm{ft}$ \\
\hline Area & 80 & acres \\
\hline Top of fracture & 6890 & $\mathrm{ft}$ \\
\hline Bottom of fracture & 6940 & $\mathrm{ft}$ \\
\hline Fracture por & 0.005 & \\
\hline Matrix por & 0.05 & \\
\hline Fracture perm & 0.002 & md \\
\hline Dimensiosn & $1867 * 1867$ & $\mathrm{ft}^{\wedge} 2$ \\
\hline Matrix perm & 0.0002 & $\mathrm{md}$ \\
\hline Rock Density & 100 & $\mathrm{lb} / \mathrm{ft}^{\wedge} 3$ \\
\hline Initial Pressure & 3500 & psia \\
\hline Sw & 15 & $\%$ \\
\hline
\end{tabular}

\begin{tabular}{|c|c|c|}
\hline \multicolumn{3}{|c|}{ Final parameters for the match } \\
\hline Thickness & 50 & $\mathrm{ft}$ \\
\hline Area & 80 & acres \\
\hline Top of fracture & 6890 & $\mathrm{ft}$ \\
\hline Bottom of fracture & 6940 & $\mathrm{ft}$ \\
\hline Fracture por & 0.005 & \\
\hline Matrix por & 0.05 & \\
\hline Fracture perm & 0.002 & md \\
\hline Dimensiosn & $1867 * 1867$ & $\mathrm{ft}^{\wedge} 2$ \\
\hline Matrix perm & 0.0002 & md \\
\hline Rock Density & 100 & $\mathrm{lb} / \mathrm{ft}^{\wedge} 3$ \\
\hline Initial Pressure & 3500 & psia \\
\hline Sw & 15 & $\%$ \\
\hline
\end{tabular}

\begin{tabular}{|c|c|c|}
\hline Hydraulic Fracture & \multicolumn{3}{|l|}{} \\
\hline Half length & 500 & $\mathrm{ft}$ \\
\hline permeability & 20000 & $\mathrm{md}$ \\
\hline porosity & 20 & $\%$ \\
\hline Width & 0.01 & inch \\
\hline
\end{tabular}

\begin{tabular}{|c|c|c|}
\hline \multicolumn{3}{|c|}{ Hydraulic Fracture } \\
\hline Half length & 500 & $\mathrm{ft}$ \\
\hline permeability & 20000 & $\mathrm{md}$ \\
\hline porosity & 20 & $\%$ \\
\hline Width & 0.01 & inch \\
\hline
\end{tabular}

As can be seen above, natural fracture permeability was assumed to be $0.002 \mathrm{md}$. In addition, hydraulic fracture permeability is assumed to be $20000 \mathrm{md}$. Hydraulic fracture porosity does not have much impact on the initial production because there is only one stage of hydraulic fracturing that is being used for this well. Water saturation was assumed to be the same for all the vertical and horizontal wells. Since the depth of the studied Marcellus Shale wells are in 
between $6700-7200 \mathrm{ft}$, the initial pressure is assumed to be 3500 psia for all the wells. Historically matching the real field data using Eclipse for this particular well did not have any issues because the parameters that were used were identical to the base model. The above base model that was discussed earlier has been obtained after studying the Marcellus Shale parameters for months and talking to different operating and service companies regarding the chosen values. After using the above parameters, the below match was obtained,

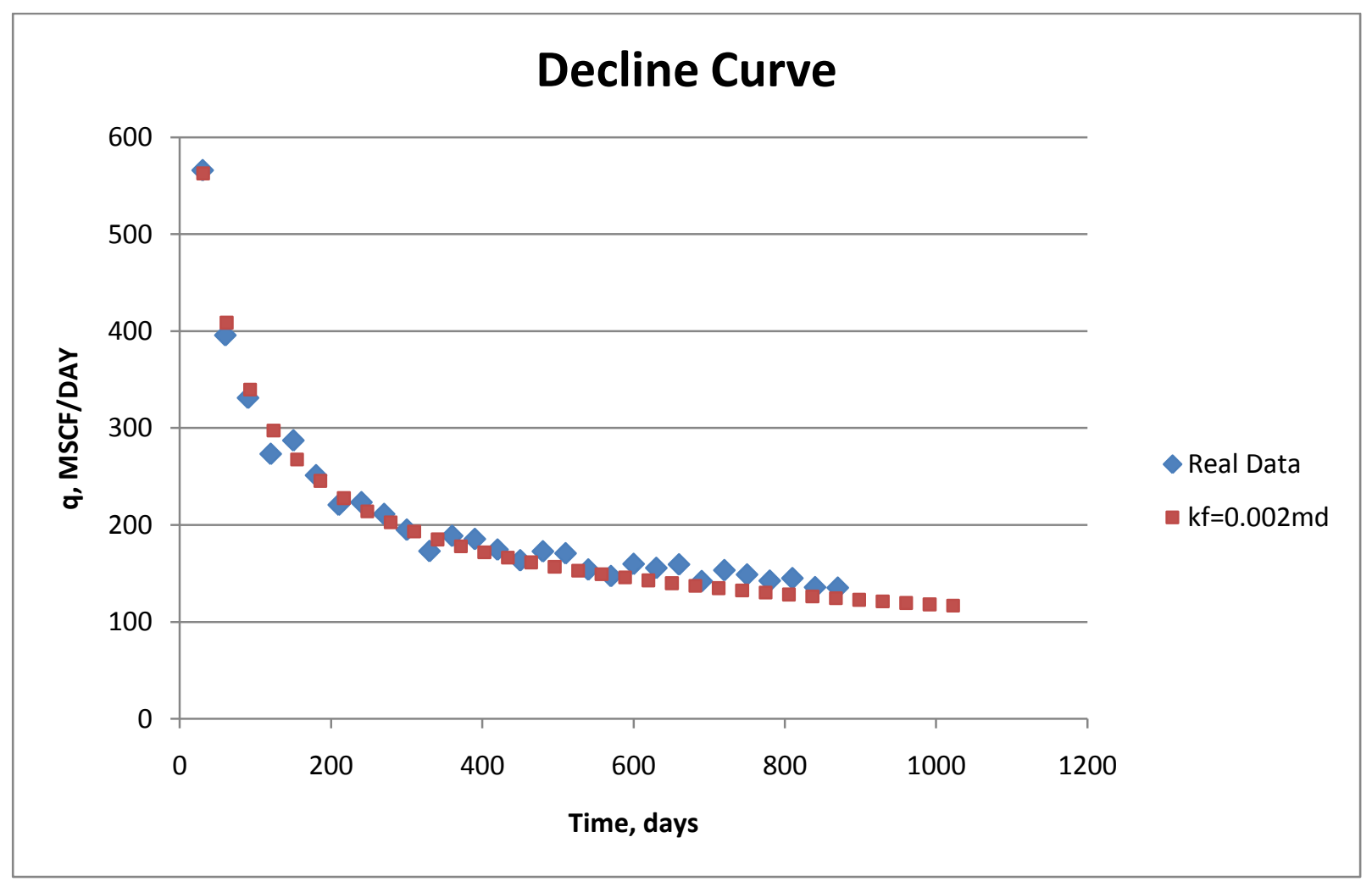

Figure 22. Final Match for Vertical \#1 


\section{Vertical \#3:}

The third well studied for this thesis is also located in Upshur County. The acreage for this well is assumed to be 80 acres and the thickness was obtained from the completion data as $57 \mathrm{ft}$. In addition, a square reservoir is assumed for this reservoir with the dimensions of $1867 * 1867\left(\mathrm{ft}^{\wedge} 2\right)$. Both initial and final parameters used for getting a match are listed below,

\begin{tabular}{|c|c|c|}
\hline \multicolumn{3}{|c|}{ Initial parameters used } \\
\hline Area & 80 & acres \\
\hline Top of fracture & 6994 & $\mathrm{ft}$ \\
\hline Bottom of fracture & 7051 & $\mathrm{ft}$ \\
\hline Thickness & 57 & $\mathrm{ft}$ \\
\hline Fracture por & 0.005 & fraction \\
\hline Matrix por & 0.05 & fraction \\
\hline Fracture perm & 0.001 & $\mathrm{md}$ \\
\hline Dimensiosn & $1867^{*} 1867$ & $\mathrm{ft}{ }^{\wedge} 2$ \\
\hline Matrix perm & 0.0002 & $\mathrm{md}$ \\
\hline Rock Density & 100 & $\mathrm{lb} / \mathrm{ft}^{\wedge} 3$ \\
\hline Pressure & 3500 & $\mathrm{psia}$ \\
\hline Sw & 15 & $\%$ \\
\hline
\end{tabular}

\begin{tabular}{|c|c|c|}
\hline \multicolumn{3}{|c|}{ Final parameters for the match } \\
\hline Area & 80 & acres \\
\hline Top of fracture & 6994 & $\mathrm{ft}$ \\
\hline Bottom of fracture & 7051 & $\mathrm{ft}$ \\
\hline Thickness & 57 & $\mathrm{ft}$ \\
\hline Fracture por & 0.005 & fraction \\
\hline Matrix por & 0.05 & fraction \\
\hline Fracture perm & 0.002 & $\mathrm{md}$ \\
\hline Dimensiosn & $1867 * 1867$ & $\mathrm{ft}^{\wedge} 2$ \\
\hline Matrix perm & 0.0002 & $\mathrm{md}$ \\
\hline Rock Density & 100 & $\mathrm{Ib} / \mathrm{ft}^{\wedge} 3$ \\
\hline Pressure & 3500 & psia \\
\hline Sw & 15 & $\%$ \\
\hline
\end{tabular}

\section{Hydraulic Fracture}

\begin{tabular}{|c|c|c|}
\hline Half length & 500 & $\mathrm{ft}$ \\
\hline permeability & 20000 & $\mathrm{md}$ \\
\hline porosity & 20 & $\%$ \\
\hline width & 0.01 & inch \\
\hline
\end{tabular}

Hydraulic Fracture
\begin{tabular}{|c|c|c|}
\hline Half length & 500 & $\mathrm{ft}$ \\
\hline permeability & 20000 & $\mathrm{md}$ \\
\hline porosity & 20 & $\%$ \\
\hline width & 0.01 & inch \\
\hline
\end{tabular}

To historically match this well, natural fracture permeability had to be changed because it has a great impact on the production decline curve by brining the curve up and down. Below is a visual illustration of what happens when natural fracture permeability changes from 0.001 to different permeabilities. 


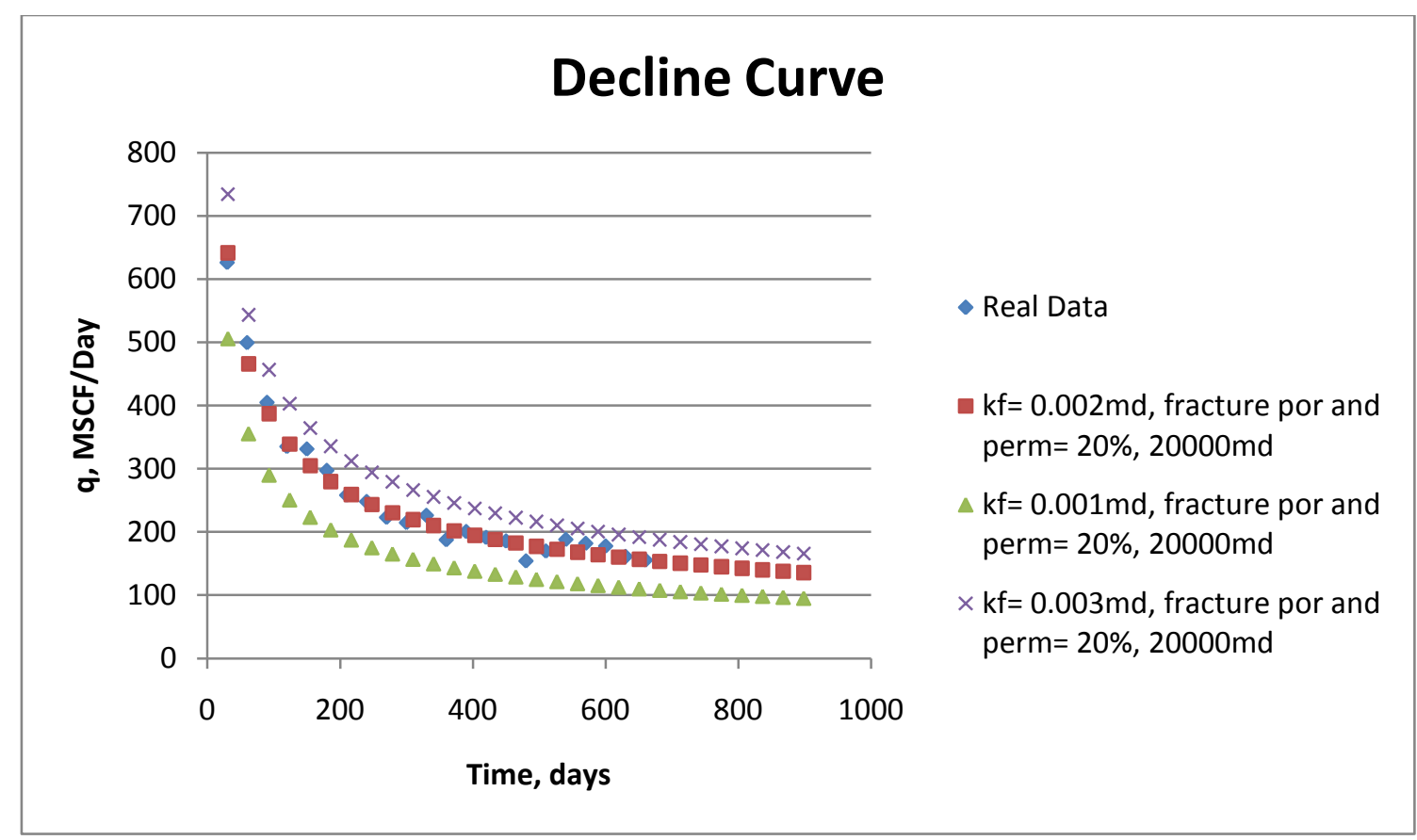

Figure 23. History Matching for Vertical \#3

As can be seen in the above plot, when natural fracture permeability changes from $0.001 \mathrm{md}$ to $0.002 \mathrm{md}$; the entire production decline curve moves up. This is an indication of the importance of natural fracture permeability in dual porosity model and unconventional reservoirs. Below plot is the final match for the third vertical well which can be seen in the above plot as well. 


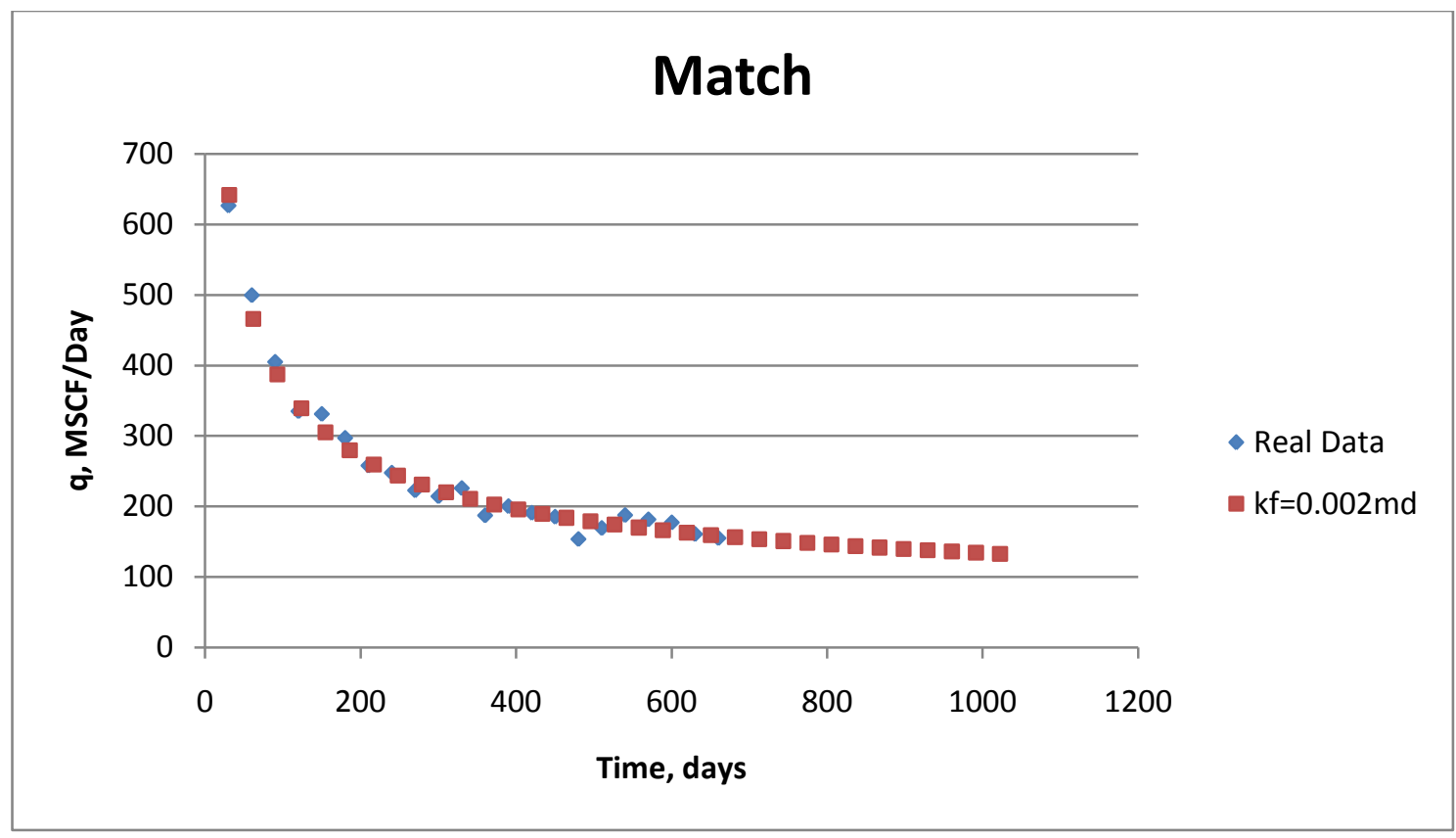

Figure 24. Final Match for Vertical \#3

\section{Vertical \#4:}

The forth well studied for this thesis is located in Doddridge County. The acreage for this well is assumed to be 80 acres and the thickness was obtained from the completion data as $38 \mathrm{ft}$. In addition, a square reservoir is assumed for this reservoir with dimensions of $1867^{*} 1867\left(\mathrm{ft}^{\wedge} 2\right)$. Both initial and final parameters used for getting a match are listed below,

\begin{tabular}{|c|c|c|}
\hline \multicolumn{3}{|c|}{ Initial parameters used } \\
\hline Area & 80 & acres \\
\hline Top of fracture & 7324 & $\mathrm{ft}$ \\
\hline Bottom of fracture & 7362 & $\mathrm{ft}$ \\
\hline Thickness & 38 & $\mathrm{ft}$ \\
\hline Fracture por & 0.005 & \\
\hline Matrix por & 0.05 & \\
\hline Fracture perm & 0.002 & $\mathrm{md}$ \\
\hline Dimensions & $1867 * 1867$ & $\mathrm{ft} \wedge 2$ \\
\hline Matrix perm & 0.0002 & $\mathrm{md}$ \\
\hline Rock Density & 100 & $\mathrm{lb} / \mathrm{ft} \wedge 3$ \\
\hline
\end{tabular}

\begin{tabular}{|c|c|c|}
\hline \multicolumn{3}{|c|}{ Final parameters for the match } \\
\hline Area & 80 & acres \\
\hline Top of fracture & 7324 & $\mathrm{ft}$ \\
\hline Bottom of fracture & 7362 & $\mathrm{ft}$ \\
\hline Thickness & 38 & $\mathrm{ft}$ \\
\hline Fracture por & 0.005 & \\
\hline Matrix por & 0.05 & \\
\hline Fracture perm & 0.002 & $\mathrm{md}$ \\
\hline Dimensions & $1867 * 1867$ & $\mathrm{ft} \wedge 2$ \\
\hline Matrix perm & 0.0002 & $\mathrm{md}$ \\
\hline Rock Density & 100 & $\mathrm{Ib} / \mathrm{ft} \wedge 3$ \\
\hline
\end{tabular}




\begin{tabular}{|c|c|c|} 
Pressure & 3500 & psia \\
\hline Sw & 15 & $\%$ \\
\hline
\end{tabular}

\section{Hydraulic Fracture}

\begin{tabular}{|c|c|c|}
\hline Half length & 500 & $\mathrm{ft}$ \\
\hline permeability & 20,000 & $\mathrm{md}$ \\
\hline porosity & 20 & $\%$ \\
\hline width & 0.01 & inch \\
\hline
\end{tabular}

\begin{tabular}{|c|c|c|} 
Pressure & 3500 & psia \\
\hline Sw & 15 & $\%$ \\
\hline
\end{tabular}

\section{Hydraulic Fracture}

\begin{tabular}{|c|c|c|}
\hline Half length & 500 & $\mathrm{ft}$ \\
\hline permeability & 12,000 & $\mathrm{md}$ \\
\hline porosity & 20 & $\%$ \\
\hline width & 0.01 & inch \\
\hline
\end{tabular}

To historically match this well, hydraulic fracture permeability was reduced from 20,000 md to $12,000 \mathrm{md}$ in order to bring the production decline curve down. The below plot shows how changing hydraulic fracture permeability would change the initial production behavior,

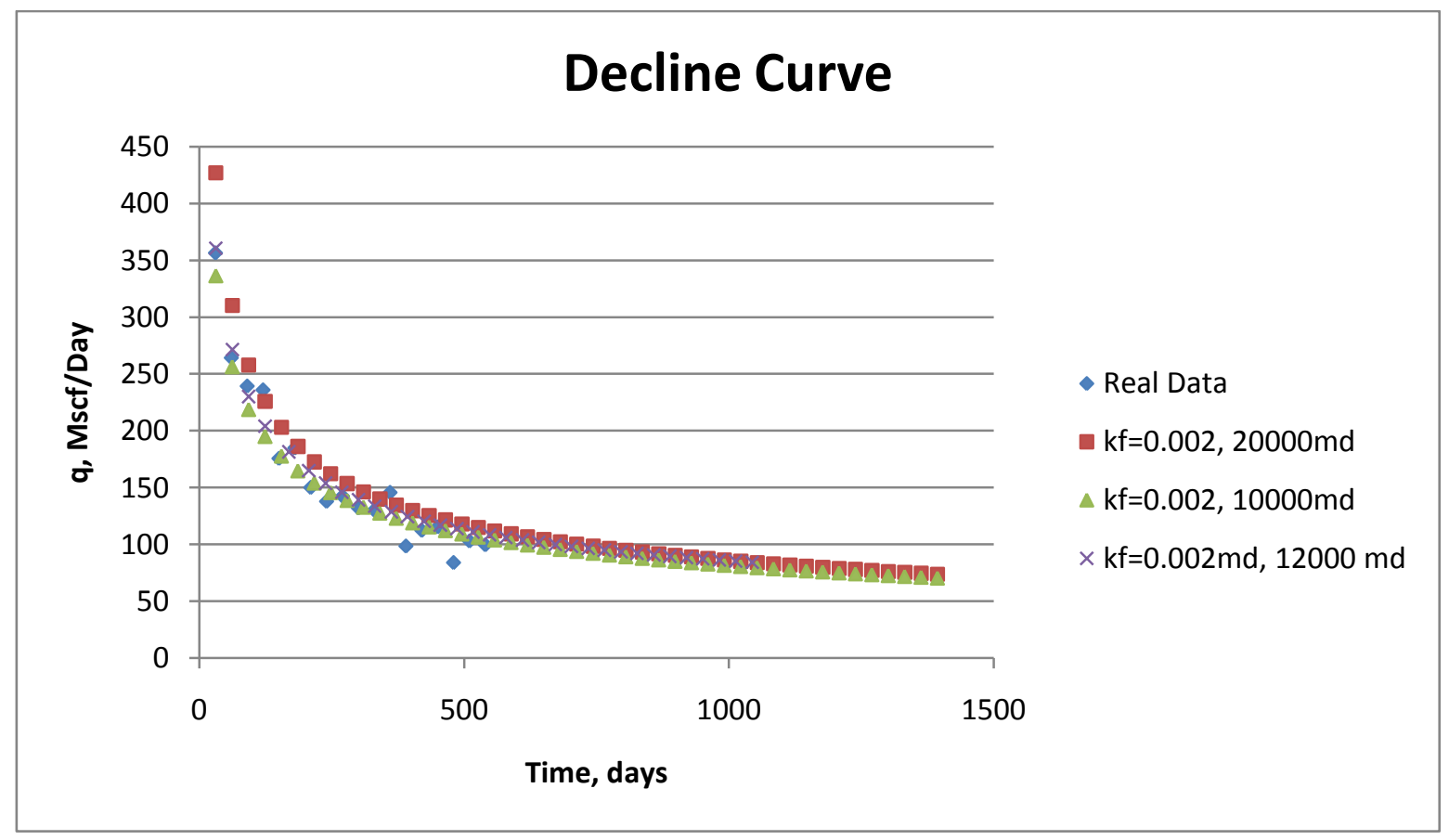

Figure 25. History Matching for Vertical \#4

As can be seen in the above plot, when the hydraulic fracture permeability is $20,000 \mathrm{md}$, the initial production starts approximately at $430 \mathrm{MSCF} / \mathrm{DAY}$; however when it was reduced to $12,000 \mathrm{md}$, the initial production was declined to approximately $360 \mathrm{MSCF} / \mathrm{DAY}$ which is 
almost the same as initial real field data. This indicates that hydraulic fracture permeability has most of its impact on the initial production. Finally, the match for the forth horizontal well is shown below,

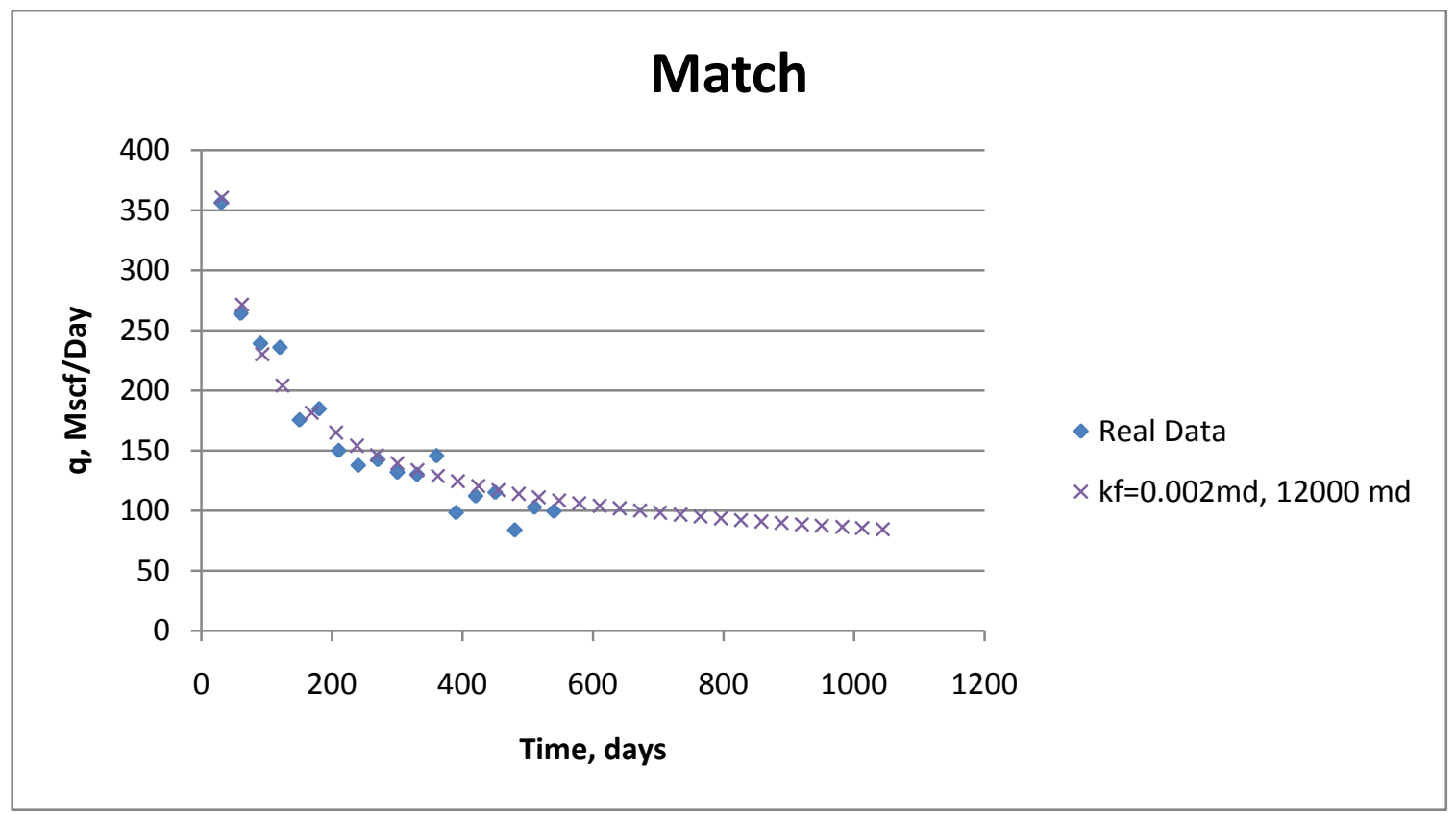

Figure 26. Final Match for Vertical \#4

\section{Vertical \#5:}

The fifth vertical well studied for this thesis is located in Harrison County. The acreage for this well is assumed to be 80 acres and the thickness was obtained from the completion data as $60 \mathrm{ft}$. In addition, a square reservoir is assumed for this reservoir with dimensions of $1867 * 1867\left(\mathrm{ft}^{\wedge} 2\right)$. Both initial and final parameters used for getting a match are listed below,

\begin{tabular}{|c|c|c|}
\hline \multicolumn{3}{|c|}{ Final parameters for the match } \\
\hline Area & 80 & acres \\
\hline Top of fracture & 7320 & $\mathrm{ft}$ \\
\hline Bottom of fracture & 7400 & $\mathrm{ft}$ \\
\hline $\begin{array}{c}\text { Thickness } \\
\text { (assumption) }\end{array}$ & 80 & $\mathrm{ft}$ \\
\hline
\end{tabular}

\begin{tabular}{|c|c|c|}
\hline \multicolumn{3}{|c|}{ Final parameters for the match } \\
\hline Area & 80 & acres \\
\hline Top of fracture & 7320 & $\mathrm{ft}$ \\
\hline Bottom of fracture & 7400 & $\mathrm{ft}$ \\
\hline $\begin{array}{c}\text { Thickness } \\
\text { (assumption) }\end{array}$ & 80 & $\mathrm{ft}$ \\
\hline
\end{tabular}




\begin{tabular}{|c|c|c|} 
Fracture por & 0.005 & \\
\hline Matrix por & 0.05 & \\
\hline Fracture perm & 0.002 & $\mathrm{md}$ \\
\hline Dimensions & $\begin{array}{c}1867^{*} 186 \\
7\end{array}$ & $\mathrm{ft}^{\wedge} 2$ \\
\hline Matrix perm & 0.0002 & $\mathrm{md}$ \\
\hline Rock Density & 100 & $\begin{array}{c}\mathrm{lb} / \mathrm{ft}^{\wedge} \\
3\end{array}$ \\
\hline Pressure & 3500 & $\mathrm{psia}$ \\
\hline Sw & 15 & $\%$ \\
\hline
\end{tabular}

\begin{tabular}{|c|c|c|} 
Hydraulic Fracture & \multicolumn{1}{|c|}{} \\
\hline Half length & 500 & $\mathrm{ft}$ \\
\hline permeability & 20,000 & $\mathrm{md}$ \\
\hline porosity & 20 & $\%$ \\
\hline width & 0.01 & inch \\
\hline
\end{tabular}

\begin{tabular}{|c|c|c|} 
Fracture por & 0.005 & \\
\hline Matrix por & 0.05 & \\
\hline Fracture perm & 0.001 & $\mathrm{md}$ \\
\hline Dimensions & $\begin{array}{c}1867^{*} 186 \\
7\end{array}$ & $\mathrm{ft}^{\wedge} 2$ \\
\hline Matrix perm & 0.0002 & $\mathrm{md}$ \\
\hline Rock Density & 100 & $\begin{array}{c}\mathrm{Ib} / \mathrm{ft}^{\wedge} \\
3\end{array}$ \\
\hline Pressure & 3500 & $\mathrm{psia}$ \\
\hline Sw & 15 & $\%$ \\
\hline
\end{tabular}

\begin{tabular}{|c|c|c|} 
Hydraulic Fracture \\
\hline Half length & 500 & $\mathrm{ft}$ \\
\hline permeability & 13,000 & $\mathrm{md}$ \\
\hline porosity & 20 & $\%$ \\
\hline width & 0.01 & inch \\
\hline
\end{tabular}

To historically match this well, hydraulic fracture permeability was changed from 20,000 md to $13,000 \mathrm{md}$ in order to bring the initial values down. In addition, natural fracture permeability was decreased from $0.002 \mathrm{md}$ to $0.001 \mathrm{md}$ to bring the entire production decline curve down. The below plot shows how changing hydraulic fracture permeability changes the initial production behavior, 


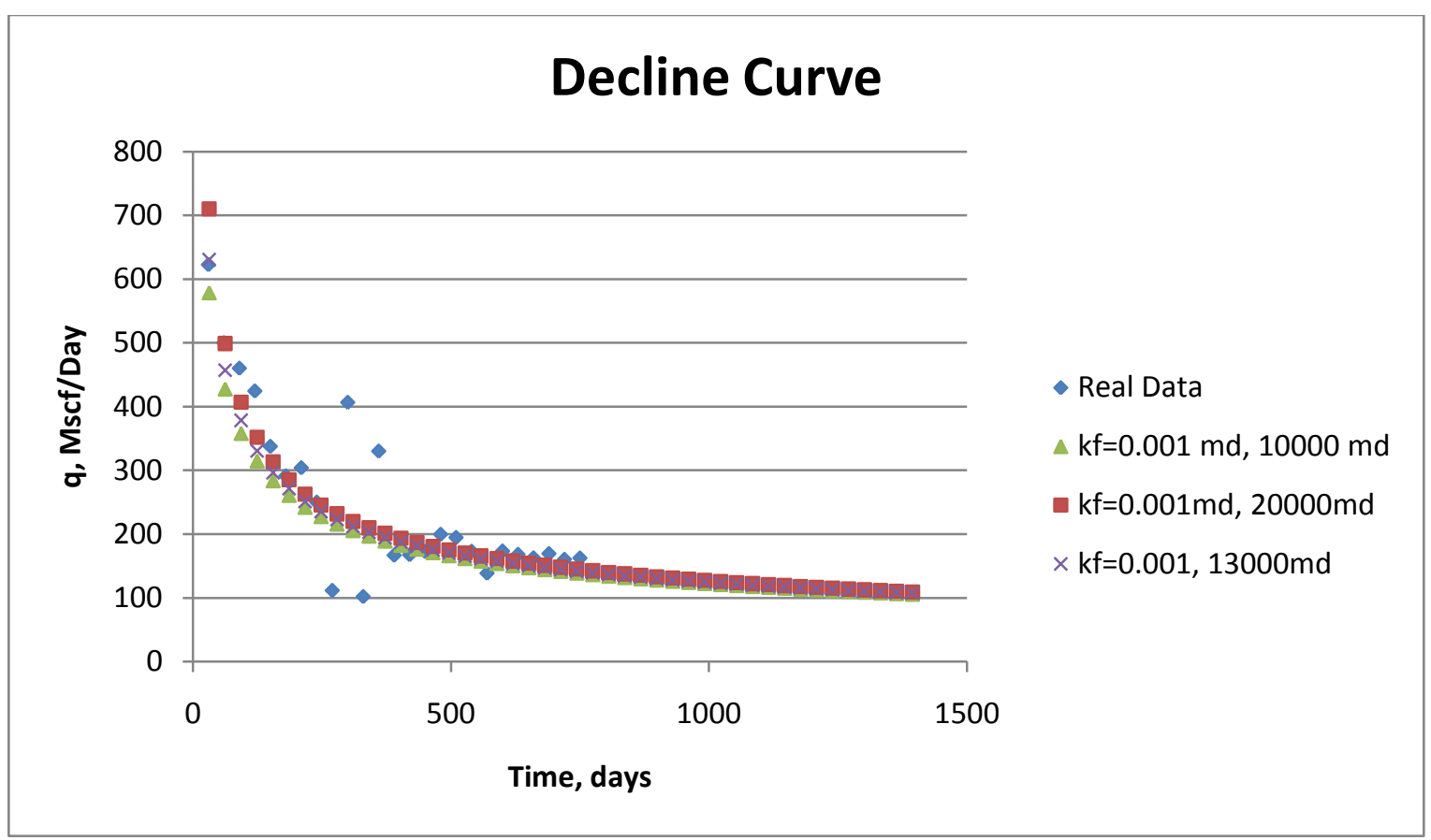

Figure 27. History Matching for Vertical \#5

As can be seen in the above plot, when hydraulic fracture permeability changes from 20,000 md to 13,000 , the initial production decreases to have a close match to the real field data. Finally, the match for this well is achieved by having 13,000 md as the hydraulic fracture permeability and $0.001 \mathrm{md}$ as natural fracture permeability as shown below, 


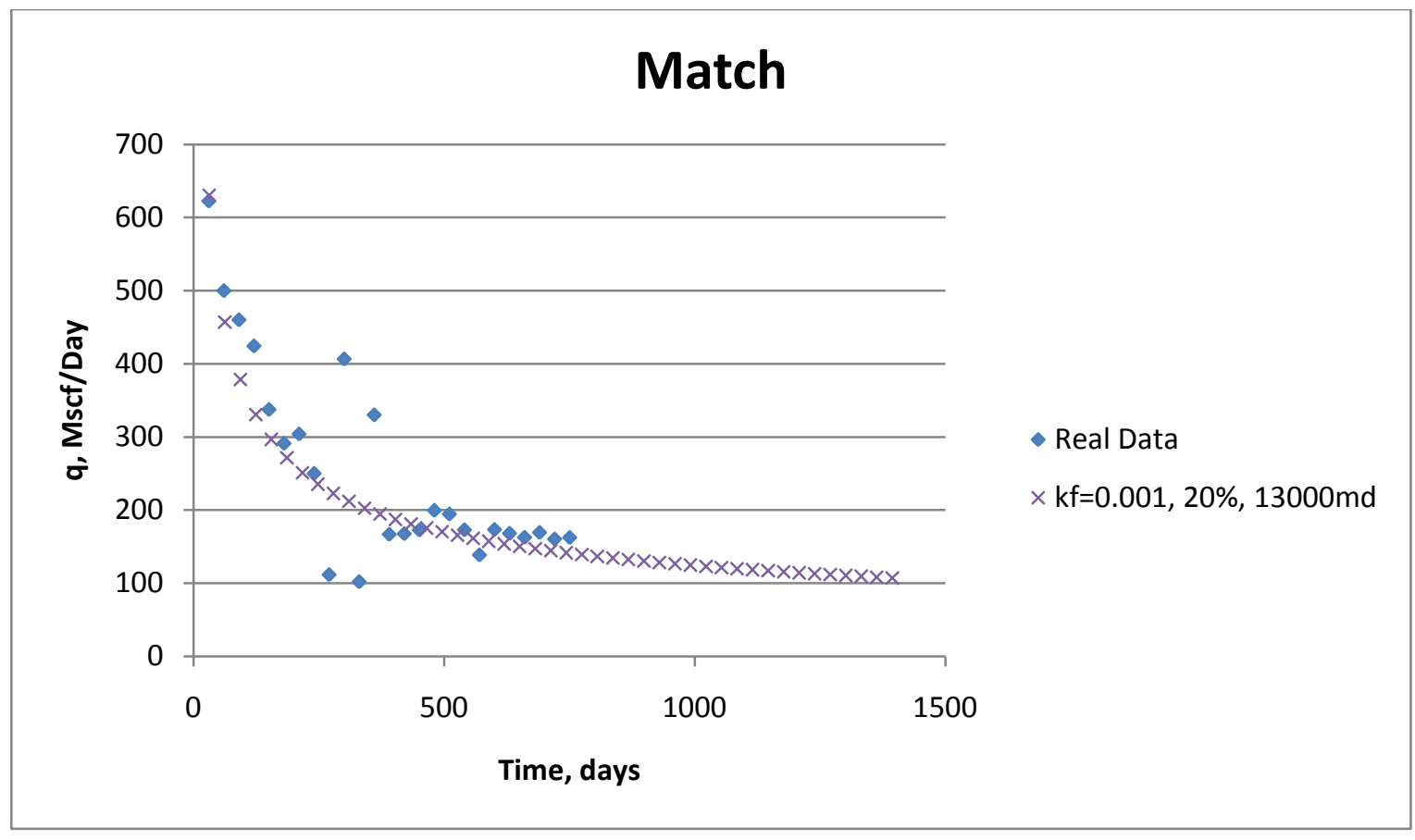

Figure 28. Final Match for Vertical \#5

\section{Vertical \#6:}

The sixth vertical well studied for this thesis is located in Upshur County. The acreage for this well is assumed to be 40 acres and the thickness was obtained from the Upshur County thickness map as $80 \mathrm{ft}$. In addition, a square reservoir is assumed for this reservoir with dimensions of $1320 * 1320\left(\mathrm{ft}^{\wedge} 2\right)$. Both initial and final parameters used for getting a match are listed below,

\begin{tabular}{|c|c|c|}
\hline \multicolumn{3}{|c|}{ Initial parameters used } \\
\hline Area & 80 & acres \\
\hline Top of fracture & 7050 & $\mathrm{ft}$ \\
\hline Bottom of fracture & 7130 & $\mathrm{ft}$ \\
\hline Thickness & 80 & $\mathrm{ft}$ \\
\hline Fracture por & 0.005 & \\
\hline Matrix por & 0.05 & \\
\hline Fracture perm & 0.002 & $\mathrm{md}$ \\
\hline Dimensions & $1867^{*} 1867$ & $\mathrm{ft} \wedge 2$ \\
\hline
\end{tabular}

\begin{tabular}{|c|c|c|}
\hline \multicolumn{3}{|c|}{ Final parameters for the match } \\
\hline Area & 40 & acres \\
\hline Top of fracture & 7050 & $\mathrm{ft}$ \\
\hline Bottom of fracture & 7130 & $\mathrm{ft}$ \\
\hline Thickness & 80 & $\mathrm{ft}$ \\
\hline Fracture por & 0.005 & \\
\hline Matrix por & 0.05 & \\
\hline Fracture perm & 0.0006 & $\mathrm{md}$ \\
\hline Dimensions & $1320 * 1320$ & $\mathrm{ft} \wedge 2$ \\
\hline
\end{tabular}




\begin{tabular}{|c|c|c|} 
Matrix perm & 0.0002 & $\mathrm{md}$ \\
\hline Rock Density & 100 & $\mathrm{lb} / \mathrm{ft} \wedge 3$ \\
\hline Pressure & 3500 & $\mathrm{psia}$ \\
\hline Sw & 15 & $\%$ \\
\hline Hydraulic Fracture & & \\
\hline Half length & 500 & $\mathrm{ft}$ \\
\hline permeability & 20,000 & $\mathrm{md}$ \\
\hline porosity & 20 & $\%$ \\
\hline width & 0.01 & inch \\
\hline
\end{tabular}

\begin{tabular}{|c|c|c|} 
Matrix perm & 0.0002 & $\mathrm{md}$ \\
\hline Rock Density & 100 & $\mathrm{lb} / \mathrm{ft}^{\wedge} 3$ \\
\hline Pressure & 3500 & $\mathrm{psia}$ \\
\hline Sw & 15 & $\%$ \\
\hline Hydraulic Fracture & & \\
\hline Half length & 500 & $\mathrm{ft}$ \\
\hline permeability & 15,000 & $\mathrm{md}$ \\
\hline porosity & 20 & $\%$ \\
\hline width & 0.01 & inch \\
\hline
\end{tabular}

To get a match for this well, variety of parameters had to be altered. First of all, natural fracture permeability had to be reduced from $0.002 \mathrm{md}$ to $0.0006 \mathrm{md}$ which is very low for typical unconventional reservoir; however that was the only way to get a match. In order to try other parameters for a match, natural fracture porosity was reduced to different values but unfortunately it does not have as much impact as natural fracture permeability. The next parameter that was changed to reduce the initial production down was the hydraulic fracture permeability. Hydraulic fracture permeability was reduced from 20,000 md to 15,000md. Furthermore, as can be seen in the below plot, when natural fracture porosity was changed from 0.004 to 0.003 , there were only little impact on the initial production and as a result, it does not have much impact on the later part of the production curve.

Acreage was assumed to be 40 acres for this wells since 80 acres would be a large drainage area for such a low natural fracture permeability. When reducing the drainage area from 80 acres to 40 acres, recoverable reserves did not decrease significantly which indicates assigning 80 acres for this particular well is exaggerating and this well can be assumed to be 40 acres. 


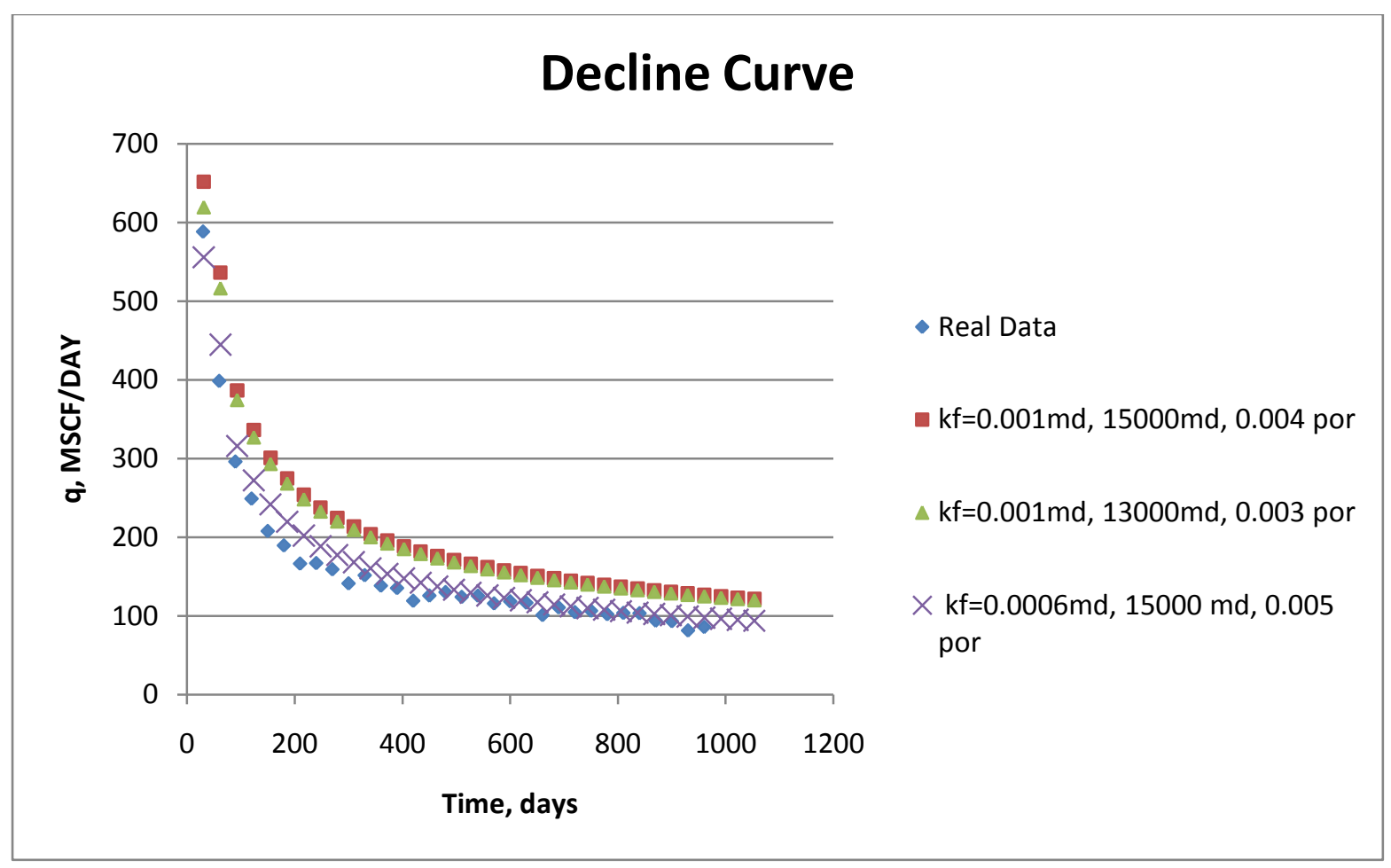

Figure 29. History Matching for Vertical \#6

Final parameters that were used for the match are $\mathrm{kf}=0.0006 \mathrm{md}$, and natural fracture permeability $=15,000 \mathrm{md}$ as shown in the below plot, 


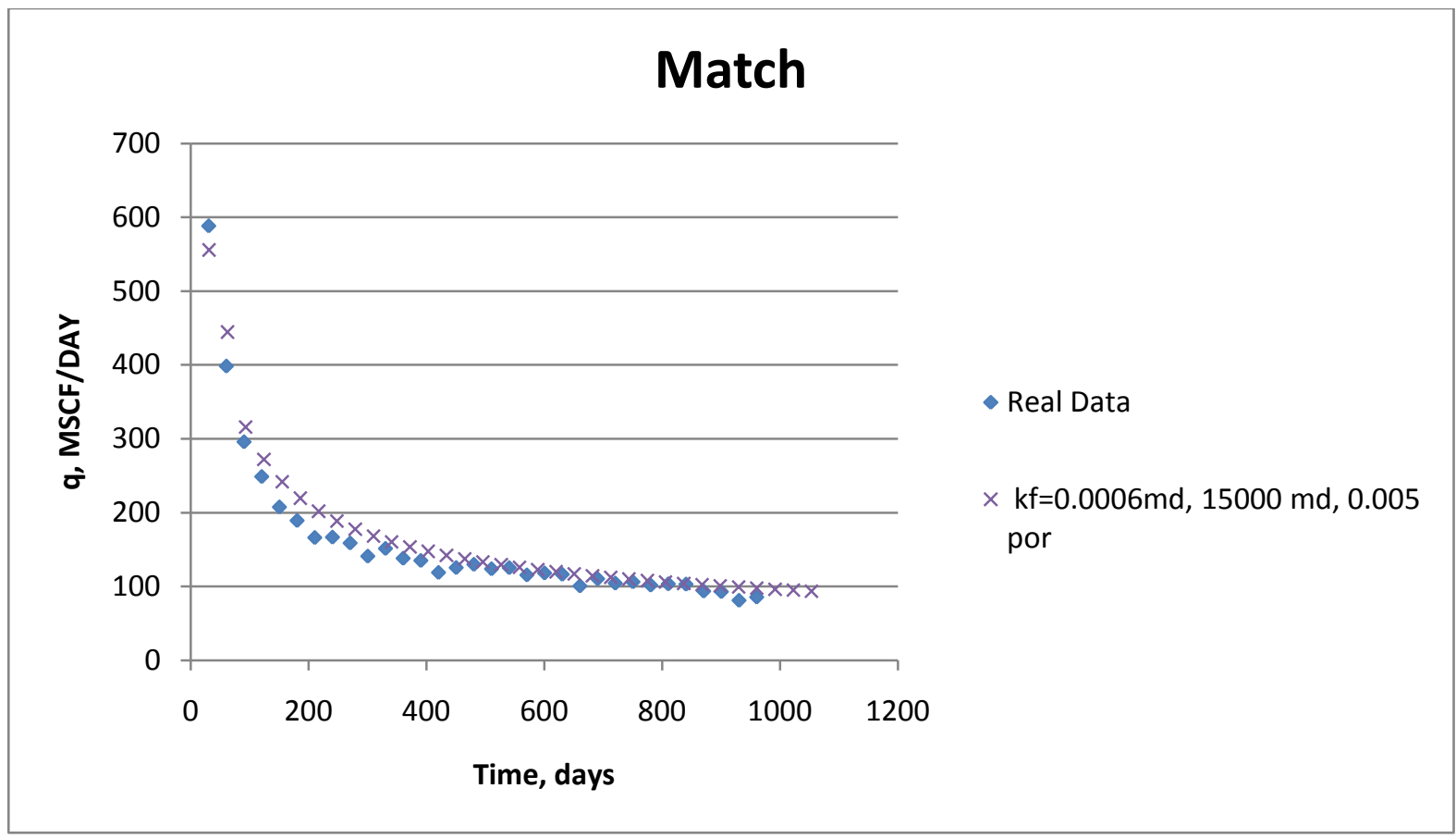

Figure 30. Final Match for Vertical \#6

\section{Vertical \#7:}

The seventh vertical well studied for this thesis is located in Doddridge County. The acreage for this well is assumed to be 80 acres and the thickness was obtained from the Doddridge County thickness map as $50 \mathrm{ft}$. In addition, a square reservoir is assumed for this reservoir with dimensions of $1867 * 1867\left(\mathrm{ft}^{\wedge} 2\right)$. Both initial and final parameters used for getting a match are listed below,

\begin{tabular}{|c|c|c|}
\hline \multicolumn{3}{|c|}{ Initial parameters used } \\
\hline Area & 80 & acres \\
\hline Top of fracture & 6985 & $\mathrm{ft}$ \\
\hline $\begin{array}{c}\text { Bottom of } \\
\text { fracture }\end{array}$ & 7035 & $\mathrm{ft}$ \\
\hline Thickness & 50 & $\mathrm{ft}$ \\
\hline Fracture por & 0.005 & \\
\hline Matrix por & 0.05 & \\
\hline Fracture perm & 0.002 & $\mathrm{md}$ \\
\hline
\end{tabular}

\begin{tabular}{|c|c|c|}
\hline \multicolumn{3}{|c|}{ Final parameters for the match } \\
\hline Area & 80 & acres \\
\hline Top of fracture & 6985 & $\mathrm{ft}$ \\
\hline $\begin{array}{c}\text { Bottom of } \\
\text { fracture }\end{array}$ & 7035 & $\mathrm{ft}$ \\
\hline Thickness & 50 & $\mathrm{ft}$ \\
\hline Fracture por & 0.005 & \\
\hline Matrix por & 0.05 & \\
\hline Fracture perm & 0.001 & $\mathrm{md}$ \\
\hline
\end{tabular}




\begin{tabular}{|c|c|c|}
\hline Dimensions & $\begin{array}{c}1867 * 186 \\
7\end{array}$ & $\mathrm{ft}^{\wedge} 2$ \\
\hline Matrix perm & 0.0002 & $\mathrm{md}$ \\
\hline Rock Density & 100 & $\begin{array}{c}\mathrm{Ib} / \mathrm{ft}^{\wedge} \\
3\end{array}$ \\
\hline Pressure & 3500 & psia \\
\hline Sw & 15 & $\%$ \\
\hline
\end{tabular}

\begin{tabular}{|c|c|c|} 
& $1867^{*} 186$ & \\
7 & $\mathrm{ft}^{\wedge} 2$ \\
\hline Dimensions & 0.0002 & $\mathrm{md}$ \\
\hline Rock Density & 100 & $\begin{array}{c}\mathrm{Ib} / \mathrm{ft}^{\wedge} \\
3\end{array}$ \\
\hline Pressure & 3500 & $\mathrm{psia}$ \\
\hline Sw & 15 & $\%$ \\
\hline
\end{tabular}

Hydraulic

Fracture

\begin{tabular}{|c|c|c|}
\hline Half length & 500 & $\mathrm{ft}$ \\
\hline permeability & 20,000 & $\mathrm{md}$ \\
\hline porosity & 20 & $\%$ \\
\hline width & 0.01 & inch \\
\hline
\end{tabular}

Hydraulic

Fracture

\begin{tabular}{|c|c|c|}
\hline Half length & 500 & $\mathrm{ft}$ \\
\hline permeability & 10,000 & $\mathrm{md}$ \\
\hline porosity & 20 & $\%$ \\
\hline width & 0.01 & inch \\
\hline
\end{tabular}

To get a match for this case, natural fracture permeability is decreased from $0.002 \mathrm{md}$ to 0.001md. In addition, the hydraulic fracture permeability is reduced to $10,000 \mathrm{md}$ in order to match the real field decline curve. These changes can be seen in the below plot,

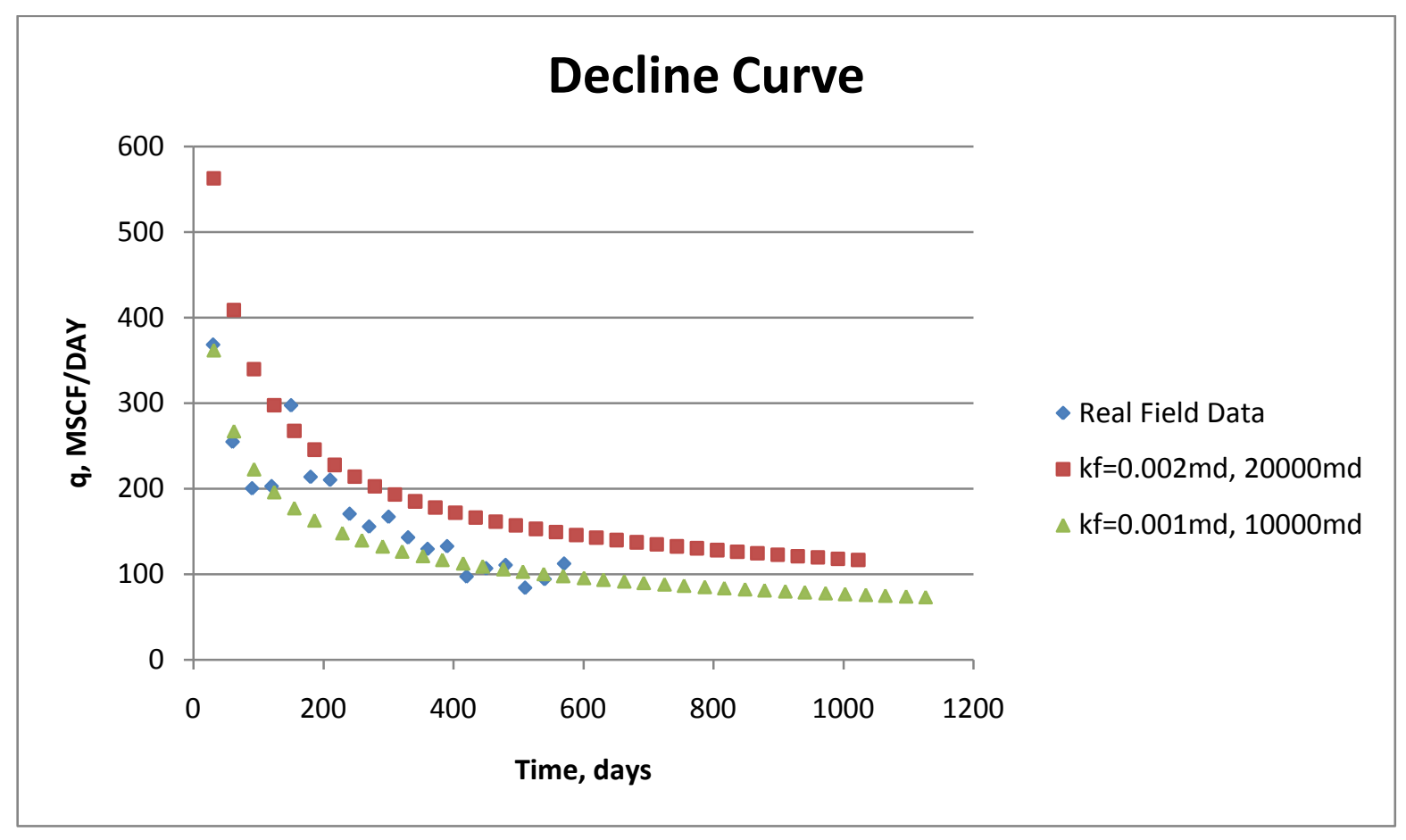

Figure 31. History Matching for Vertical \#7 
As can be seen in the above plot when natural fracture permeability is decreased, the entire curve shifts downward and when the hydraulic fracture permeability is decreased, the initial production is decreased as well. Below is the final match that was obtained from the seventh vertical well,

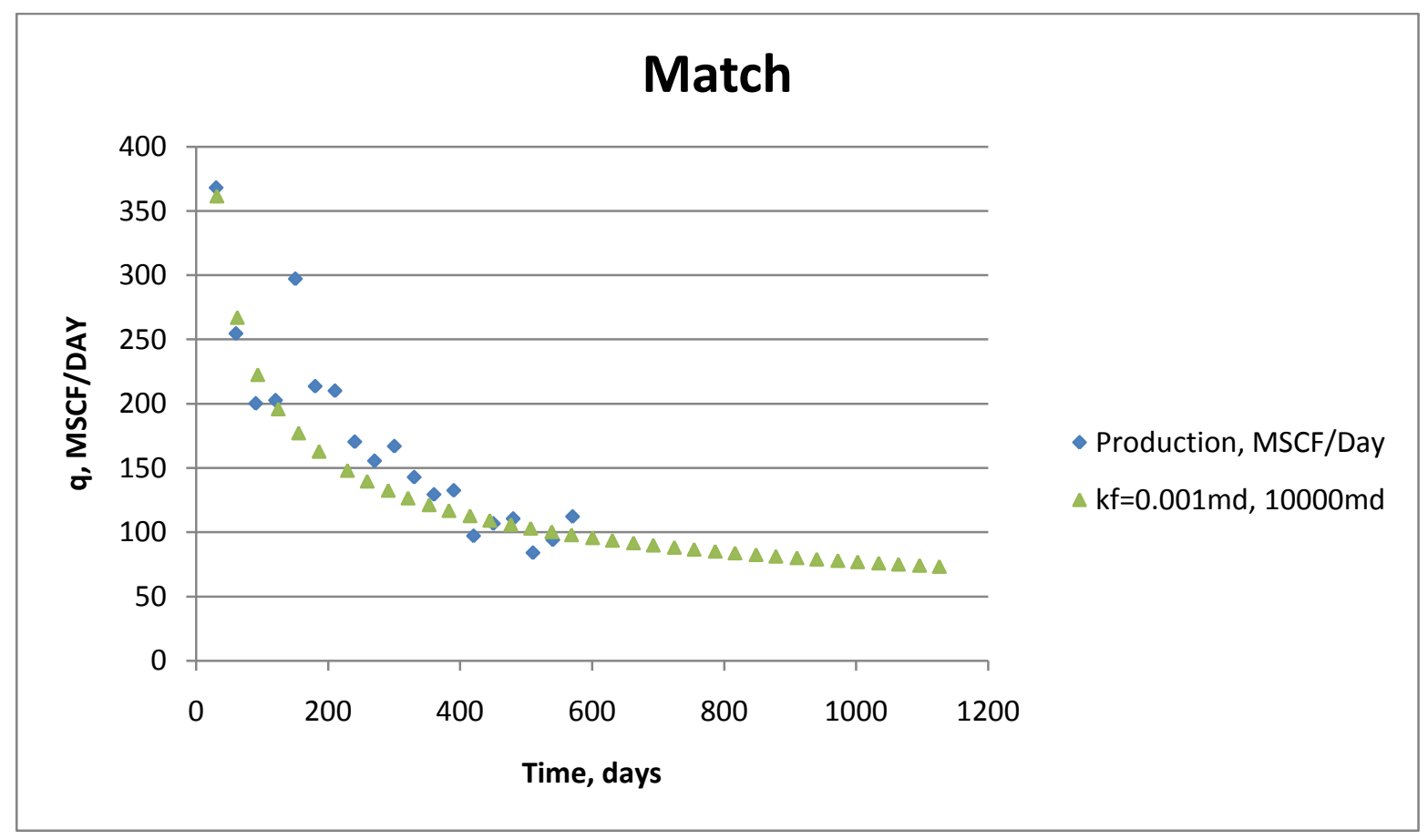

Figure 32. Final Match for Vertical \#7

\section{Vertical \#8:}

The eighth vertical well that was studied for this thesis is located in Doddridge County. The acreage for this well is assumed to be 40 acres and the thickness was obtained from the completion data as $47 \mathrm{ft}$. In addition, a square reservoir is assumed for this reservoir with dimensions of $1320 * 1320\left(\mathrm{ft}^{\wedge} 2\right)$. Both initial and final parameters used for getting a match are listed below, 


\begin{tabular}{|c|c|c|}
\hline \multicolumn{3}{|c|}{ Initial parameters used } \\
\hline Area & 80 & acres \\
\hline Top of fracture & 6870 & $\mathrm{ft}$ \\
\hline Bottom of fracture & 6916 & $\mathrm{ft}$ \\
\hline Thickness & 46 & $\mathrm{ft}$ \\
\hline Fracture por & 0.005 & \\
\hline Matrix por & 0.05 & \\
\hline Fracture perm & 0.002 & $\mathrm{md}$ \\
\hline Dimensions & $1867 * 1867$ & $\mathrm{ft} \wedge 2$ \\
\hline Matrix perm & 0.0002 & $\mathrm{md}$ \\
\hline Rock Density & 100 & $\mathrm{lb} / \mathrm{ft} \wedge 3$ \\
\hline Pressure & 3500 & $\mathrm{psia}$ \\
\hline Sw & 15 & $\%$ \\
\hline Hydraulic Fracture & & \\
\hline Half length & 500 & $\mathrm{ft}$ \\
\hline permeability & 20000 & $\mathrm{md}$ \\
\hline porosity & 20 & $\%$ \\
\hline width & 0.01 & inch \\
\hline Minimum pressure & 500 & $\mathrm{psia}$ \\
\hline
\end{tabular}

\begin{tabular}{|c|c|c|}
\hline \multicolumn{3}{|c|}{ Final parameters for the match } \\
\hline Area & 40 & acres \\
\hline Top of fracture & 6870 & $\mathrm{ft}$ \\
\hline Bottom of fracture & 6916 & $\mathrm{ft}$ \\
\hline Thickness & 46 & $\mathrm{ft}$ \\
\hline Fracture por & 0.003 & \\
\hline Matrix por & 0.05 & \\
\hline Fracture perm & 0.002 & $\mathrm{md}$ \\
\hline Dimensions & $1320 * 1320$ & $\mathrm{ft}$ ^2 \\
\hline Matrix perm & 0.0002 & $\mathrm{md}$ \\
\hline Rock Density & 100 & $\mathrm{lb} / \mathrm{ft}$ ^3 \\
\hline Pressure & 3500 & $\mathrm{psia}$ \\
\hline Sw & 15 & $\%$ \\
\hline Hydraulic Fracture & & \\
\hline Half length & 200 & $\mathrm{ft}$ \\
\hline permeability & 10000 & $\mathrm{md}$ \\
\hline porosity & 20 & $\%$ \\
\hline width & 0.01 & inch \\
\hline Minimum pressure & 700 & $\mathrm{psia}$ \\
\hline
\end{tabular}

This particular vertical well is producing at low average monthly rate compared to the other vertical wells studies thus far. As a result, majority of parameters are assumed to be low in order to get a good match for the production decline curve. First of all, natural fracture permeability is remained constant as the base model $(0.002 \mathrm{md})$; however fracture half length which used to be $500 \mathrm{ft}$ for majority of the vertical wells is brought down to $200 \mathrm{ft}$. In addition, hydraulic fracture permeability is assumed to be $10,000 \mathrm{md}$, and minimum bottom hole pressure is set to be 700 psia.

Reducing the fracture half length from $500 \mathrm{ft}$ to $200 \mathrm{ft}$ will essentially reduce the production in general. This means the entire decline curves shift downward by reducing the fracture half length. The dual porosity model in Eclipse assumes that the fracture half length 
which is entered in the model is the propped fracture half length and as a result altering this fracture half length has a huge impact on the production capability of the reservoir.

Minimum bottom hole pressure is typically defined in reservoir simulation to emphasize the importance of having enough pressure downhole in order for the diffusion to take place. For majority of the vertical wells studies up to now, the minimum bottom hole pressure is set as a constant pressure to be 500 psia; however for this particular well since the production decline curve is pretty low, the minimum bottom hole pressure was increases to 700 psia in order for the reservoir to produce less.

The last thing that was changed in order to reduce the production decline curve was decreasing the natural fracture porosity from 0.005 to 0.003 . Although this has some impact on the initial production curve, typically it does not have any significant impact on the later part of the curve.

Finally the area that was assumed for this well is 40 acres because of the low production data. As previously mentioned, having a larger drainage area will not impact the recoverable reserve by much. The below two tables demonstrate the difference between 40 acres and 80 acres,

\begin{tabular}{|c|c|c|c|}
\hline 40 acres & & & \\
\hline $\begin{array}{c}\text { Time } \\
\text { (years) }\end{array}$ & $\begin{array}{c}\text { EUR } \\
\text { (MSCF) }\end{array}$ & IGIP (MSCF) & RF \\
\hline 10.015059 & $208,071.53$ & $846,513.63$ & 24.57982041 \\
\hline 20.004107 & $323,958.31$ & $846,513.63$ & 38.26970985 \\
\hline 29.913757 & $406,782.31$ & $846,513.63$ & 48.05384055 \\
\hline
\end{tabular}




\begin{tabular}{|c|c|c|c|}
\hline $\begin{array}{c}80 \text { acres } \\
\text { Time } \\
\text { (years) }\end{array}$ & $\begin{array}{c}\text { EUR } \\
\text { (MSCF) }\end{array}$ & IGIP (MSCF) & RF \\
\hline 10.015059 & $214,505.05$ & $1,693,985.60$ & 12.66274341 \\
\hline 20.002737 & $351,957.06$ & $1,693,985.60$ & 20.77686257 \\
\hline 29.913757 & $466,500.91$ & $1,693,985.60$ & 27.53865853 \\
\hline
\end{tabular}

As can be seen in the above table, when drainage area was reduced from 80 acres to 40 acres, the EUR (estimated ultimate recovery) did not modify significantly after 30 years but the initial gas in place has decreased extensively. This big decrease in IGIP has caused the RF to be completely different when using 40 acres or 80 acres. As a result, the drainage area of 40 acres has been chosen for this well because the well does not have more capacity to produce even with a larger drainage area.

The below plot shows the impact of reducing the fracture half length from $400 \mathrm{ft}$ to $300 \mathrm{ft}$,

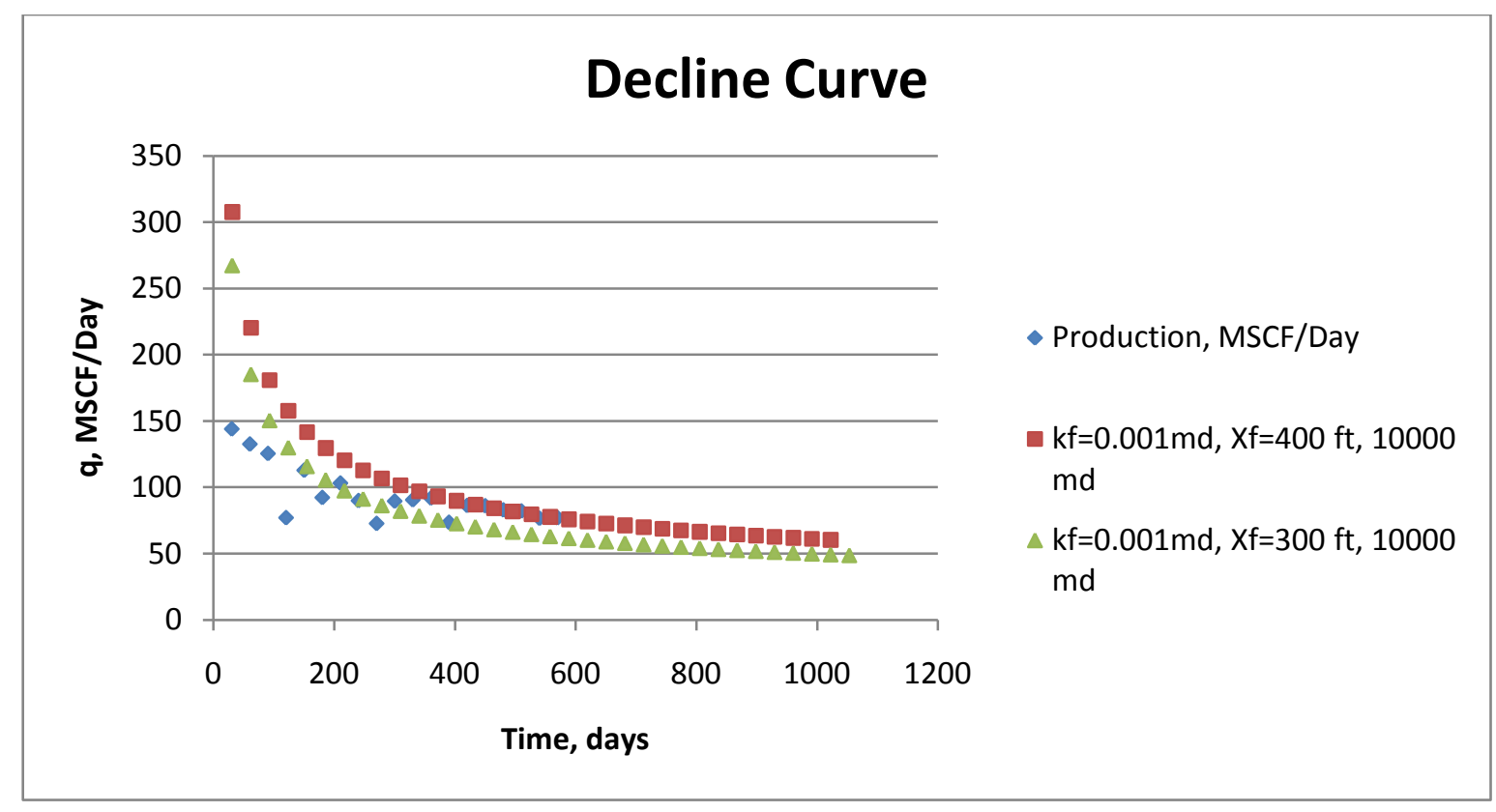

Figure 33. History Matching for Vertical \#8 
As can be seen in the above plot, when every parameter stays constant and only fracture half length changes from $400 \mathrm{ft}$ to $300 \mathrm{ft}$, the curve shifts downward and this change in production can be associated with the change in natural fracture permeability since both parameters have similar impact on the production decline curve. Although fracture half length that was used for this well is $200 \mathrm{ft}$, the above illustration is just to show the impact of changing fracture half length. Below is the match obtained from the eight vertical well with the indicated parameters in the plot,

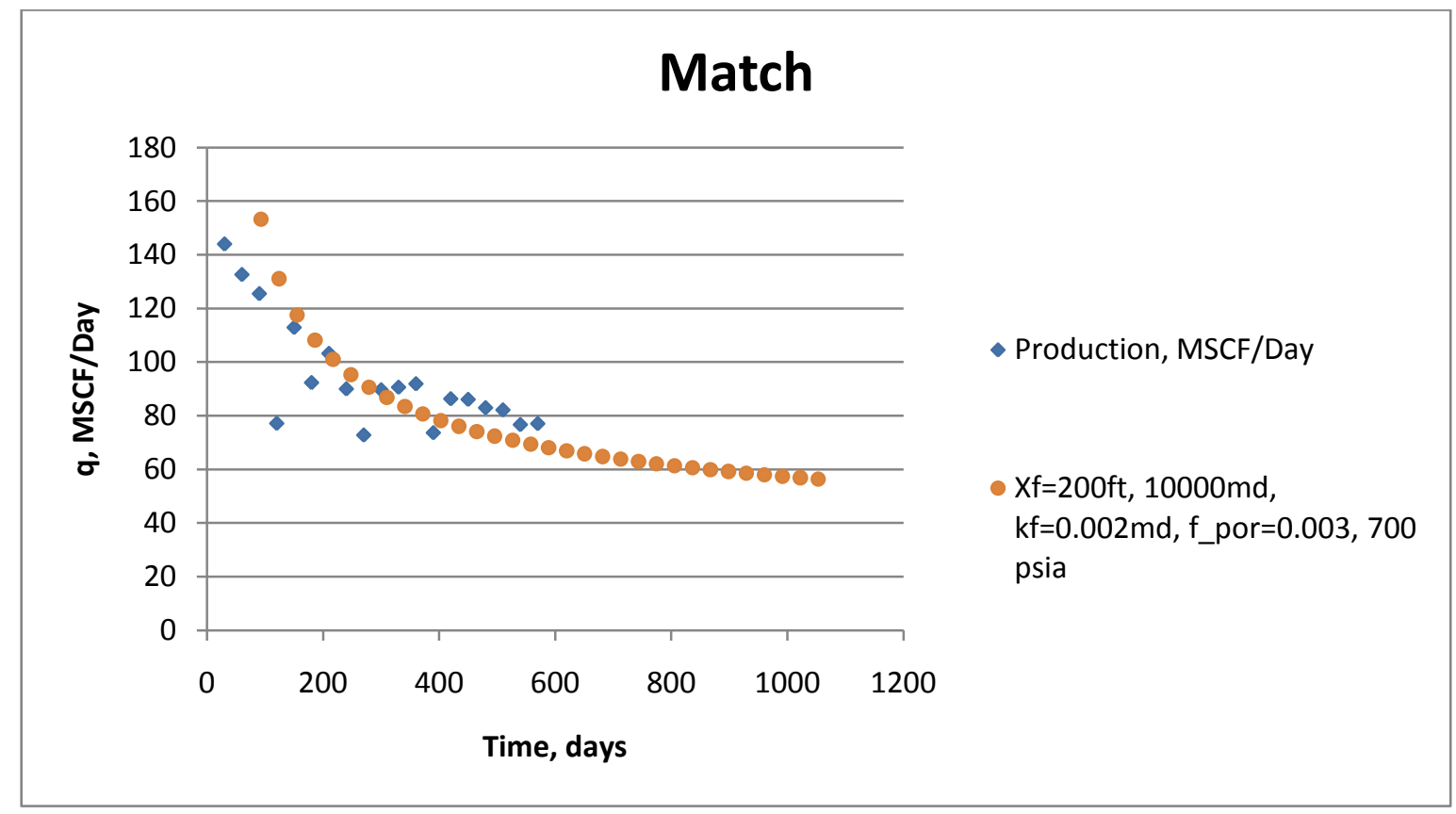

Figure 34. Final Match for Vertical \#8

\section{Vertical \#9:}

The ninth vertical well that was studied for this thesis is located in Doddridge County. The acreage for this well is assumed to be 80 acres and the thickness was obtained from the thickness map of Doddridge County as $50 \mathrm{ft}$. In addition, a square reservoir is assumed for this reservoir with dimensions of $1867 * 1867\left(\mathrm{ft}^{\wedge} 2\right)$. Both initial and final parameters used for getting a match are listed below, 


\begin{tabular}{|c|c|c|}
\hline \multicolumn{3}{|c|}{ Initial parameters used } \\
\hline Area & 120 & acres \\
\hline Top of fracture & 7183 & $\mathrm{ft}$ \\
\hline Bottom of fracture & 7233 & $\mathrm{ft}$ \\
\hline Thickness & 50 & $\mathrm{ft}$ \\
\hline Fracture por & 0.005 & \\
\hline Matrix por & 0.05 & \\
\hline Fracture perm & 0.002 & $\mathrm{md}$ \\
\hline Dimensions & $2286 * 2286$ & $\mathrm{ft}^{\wedge} 2$ \\
\hline Matrix perm & 0.0002 & $\mathrm{md}$ \\
\hline Rock Density & 100 & $\mathrm{lb} / \mathrm{ft}^{\wedge} 3$ \\
\hline Pressure & 3500 & psia \\
\hline Sw & 15 & $\%$ \\
\hline
\end{tabular}

\begin{tabular}{|c|c|c|}
\hline \multicolumn{3}{|c|}{ Final parameters for the match } \\
\hline Area & 80 & acres \\
\hline Top of fracture & 7183 & $\mathrm{ft}$ \\
\hline Bottom of fracture & 7233 & $\mathrm{ft}$ \\
\hline Thickness & 50 & $\mathrm{ft}$ \\
\hline Fracture por & 0.005 & \\
\hline Matrix por & 0.05 & \\
\hline Fracture perm & 0.003 & $\mathrm{md}$ \\
\hline Dimensions & $1867 * 1867$ & $\mathrm{ft}^{\wedge} 2$ \\
\hline Matrix perm & 0.0002 & $\mathrm{md}$ \\
\hline Rock Density & 100 & $\mathrm{lb} / \mathrm{ft} \wedge 3$ \\
\hline Pressure & 3500 & psia \\
\hline Sw & 15 & $\%$ \\
\hline
\end{tabular}

\begin{tabular}{|c|c|c|}
\hline Hydraulic Fracture \\
\hline Half length & 500 & $\mathrm{ft}$ \\
\hline permeability & 20000 & $\mathrm{md}$ \\
\hline porosity & 20 & $\%$ \\
\hline width & 0.01 & inch \\
\hline Minimum pressure & 500 & psia \\
\hline
\end{tabular}

\begin{tabular}{|c|c|c|} 
Hydraulic Fracture \\
\hline Half length & 500 & $\mathrm{ft}$ \\
\hline permeability & 20000 & $\mathrm{md}$ \\
\hline porosity & 20 & $\%$ \\
\hline width & 0.01 & inch \\
\hline Minimum pressure & 500 & psia \\
\hline
\end{tabular}

For this specific well, natural fracture permeability has increased from 0.002 md to 0.003 md to account for big production data. Moreover, the drainage area was examined for both 80 and 120 acres to distinguish if having a larger drainage area makes a huge impact on the recoverable reserve or not. As explained for the previous well, it turned out that 80 acres would be a more reasonable number compared to 120 acres because the recoverable reserved from 80 acres is almost the same as 120 acres. As a result, 80 acres was chosen for this well as well. Below is an illustration of different natural fracture permeability values. 


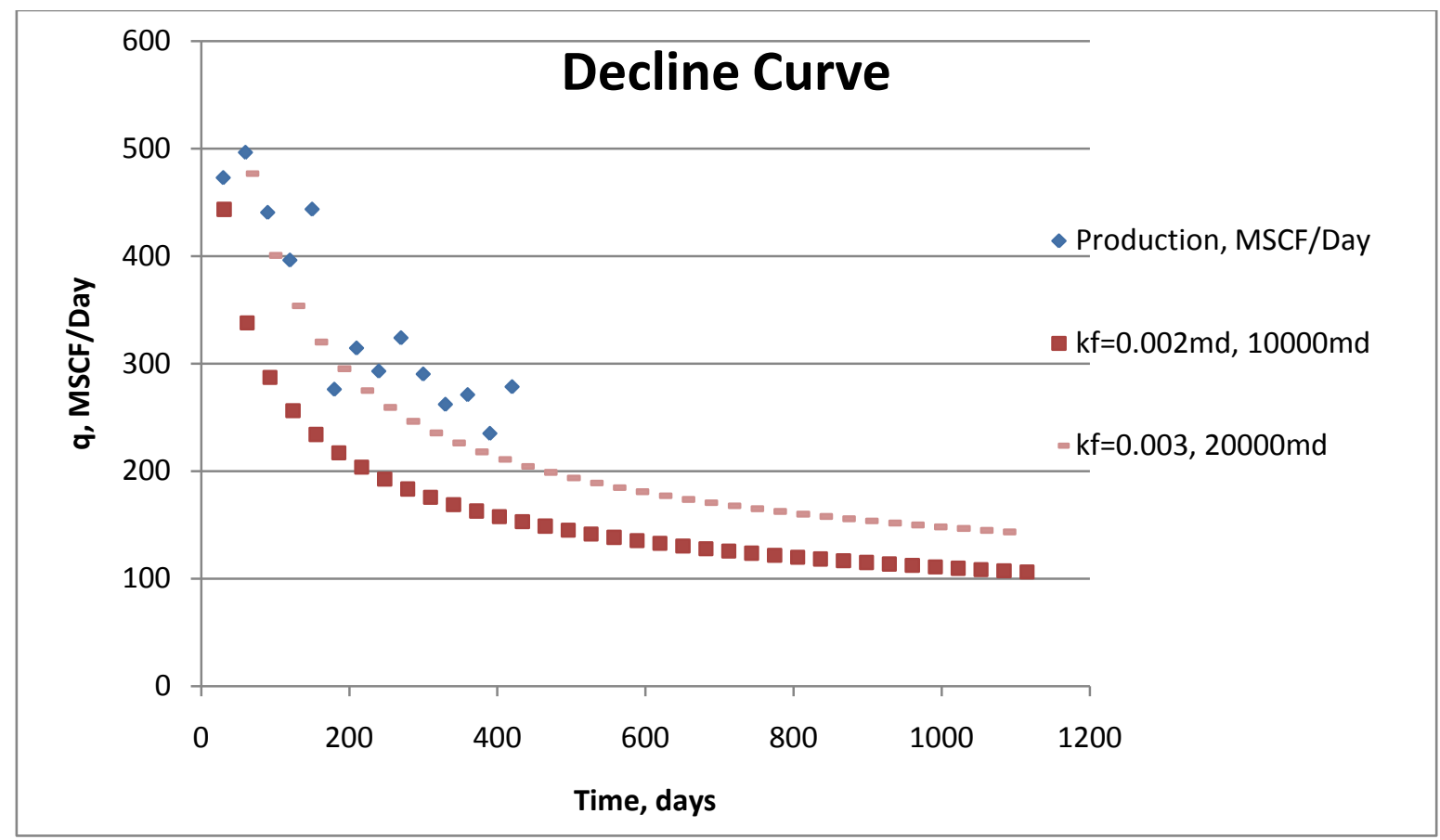

Figure 35. History Matching for Vertical \#9

Finally the match for this well is obtained from $\mathrm{kf}=0.003 \mathrm{md} 20,000 \mathrm{md}$ of hydraulic fracture permeability. 


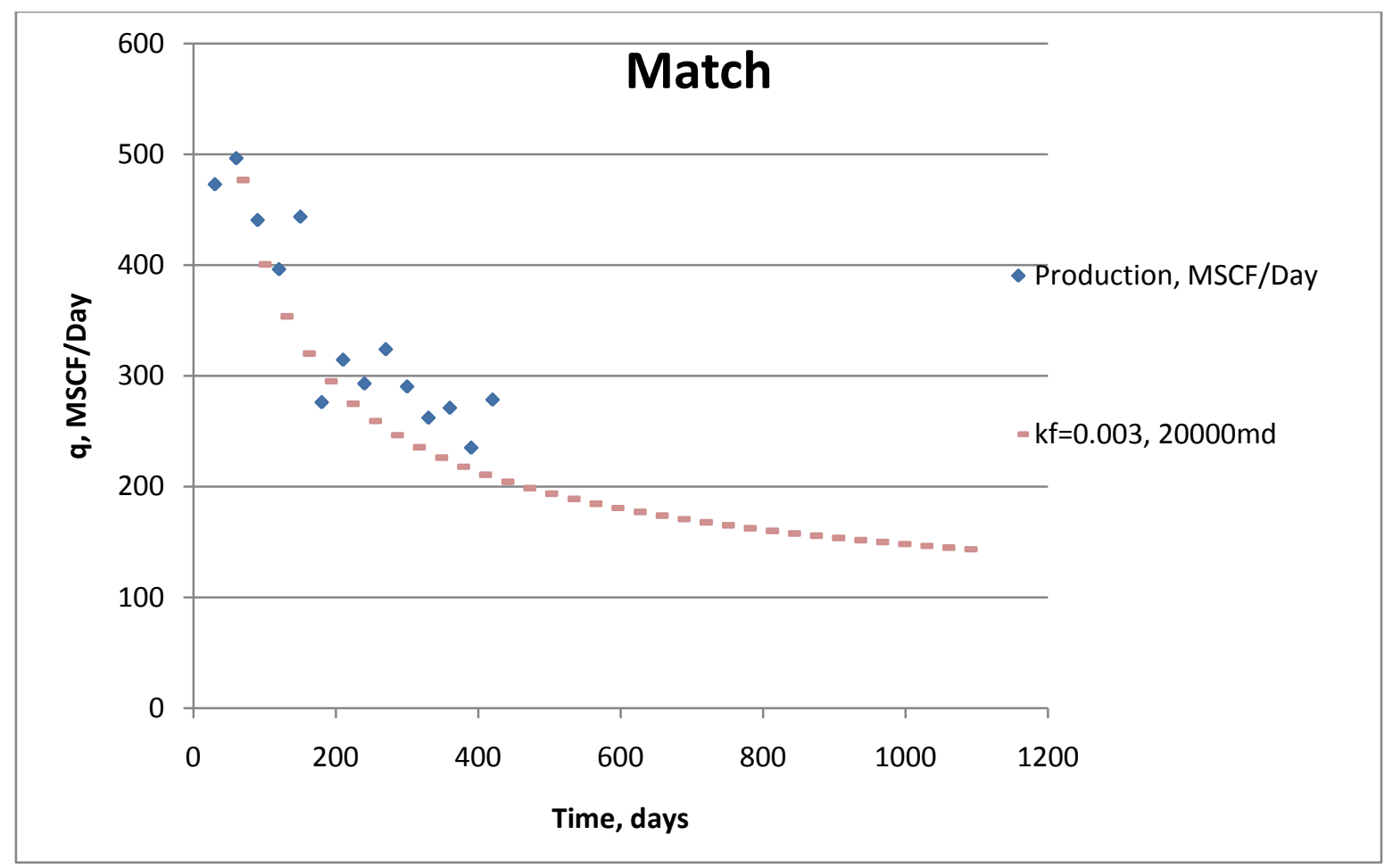

Figure 36. Final Match for Vertical \#9

\section{Horizontal \#2:}

The second horizontal well studied for this thesis is located in Upshur County. The acreage for this well is assumed to be 151 acres and the thickness was obtained from the thickness map of Upshur County as $75 \mathrm{ft}$. In addition, a rectangular reservoir is assumed for this reservoir with dimensions of $3624 * 1812\left(\mathrm{ft}^{\wedge} 2\right)$. The length of the horizontal segment of this reservoir is $1812 \mathrm{ft}$ is provided in the well data section of Geological Survey website. Both initial and final parameters used for getting a match are listed below,

\begin{tabular}{|c|c|c|}
\hline \multicolumn{3}{|c|}{ Initial parameters used } \\
\hline Horizontal length & 1812 & $\mathrm{ft}$ \\
\hline acreage & 151 & acres \\
\hline Top of fracture & 7000 & $\mathrm{ft}$ \\
\hline Bottom of fracture & 7075 & $\mathrm{ft}$ \\
\hline Thickness & 75 & $\mathrm{ft}$ \\
\hline
\end{tabular}

\begin{tabular}{|c|c|c|}
\hline \multicolumn{3}{|c|}{ Final parameters for the match } \\
\hline Horizontal length & 1812 & $\mathrm{ft}$ \\
\hline acreage & 151 & acres \\
\hline Top of fracture & 7000 & $\mathrm{ft}$ \\
\hline Bottom of fracture & 7075 & $\mathrm{ft}$ \\
\hline Thickness & 75 & $\mathrm{ft}$ \\
\hline
\end{tabular}




\begin{tabular}{|c|c|c|}
\hline Fracture por & 0.005 & \\
\hline Matrix por & 0.05 & \\
\hline Fracture perm & 0.001 & md \\
\hline Dimensions & $3624 * 1812$ & $\mathrm{ft}^{\wedge} 2$ \\
\hline Matrix perm & 0.0002 & $\mathrm{md}$ \\
\hline Rock Density & 100 & $\mathrm{lb} / \mathrm{ft}^{\wedge} 3$ \\
\hline Pressure & 3500 & psia \\
\hline Sw & 15 & $\%$ \\
\hline Hydraulic Fracture: & Four fracs & \\
\hline Half length & 500 & $\mathrm{ft}$ \\
\hline permeability & 20,000 & $\mathrm{md}$ \\
\hline porosity & 20 & $\%$ \\
\hline width & 0.01 & inch \\
\hline \multicolumn{3}{|l|}{ Production Data } \\
\hline Minimum pressure & 500 & psia \\
\hline
\end{tabular}

\begin{tabular}{|c|c|c|}
\hline Fracture por & 0.005 & \\
\hline Matrix por & 0.05 & \\
\hline Fracture perm & 0.002 & $\mathrm{md}$ \\
\hline Dimensions & $3624 * 1812$ & $\mathrm{ft}^{\wedge} 2$ \\
\hline Matrix perm & 0.0002 & md \\
\hline Rock Density & 100 & $\mathrm{Ib} / \mathrm{ft}^{\wedge} 3$ \\
\hline Pressure & 3500 & psia \\
\hline Sw & 15 & $\%$ \\
\hline Hydraulic Fracture: & Four fracs & \\
\hline Half length & 350 & $\mathrm{ft}$ \\
\hline permeability & 10,000 & $\mathrm{md}$ \\
\hline porosity & 10 & $\%$ \\
\hline width & 0.01 & inch \\
\hline \multicolumn{3}{|l|}{ Production Data } \\
\hline Pwf (01/01/1981) & 800 & psia \\
\hline Pwf (08/01/1981) & 600 & psia \\
\hline
\end{tabular}

Natural fracture permeability is increased from $0.001 \mathrm{md}$ to $0.002 \mathrm{md}$ to increase the production decline curve. Hydraulic fracture parameters are very important in getting a match for horizontal wells because of the number of stages that can be used. Four stages were used for this model and it is shown below,

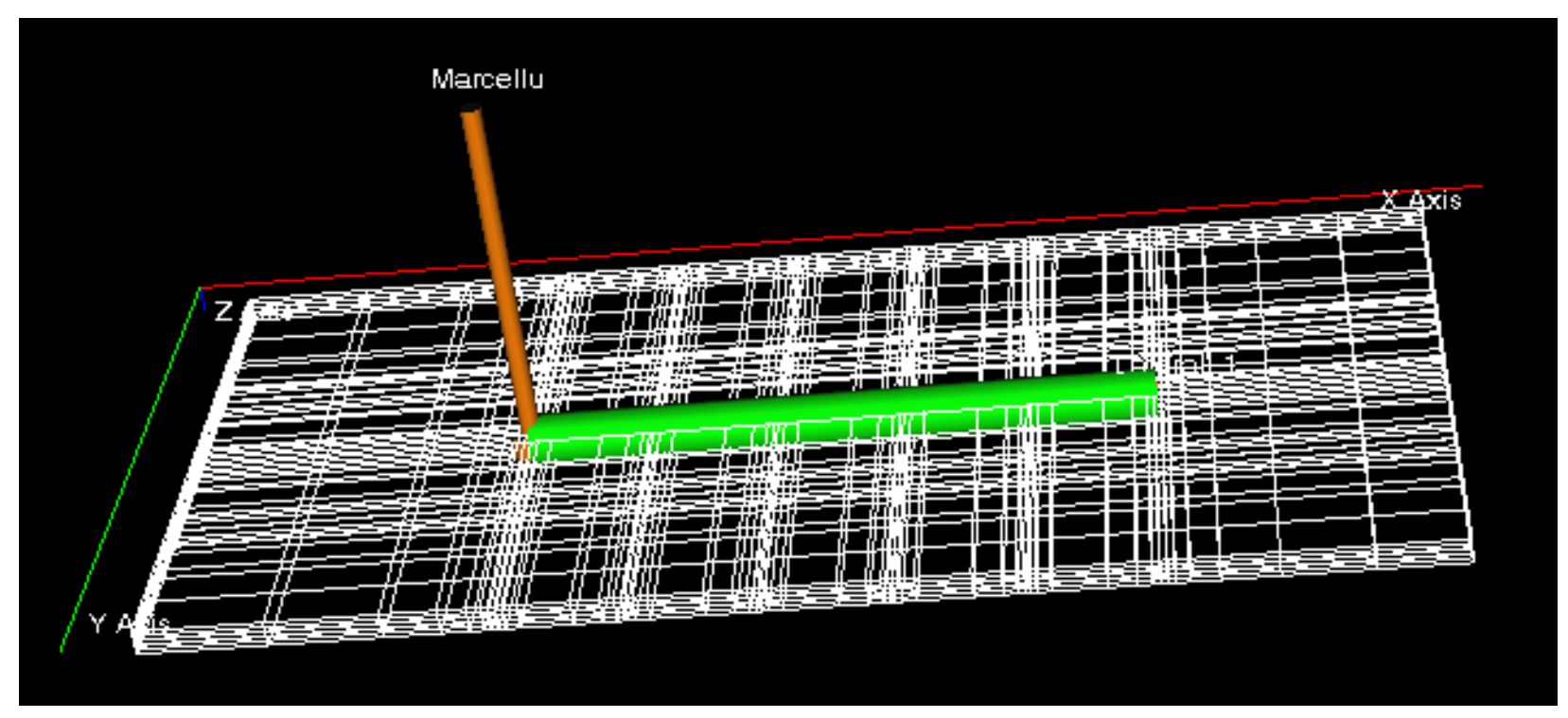

Figure 37. Horizontal \#2 
Fracture half length, porosity, and permeability have all been reduced to meet the condition of the real field data. In addition, this horizontal well act similar to the first horizontal well studied in this research and incremental pressure should be used to account for significant increase in production after 8 months. As a result, the minimum bottom hole pressure has decreased from 800 to 600 psia to account for this change. Below is a plot of change in fracture half length with 4 stages,

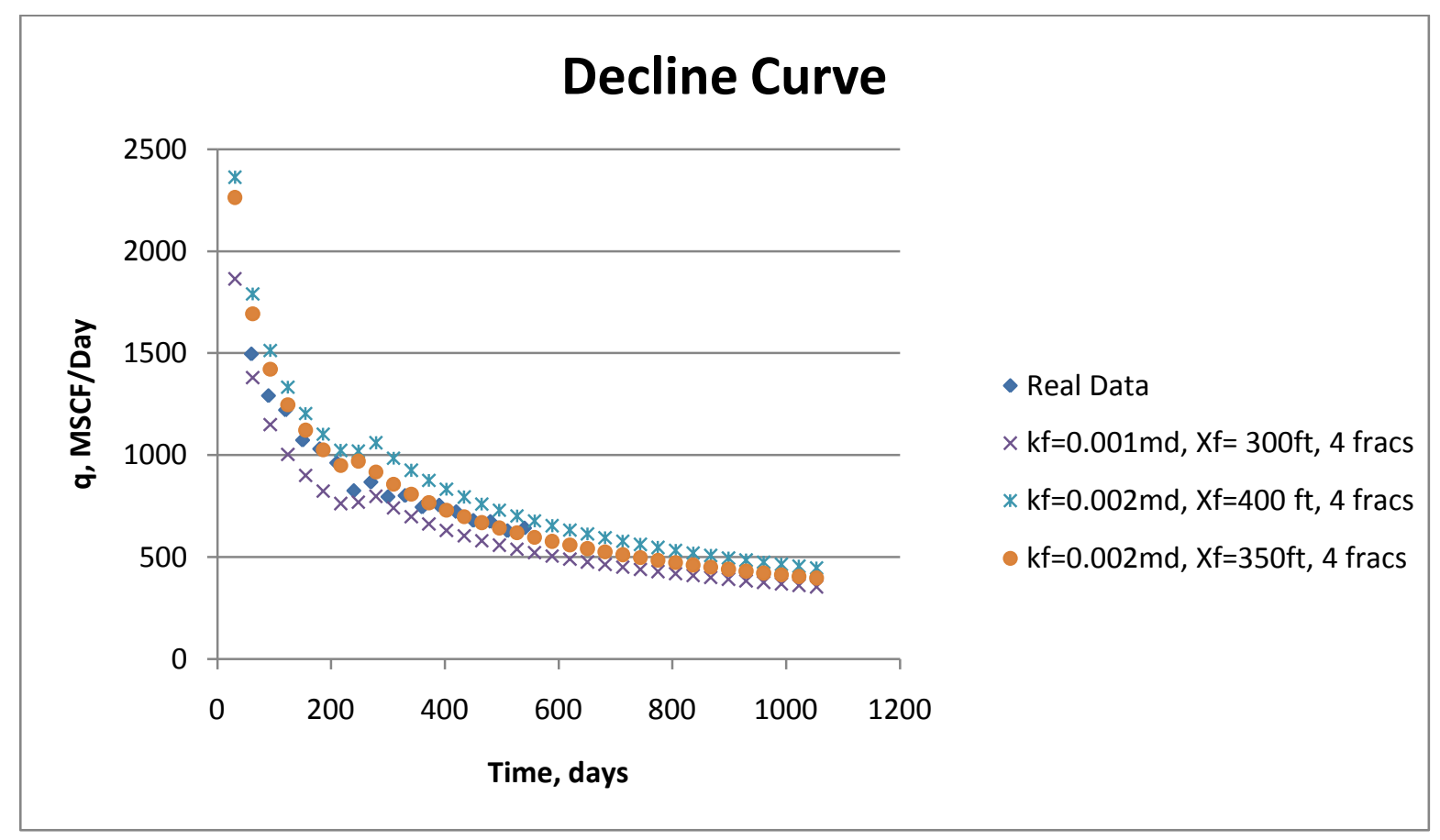

Figure 38. History Matching for Horizontal \#2

Finally, the final match is plotted below with $\mathrm{kf}=0.002 \mathrm{md}$ and $\mathrm{Xf}=350 \mathrm{ft}$, 


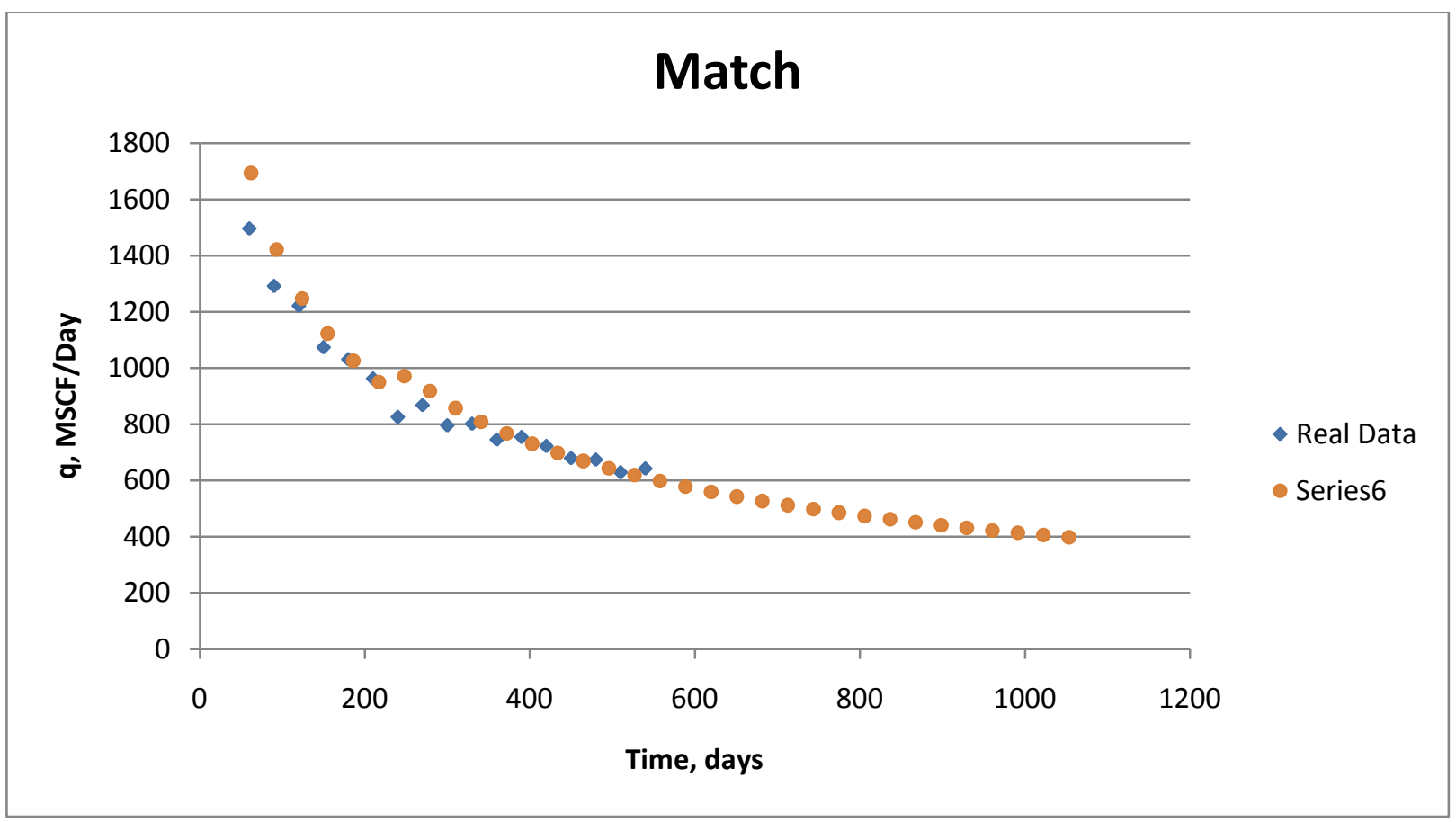

Figure 39. Final Match for Horizontal \#2

\section{Horizontal \#3:}

The third horizontal well studied for this thesis is located in Marshall County. The acreage for this well is assumed to be 216 acres and the thickness was obtained from the thickness map of Upshur County as $75 \mathrm{ft}$. In addition, a rectangular reservoir is assumed for this reservoir with dimensions of $4700 * 2000\left(\mathrm{ft}^{\wedge} 2\right)$. The length of the horizontal segment of this reservoir is $2727 \mathrm{ft}$ is provided in the well data section of Geological Survey website. Both initial and final parameters used for getting a match are listed below,

\begin{tabular}{|c|c|c|}
\hline \multicolumn{3}{|c|}{ Initial parameters used } \\
\hline Horizontal length & 2727 & $\mathrm{ft}$ \\
\hline acreage & 216 & acres \\
\hline Top of fracture & 7118 & $\mathrm{ft}$ \\
\hline Bottom of fracture & 7130 & $\mathrm{ft}$ \\
\hline Thickness & 60 & $\mathrm{ft}$ \\
\hline Fracture por & 0.005 & \\
\hline Matrix por & 0.05 & \\
\hline
\end{tabular}

\begin{tabular}{|c|c|c|}
\hline \multicolumn{3}{|c|}{ Final parameters for the match } \\
\hline Horizontal length & 2727 & $\mathrm{ft}$ \\
\hline acreage & 216 & acres \\
\hline Top of fracture & 7118 & $\mathrm{ft}$ \\
\hline Bottom of fracture & 7130 & $\mathrm{ft}$ \\
\hline Thickness & 60 & $\mathrm{ft}$ \\
\hline Fracture por & 0.005 & \\
\hline Matrix por & 0.05 & \\
\hline
\end{tabular}




\begin{tabular}{|c|c|c|}
\hline Fracture perm & 0.002 & $\mathrm{md}$ \\
\hline Dimensions & $4700 * 2000$ & $\mathrm{ft}^{\wedge} 2$ \\
\hline Matrix perm & 0.0002 & $\mathrm{md}$ \\
\hline Rock Density & 100 & $\mathrm{Ib} / \mathrm{ft}$ 3 \\
\hline Pressure & 3500 & $\mathrm{psia}$ \\
\hline Sw & 15 & $\%$ \\
\hline Hydraulic Fracture: & Six fracs \\
\hline Half length & 500 & $\mathrm{ft}$ \\
\hline permeability & 20,000 & $\mathrm{md}$ \\
\hline porosity & 20 & $\%$ \\
\hline width & 0.01 & inch \\
\hline Production Data & & \\
\hline Minimum pressure & 500 & $\mathrm{psia}$ \\
\hline
\end{tabular}

\begin{tabular}{|c|c|c|}
\hline Fracture perm & 0.004 & $\mathrm{md}$ \\
\hline Dimensions & $4700 * 2000$ & $\mathrm{ft}^{\wedge} 2$ \\
\hline Matrix perm & 0.0002 & $\mathrm{md}$ \\
\hline Rock Density & 100 & $\mathrm{lb} / \mathrm{ft}^{\wedge} 3$ \\
\hline Pressure & 3500 & $\mathrm{psia}$ \\
\hline Sw & 15 & $\%$ \\
\hline Hydraulic Fracture: & Six fracs & \\
\hline Half length & 500 & $\mathrm{ft}$ \\
\hline permeability & 20,000 & $\mathrm{md}$ \\
\hline porosity & 20 & $\%$ \\
\hline width & 0.01 & inch \\
\hline Production Data & \multicolumn{2}{|c|}{} \\
\hline Minimum pressure & 400 & psia \\
\hline
\end{tabular}

To get a match for the last horizontal well, natural fracture permeability is increased from $0.002 \mathrm{md}$ to $0.004 \mathrm{md}$. In addition, the minimum bottom hole pressure is brought down to 400 psia in order to produce more from the reservoir. Below is the third horizontal well with 6 stages. As can be seen in the below graph, the fractures are equally spaced and the spacing between fractures are approximately $390 \mathrm{ft}$.

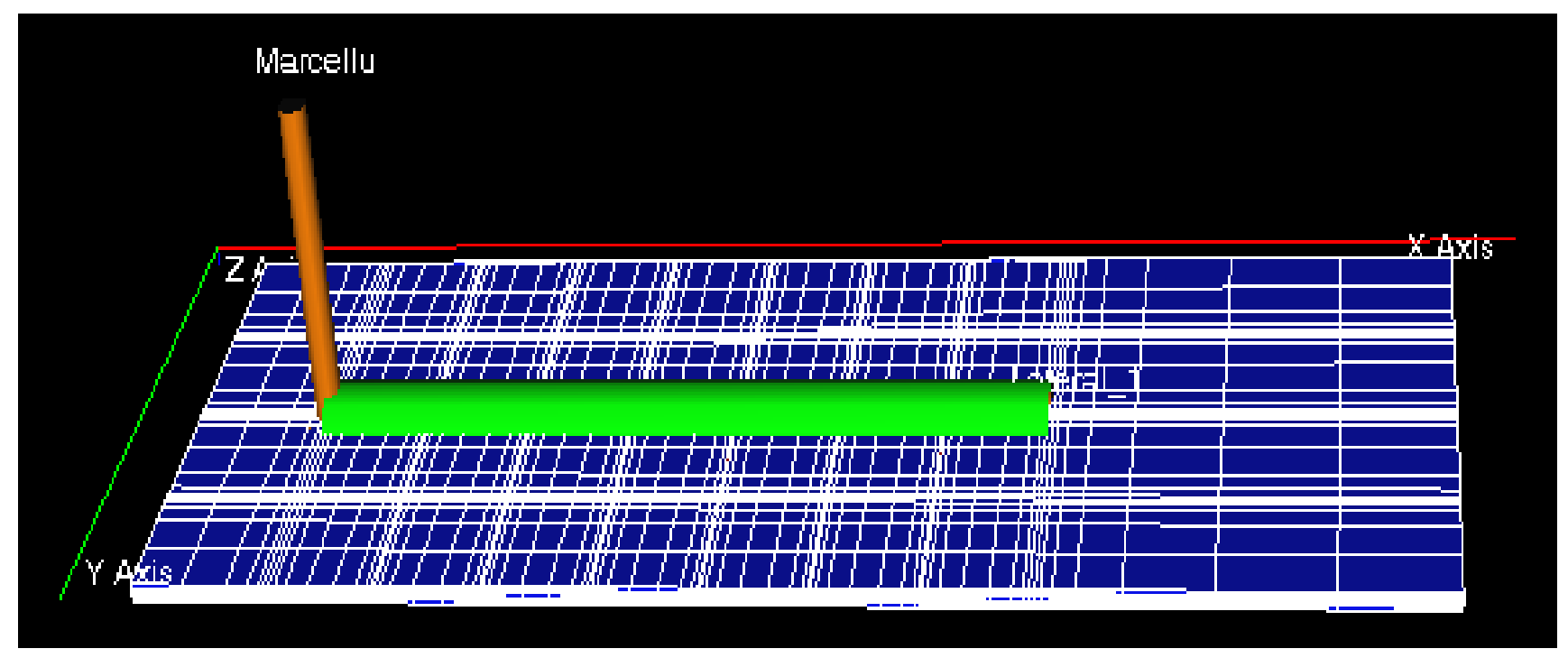

Figure 40. Horizontal \#3 
Below is the plot that illustrates the procedure with different parameters used to get a match,

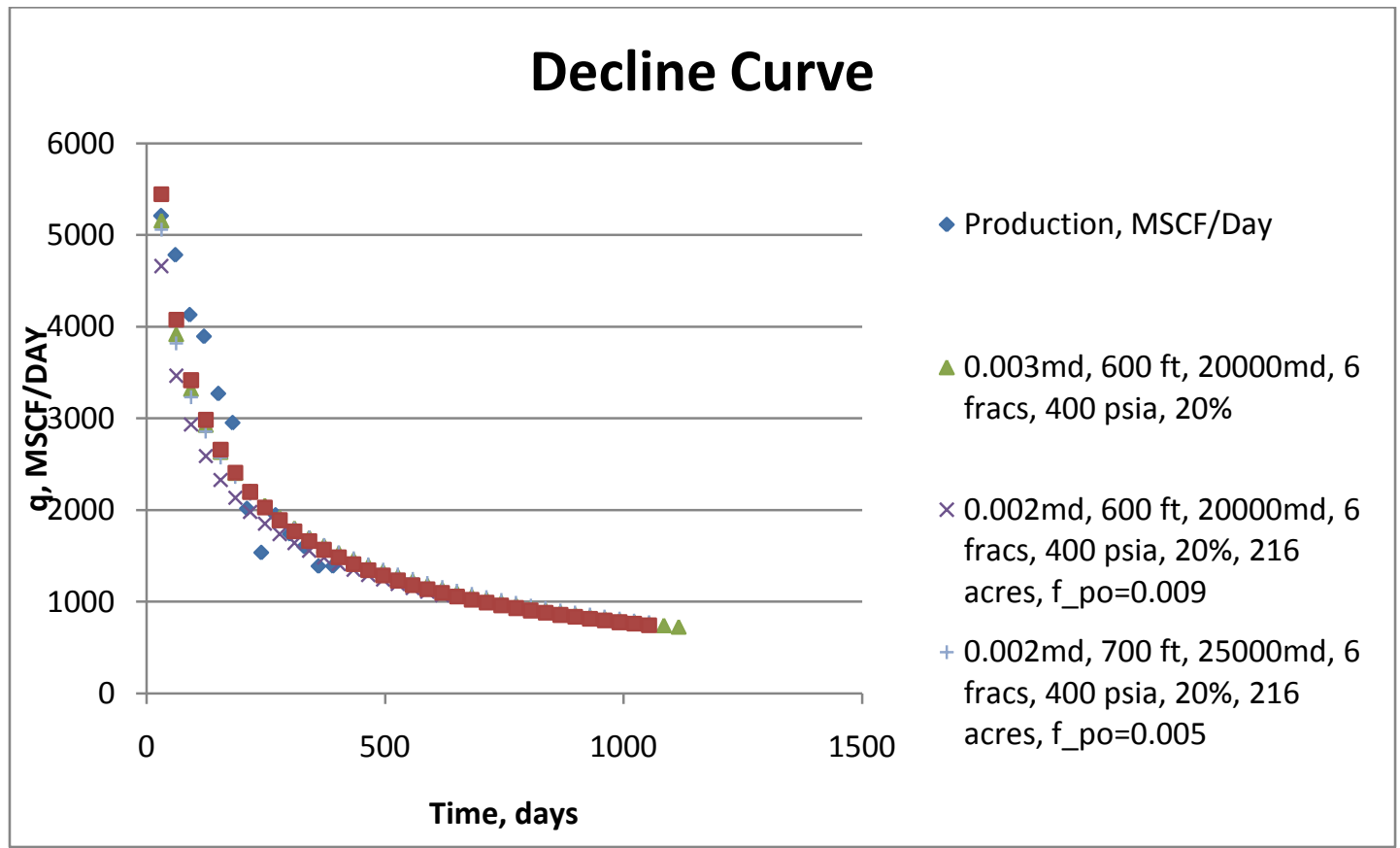

Figure 41. History Matching for Horizontal \#3

And finally the final match for the third horizontal well is as follows,

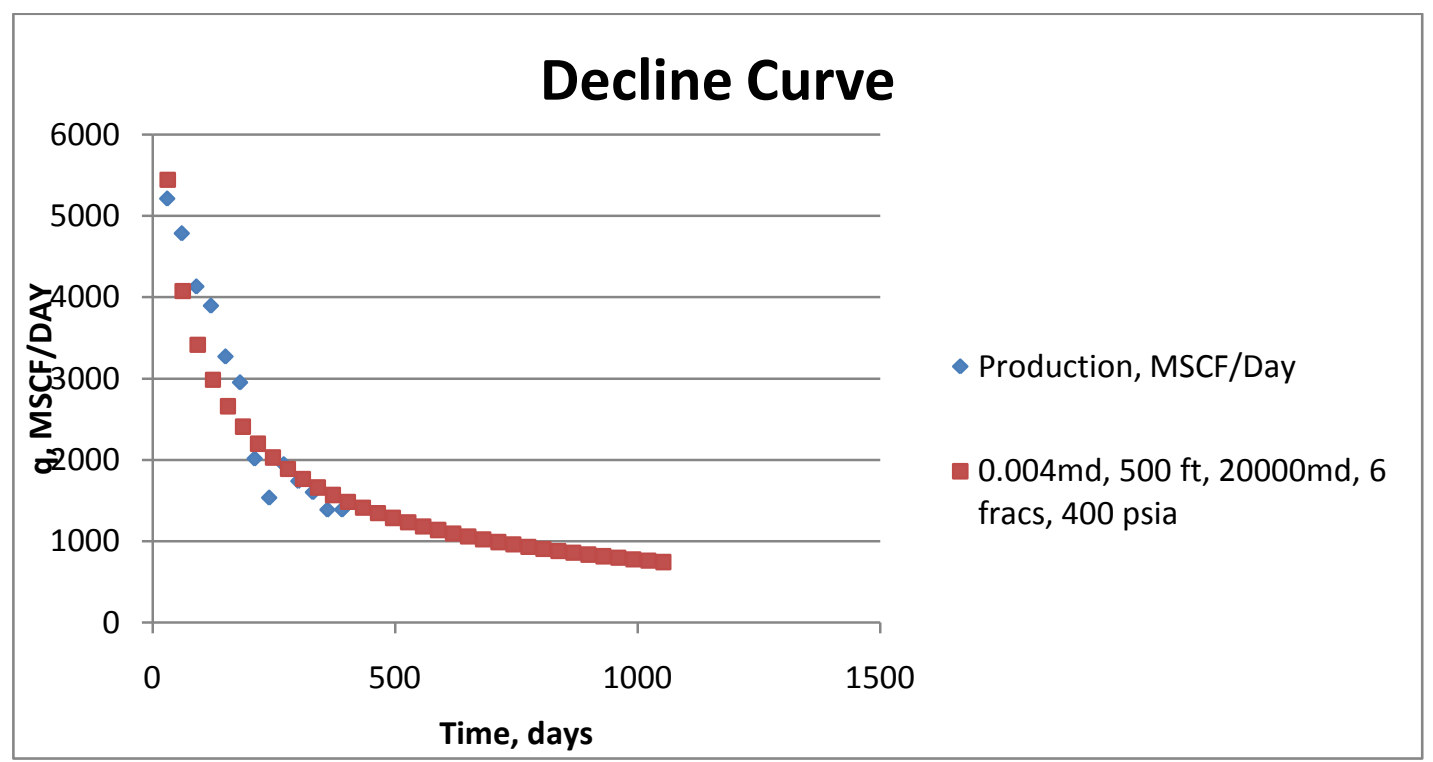

Figure 42. Final Match for Horizontal \#3 


\section{Curriculum Vitae}

Hossein Belyadi

1428B, Center Hill Ave, Morgantown, WV 26505 304-282-3748ｈbelyadi@gmail.com

\section{Education}

West Virginia University- Morgantown, WV, Expected Graduation Date: August 2011

- College of Engineering and Mineral Resources: Master of Science

- Department of Petroleum and Natural Gas Engineering

- GPA: 4.00/4.00

West Virginia University- Morgantown, WV, May 2010

- College of Engineering and Mineral Resources: Bachelor of Science

- Department of Petroleum and Natural Gas Engineering

- Major GPA: 3.89/4.00, Cumulative GPA: 3.57/4.00

Work Experience

Research Assistantship- Morgantown, WV August 2010 - Present

Graduate Research Assistant

- Marcellus Shale Characteristics Analysis

- Production Data Analysis and History Matching Using Real Field Data

- Prediction of Future Reservoir Behavior

- Natural Fracture Spacing in Shale Gas Reservoir

Summer Internship- Morgantown, WV May 2010 - August 2010

Marcellus Shale Research

- Marcellus Shale Development \& Reservoir Modeling in Gas Shale

- Comparison Between Single Porosity Model and Dual Porosity Model in Shale Reservoir

- Stimulation Effectiveness and Flow Regime in Shale Reservoir

Health Science \& Technology Academy- Morgantown, WV Summer 2009

HSTA Mentor

- Tutored high school students in Algebra, Trigonometry, Pre-Calculus, and Calculus

- Prepared high school students for public speaking 


\section{Engineering Computer Lab Manager}

- Provided technical support when system malfunctions

- Implemented software and hardware upgrades

\section{Projects}

Engineering Bridge Project, Drill String Designing Analysis, Initial Oil and Gas in Place Using Material Balance, Well Design Using Natural Flow and Stimulation Treatment Methods, Aquifer Reservoir Treatment, Top Down Intelligence Reservoir Modeling, Drilling Fluid for HP/HT Zones, Shale Gas Horizontal Well Hydraulic Fracturing Design, Two Phase Z-factor Analysis, Gas Condensate Reservoir Development and Optimization, Sandstone Reservoir Development Using Reservoir Simulation

\section{Honors and Awards}

- Outstanding Graduate Student for Academic Achievement (2010-2011)

- Halliburton Award Recipient for Academic Excellence (2009-2010)

- Obtained Dean's List every academic year and President's List for the last two years

- Recipient of the West Virginia University's highly competitive Merit Scholarship (20072008)

\section{Skills and Certifications}

- Well Control Certificate from Wild Well Control Co. (September 2009)

- Fluent speaking, reading, and writing in English, French, Persian, and Arabic

- Proficient using Microsoft Office Suite, Adobe and HTML, MS Windows, IPDA, Eclipse, Computer Group Modeling (CMG), Mfrac (hydraulic fracturing software)

\section{Activities and Interests}

- Recruiter, Society of Petroleum Engineers, 2010-2011

- Vice president, American Association of Drilling Engineers, 2008-2009

- Vice President, Persian Student Association, 2007-2009 